Universitat Oberta de Catalunya

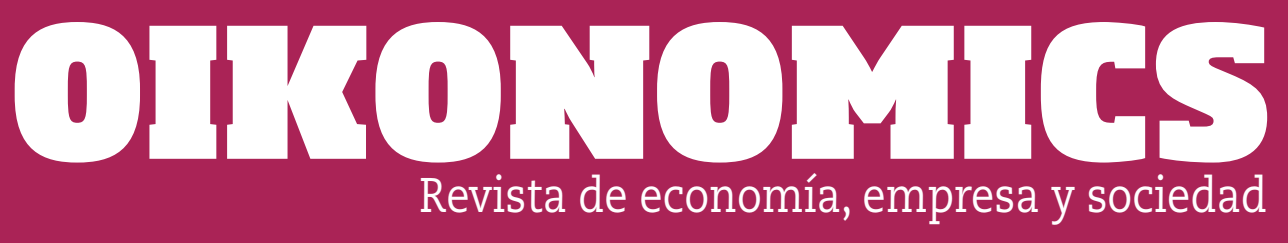

N. 15, mayo de 2021

Dosier sobre economia colaborativa (y II): Wuevas estrategias y dimensiones alternativas de la economia de plataforman coordinado por Huís Alfons Garay Tamajón 


\section{OTHONOMICS}

Revista de economía, empresa y sociedad

ÍNDICE

\section{N. 15, mayo de 2021}

\section{Dosier «Sobre economía colaborativa (y II): Nuevas estrategias y dimensiones alternativas de la economía de plataforma» coordinado por Lluís Alfons Garay Tamajón}

Editorial: Nuevas estrategias y dimensiones alternativas de la economía de plataforma. Propuestas de transición de la EP hacia la sostenibilidad

Lluís Alfons Garay Tamajón

Democratizando la economía de plataforma

Melissa Renau Cano, Mayo Fuster Morell, Ricard Espelt

El futuro es colectivo y los colectivos son el futuro

Albert Cañigueral Bagó

Economía colaborativa y regulación laboral

Miguel Rodríguez-Piñero Royo

Plataformas digitales en el sector de los VTC

Gabriel Doménech Pascual

Alojamientos desinfectados y cuerpos sanos: reflexiones sobre la respuesta de Airbnb a la pandemia

Maartje Roelofsen, Claudio Minca

Cambios en la oferta de Airbnb durante la pandemia de COVID-19

Czesław Adamiak 


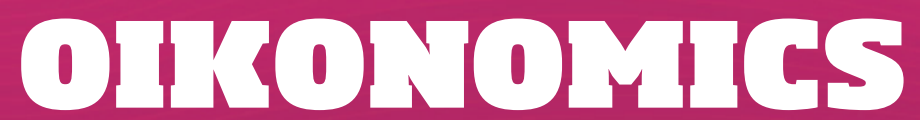

Revista de economía, empresa y sociedad

Dosier sobre economía colaborativa (y II)

Nuevas estrategias y dimensiones alternativas de la economía de plataforma

Coordinador: Lluís Alfons Garay Tamajón

EDITORIAL

\title{
Nuevas estrategias y dimensiones alternativas de la economía de plataforma. Propuestas de transición de la HP hacia la sostenibilidad
}

\author{
Lluís Alfons Garay Tamajón \\ Estudios de Economía y Empresa, Universitat Oberta de Catalunya (UOC)
}

Querría empezar haciendo una declaración de percepciones e intenciones: es un todo un lujo poder escribir estas líneas de la editorial del segundo monográfico que elaboramos desde Oikonomics por diferentes razones. En primer lugar, porque supone intentar dar cierta continuidad al primer monográfico, coordinado por el catedrático Joan Torrent, uno de los académicos con más prestigio en relación con el análisis de la economía de plataforma (EP) en el ámbito internacional. En segundo lugar, porque contamos con seis propuestas que, como veremos, son de altísima calidad e interés. Finalmente, en tercer lugar, porque estos dos monográficos son una manifestación más de la apuesta de la Universitat Oberta de Catalunya, y en concreto de sus Estudios de Economía y Empresa, para entender uno de los fenómenos con más impacto en nuestras economías y sociedades contemporáneas. Es por ello que querría manifestar mi agradecimiento a las dos directoras de los estudios, inicialmente la doctora Àngels Fitó y posteriormente la doctora Maria Jesús Martínez, por mantener el impulso de este tipo de estudio con importante repercusión en la actividad docente y de investigación de nuestra universidad, que con la mejor intención hemos intentado trasladar a la sociedad (este dosier es un buen ejemplo).

En el primer monográfico de este número especial, el doctor Torrent iniciaba su presentación afirmando que no hay recuperación posible de la crisis causada por la pandemia del COVID-19 sin profundizar analíticamente en el proceso de transformación digital y sin reorganizar la actividad económica para hacerla más sostenible. En este sentido, se apuntaban algunos elementos que caracterizan la situación actual de la EP en una coyuntura tan particular como la presente. Así, se destacaba el hecho de que las organizaciones y los sectores que han introducido de manera más intensa las tecnologías digitales se han mostrado más flexibles en la instauración de nuevas prácticas remotas y virtuales y, en consecuencia, estaban sufriendo menos los efectos negativos de la crisis originada por la pandemia. Con todo, se realzaba también la idea de que estos usos de las tecnologías y de los sistemas de la transformación digital eran todavía muy escasos en las empresas de menor dimensión, lo que provocaba rigideces y menguaba su capacidad de supervivencia en contextos como el actual. Finalmente, se hacía también alusión al hecho de que precisamente en un contexto de crisis como el originado por el COVID-19 era necesario que estas empresas tuvieran en cuenta la necesidad de reorientar los resultados esperados, desde privilegiar tan solo los resultados económicos hasta entender que la sostenibilidad es un vector que aglutina objetivos que 
hacen referencia a la justicia económica, social y ambiental. Es precisamente en este punto en el que el presente monográfico toma el relevo de su antecesor y quiere profundizar en las estrategias que están transformando la EP en los últimos años para recuperar una «perdida» idea original que la vinculaba a la sostenibilidad, así como las implicaciones de su desarrollo en otros fenómenos económicos y sociales.

De hecho, desde sus inicios, la EP ha generado un notable debate conceptual dada su naturaleza contradictoria y su posible interpretación como alternativa sostenible o aceleradora del tardocapitalismo, gracias a su carácter de innovación disruptiva. Así, las visiones tempranas depositaron grandes esperanzas en que el uso compartido entre peers o iguales (P2P) implicara un aumento de la eficiencia gracias al desarrollo de servicios realmente centrados en las necesidades de los usuarios y que evitara la infrautilización de recursos, dando también un nuevo impulso a un emprendimiento fundamentado en la generación de relaciones de confianza basadas en la reputación. No obstante, esta visión optimista ha sido crecientemente confrontada con la realidad de lo que algunos califican como "capitalismo de plataforma». Por un lado, porque en los últimos años se ha demostrado que gran parte de las plataformas con más éxito eran controladas y gestionadas de manera oligopólica, con intereses alejados de la compartición, financiadas en ocasiones por capital riesgo y, aprovechando vacíos legales, responsables de diferentes formas de dumping económico y social. Y también, porque más allá de su naturaleza, han afianzado las denuncias de estar generando importantes afectaciones negativas en distintos contextos, muy lejos de la alternativa sostenible que parecían suponer originalmente. Estos impactos han tenido como principal escenario las ciudades, donde la densidad poblacional, la proximidad espacial y la especialización socioeconómica han favorecido el crecimiento de la EP con notables consecuencias, como por ejemplo en el caso de las plataformas de alquiler turístico y su impacto en el incremento de los precios del alquiler residencial, el desplazamiento poblacional o la ocupación de los espacios urbanos públicos y privados. También es así en las plataformas de transporte personal y su conflicto con el taxi, o las denuncias de precarización de los riders o transportistas a domicilio, que apuntan a una reconfiguración de las relaciones laborales y a un desafío para los tradicionales pactos entre capital y trabajo.

En todo caso, también en los últimos años han proliferado nuevas propuestas que tienen como objetivo devolver a la EP los valores próximos al ideal de colaboración y compartición que se anunciaba en sus primeros desarrollos. Tres han sido las vías (no excluyentes) para formular esta posible transición: 1) la del modelo de gobernanza, incidiendo especialmente en los beneficios de las propuestas que fomentan una gobernanza cooperativa de las plataformas; 2) la del modelo de gestión, con propuestas vinculadas a la responsabilidad social corporativa y al concepto de desarrollo sostenible, y 3) la normativa, que incide en la necesidad de una mayor o más innovadora regulación del fenómeno, que propicie aprovechar sus ventajas y evite los impactos más negativos. Estas son en gran medida las vías a tener en cuenta para un futuro análisis de las morfologías de la EP en el actual contexto de crisis, donde será fundamental conocer la existencia de estrategias de gobernanza alternativas, fortalecer los mecanismos de generación de confianza para los grupos de interés, así como observar los impactos y las respuestas reguladoras en todos los niveles y contextos territoriales. Y es en relación con estas propuestas estratégicas y normativas que se manifiestan los estudios que forman este segundo monográfico.

La primera de las propuestas nos la hacen llegar los compañeros de la Universitat Oberta de Catalunya del grupo de investigación DIMMONS, uno de los grupos con mayor trayectoria e influencia en el análisis del público (commons) como forma organizativa de producción (producción entre iguales basada en el dominio público, CBPP en sus siglas en inglés). Melissa Renau, Mayo Fuster, y Ricard Espelt hacen ya toda una declaración de intenciones desde el propio título del artículo: «Alternativas al capitalismo de plataforma: Democratizando la economía de plataforma». Es una propuesta perfecta para entender esta desafección hacia unas grandes plataformas que han generado importantes impactos en aspectos tan fundamentales como los derechos de los trabajadores. Pero, sobre todo, es un escrito especialmente propositivo y esperanzador por el hecho de destacar las bondades de cuatro plataformas alternativas de entrega a domicilio en relación con el respeto a estos derechos. Con todo, los autores no son ingenuos: aunque estas plataformas son una prometedora alternativa al capitalismo de plataforma, todavía presentan importantes retos a superar, especialmente en cuanto a la escalabilidad, pero también a otros indicadores de sostenibilidad, para poder tener recorrido en un futuro. 
Es también en relación con el entorno de los aspectos laborales que otros artículos de este monográfico realizan sus propuestas, empezando por el interesantísimo «El futuro es colectivo y los colectivos son el futuro» de Albert Cañigueral, que se define en su web como explorador, consultor y divulgador. Albert, uno de los nombres más conocidos de la iniciativa Ouishare, ha sido, sin ningún tipo de duda, una de las voces pioneras y privilegiadas de la economía colaborativa en España, fenómeno que ha estudiado de manera pormenorizada y sobre el cual ha escrito diferentes libros que se han convertido en referentes en nuestro país (el último de todos, el influyente El trabajo ya no es lo que era: nuevas formas de trabajar, otras maneras de vivir). En su propuesta en este monográfico, Cañigueral nos explica las dificultades que tienen los trabajadores para mantener determinados derechos en el contexto de unas crecientes relaciones laborales caracterizadas por su intermitencia y por la realización de microtareas asignadas por algoritmos. Para el autor, una manera de organizarse por parte de los trabajadores será la de los "colectivos de autónomos", que más allá de su posible estigmatización ya tienen y tendrán un papel aún más relevante para definir las formas de trabajar y de vivir en el futuro.

En el mismo contexto, pero con un enfoque más relacionado con el ámbito de la regulación, el catedrático de Derecho del trabajo de la Universidad de Sevilla, Miguel Rodríguez-Piñero, nos presenta una magnifica aportación bajo el título «Economía colaborativa y regulación laboral», en la que nos indica que la regulación del trabajo, tradicionalmente apoyada en la dicotomía asalariado-autónomo, está siendo superada por el desarrollo de nuevas formas de ocupación, entre las que destacan las relacionadas con la economía colaborativa. El autor hace una reflexión muy acertada sobre las nuevas necesidades de regulación del trabajo en el marco de los procesos contemporáneos de digitalización, y, entre otras conclusiones, entiendo que una posibilidad es la creación de un esquema triangular de regulación contractual en el que algunos actores se situarían en diferentes extremos y roles de contratación. Este tipo de propuestas tendrían que formar parte también de un nuevo Estatuto de los Trabajadores del siglo xxı en nuestro país, que hiciera frente a los nuevos desafíos sociales, económicos y tecnológicos de los tiempos presentes.

De manera más específica, y ya centrándose en un sector, tenemos la aportación particularmente relevante de Gabriel Doménech, catedrático de Derecho administrativo de la Universidad de Valencia bajo el título «Sub ludice. Plataformas digitales en el sector de los VTC». En la misma, Doménech se interesa por un sector, el del transporte de viajeros con vehículos de turismo, en el que la economía de plataforma ha provocado los conflictos más encendidos, mediáticos y controvertidos de los últimos años. El profesor Doménech somete a juicio este contexto haciendo un repaso de las cuestiones regulatorias, que todavía deben resolverse, y de los hechos ocurridos al respecto en los últimos años en la constante pugna entre los defensores de una liberalización del sector y los partidarios de mantener o incluso endurecer la regulación del mismo. Lo que nos dice el profesor es que es muy probable que en un futuro emerjan otras innovaciones tecnológicas que todavía condicionen más la situación de este sector, o muy especialmente también de los mercados que lo hacen posible.

Muy actual es la aportación de dos de los científicos sociales con más renombre en el análisis del rol e influencia del capitalismo de plataforma en nuestras sociedades, y en concreto en la definición de los conceptos de vivienda y de cotidianidad: Maartje Roelofsen, investigadora de la Universitat Oberta de Catalunya, y Claudio Minca, profesor titular de la Universidad de Bolonia. En esta ocasión, los autores realizan un muy pertinente estudio de las estrategias de adaptación de la plataforma Airbnb en el primer contexto posterior al estallido de la pandemia del COVID-19. En su artículo bajo el título "Sanitized homes and healthy bodies: reflections on Airbnb's response to the pandemic", los autores nos muestran cómo Airbnb tuvo que flexibilizar las políticas de cancelación de manera repentina, pero muy especialmente cómo ha tenido que subrayar en su comunicación las nuevas necesidades higiénicas en las viviendas que se ofrecían en su web, acercándose a los estándares que hasta ahora habían estado presentes en la hotelería tradicional. Esto puede acabar teniendo impacto en las empresas de limpieza contratadas por los hosts, máxime en un entorno que como he visto ha sido frecuentemente explotado y precarizado en relación con las condiciones laborales y los salarios. Finalmente, la compañía ha iniciado también un giro en su target, invitando a los propietarios o hosts a tener cada vez más en cuenta la posibilidad de ofrecer alquileres de medio y largo plazo a potenciales clientes o guests con un perfil bastante diferente del turista al que hasta ahora habían atendido. Todo ello hace reflexionar sobre la posibilidad de que estas plataformas de alquiler turístico puedan acabar irrumpiendo con fuerza en los mercados inmobilia- 
rios de las ciudades donde actúan, que ya habían experimentado importantes impactos de su actuación en un pasado reciente.

Finalmente, una sexta propuesta nos viene de la mano de Czeslaw Adamiak, investigador de la Universidad Nicolaus Copernicus de Torún (Polonia), y una de las voces más reputadas en el plano internacional a propósito del análisis de las características y la distribución espacial de la oferta de las plataformas de alquiler de alojamiento a corto plazo. En su artículo «Changes in global Airbnb offer during the COVID-19 pandemic», Adamiak lleva a cabo un interesante estudio sobre cómo se está adaptando al contexto pospandémico una de las plataformas más influyentes en el ámbito global, Airbnb. Por un lado, porque después de una parada especialmente abrupta en su actividad y en consonancia con el fuerte impacto de la pandemia en el sector turístico, la plataforma se ha mantenido a base de dispersarse por el territorio, conquistando nuevos terrenos más allá de su tradicional feudo urbano. Por otro lado, porque ha dado más importancia a los alquileres de viviendas enteras por encima de la compartición de espacios dentro de las mismas y, finalmente, porque al menos en una primera etapa parece haber vuelto, en cierta medida, a tomar más peso el pequeño propietario o host frente a los grandes tenedores o multihosts. En todo caso, en lo que no tiene dudas este investigador es en el hecho de que Airbnb superará la crisis y continuará siendo un actor central en la reconfiguración del homesharing en el ámbito global.

Para terminar esta presentación, querría destacar mi agradecimiento a los autores por su predisposición a participar en este monográfico. Como bien indicaba el doctor Torrent, y yo añadiría que dadas las reglas que desgraciadamente se están imponiendo en el mundo de la academia, realizar propuestas para revistas que básicamente se focalizan en la divulgación es cada vez más un acto con un componente altruista que retrata a los autores como personas realmente interesadas en que la ciencia social llegue al público en general. Si, además, la temática y el contenido de estos artículos también están llenos de preocupación y de interés para mejorar nuestra sociedad, podemos decir que desde Oikonomics estamos nuevamente orgullosos del resultado. Espero muy sinceramente que la lectura de estos artículos les pueda ser interesante y, si es posible, les haga reflexionar a propósito de cuáles son las potencialidades y posibilidades de unos procesos de digitalización que tienen y tendrán un profundo impacto sobre nuestras vidas en las próximas décadas.

Citación recomendada: GARAY TAMAJÓN, Lluís Alfons. Editorial. Nuevas estrategias y dimensiones alternativas de la economía de plataforma. Propuestas de transición de la EP hacia la sostenibilidad. Oikonomics [en línea]. Mayo 2021, núm. 15. ISSN: 2339-9546. DOl: https://doi.org/10.7238/o. n15.2105

Los textos publicados en esta revista están sujetos -si no se indica lo contrario- a una licencia de Reconocimiento 4.0 Internacional de Creative Commons. Puede copiarlos, distribuirlos, comunicarlos públicamente, hacer obras derivadas siempre que reconozca los créditos de las obras (autoría, nombre de la revista, institución editora) de la manera especificada por los autores o por la revista. La licencia completa se puede consultar en https://creativecommons.org/licenses/by/4.0/deed.es_ES.

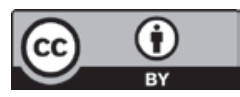




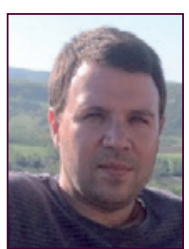

\section{Luís Alfons Garay Tamajón}

Igaray@uoc.edu

Estudios de Economía y Empresa, Universitat Oberta de Catalunya (UOC).

Profesor agregado en los Estudios de Economía y Empresa de la Universitat Oberta de Catalunya (UOC). Director del grupo de investigación Nuevas Perspectivas en Turismo y Ocio (NOUTUR) (https://noutur.uoc.edu) y del programa de doctorado en Turismo de la UOC. Especialista en el análisis del sector turístico desde diferentes perspectivas, en los últimos años ha coordinado distintos proyectos y ha escrito varios artículos en revistas indexadas que se focalizan en el estudio de la naturaleza, las características y el impacto de la EP en el turismo, una de las actividades que ha protagonizado este fenómeno en la última década. 


\section{OTIOLTOMTS}

Revista de economía, empresa y sociedad

Dosier sobre economía colaborativa (y II)

Nuevas estrategias y dimensiones alternativas de la economía de plataforma

Coordinador: Lluís Alfons Garay Tamajón

ALTERNATIVAS AL CAPITALISMO DE PLATAFORMA

\section{Democratizando la economía de plataforma}

\section{Melissa Renau Gano*}

Universitat Oberta de Catalunya

\section{Mayo Fuster Morell}

Universitat Oberta de Catalunya y Berkman Center

\section{Ricard Fspelt}

Universitat Oberta de Catalunya

RESUMEN Plataformas como Glovo, Deliveroo y UberEats dedicadas a la entrega a domicilio se han implantado en ciudades de todo el mundo. Su expansión ha ido acompañada de un impacto sobre los derechos de los trabajadores y trabajadoras, en lo que se considera capitalismo de plataforma. Aun así, existen alternativas democráticas vinculadas a la economía social y solidaria y a los comunes digitales. Este artículo analiza las calidades democráticas de cuatro plataformas alternativas de entrega a domicilio que tienen sede en Europa (CoopCycle, CILFé, Crow y Mensakas). Por un lado, los resultados muestran que estas plataformas tienen en consideración los derechos de sus trabajadores y trabajadoras y, por lo tanto, son una alternativa al capitalismo de plataforma. Por otro lado, se demuestra que estas plataformas tienen retos importantes, especialmente en relación con su sostenibilidad económica y escalabilidad.

PALABRAS CLAVE economía de plataforma; cooperativismo de plataforma; economía social; gig work; riders 


\title{
Democratising the platform economy
}

\begin{abstract}
Platforms such as Glovo, Deliveroo and Uber Eats that operate in the field of food delivery have set up in cities all around the world. The expansion of these platforms has had an impact on workers' rights in what is considered as platform capitalism. Even then, democratic alternatives connected to the social and solidarity economy and digital commons exist. This article analyses the democratic qualities of four alternative food delivery platforms with headquarters in Europe (CoopCycle, CILFé, Crow and Mensakas). On the one hand, the results show that these platforms consider their workers' rights; that is the main reason why they form an alternative to platform capitalism. On the other hand, the analysis shows that these platforms face important challenges, especially regarding their economic sustainability and scalability.
\end{abstract}

KEYWORDS platform economy; platform cooperativism; social economy; gig work; riders

\section{Introducción}

Al mismo tiempo que empresas como Glovo, Deliveroo y UberEats han atraído muchas inversiones, sus modelos de negocio son ampliamente cuestionados (Ball, 2020). Bajos salarios, malas condiciones laborales o carencia de protección social son características comunes de todas ellas (Urzì Brancati et al., 2020). A pesar de que estas plataformas difieren mucho en cuanto a los servicios que ofrecen, tienen en común que su modelo de negocio no sería posible sin la incorporación de sistemas de inteligencia artificial (IA) o dispositivos de geolocalización que permiten la recopilación masiva de datos (Lee et al., 2015; Ivanova et al., 2018; Veen et al., 2020). En definitiva, estas plataformas ejercen un gran control sobre sus trabajadores a través de la propia tecnología y no facilitan el acceso a los sistemas de protección social ni un desarrollo profesional (Forde et al., 2017; Parent-Thirion et al., 2017; Pesole et al., 2018; Kilhoffer et al., 2019). Así mismo estas plataformas también aceptan más trabajadores de los necesarios, cosa que exacerba todavía más la competencia por turnos y sirve como una herramienta más para disciplinar el trabajo (Altenried, 2019; Ivanova et al., 2018).

Estas prácticas que se aplican actualmente en la economía de plataforma gracias al apoyo de la tecnología (Lee et al., 2015; Rosenblat y Stark, 2015; Jarrahi y Sutherland, 2019) se basan en los principios del taylorismo (Taylor, 2006). Es decir, buscan mejorar la eficiencia económica y la productividad laboral implementando prácticas como incrementar el control sobre el proceso laboral, dividir las tareas en otras más simples y ofrecer un pago basado en el rendimiento de los trabajadores (McGaughey, 2018; Wood et al., 2019).

A pesar de que el debate público y la investigación se han centrado en estas plataformas extractivistas situadas bajo el paraguas del capitalismo de plataforma (Srnicek, 2016), existen plataformas realmente colaborativas basadas en la Economía Social y Solidaria (ESS) y el conocimiento abierto. De todos modos, hay pocos estudios basados en análisis de casos empíricos de plataformas alternativas o estos están centrados en proyectos paradigmáticos, como Fairbnb (Foramitti et al., 2020; Petruzzi et al., 2019) o SMart (Charles et al., 2020). Martinelli et al. (2019) estudiaron diferentes casos de cooperativas de plataforma, destacando su potencial para crear y promover puestos de trabajo de calidad mediante plataformas digitales, pero sin analizar en profundidad sus condiciones laborales o las calidades democráticas que las configuran.

El presente artículo pretende contribuir a este vacío proporcionando un análisis holístico de los elementos clave que permiten distinguir entre modelos de plataforma (Fuster Morell, 2018). En base al marco de las calidades democráticas de la economía de plataforma (figura 1), proponemos un análisis holístico de los elementos clave que constituyen una plataforma y su impacto (Fuster Morell y Espelt, 2019). Para hacerlo hemos hecho una et- 
nografía digital de cuatro plataformas de entrega a domicilio y una entrevista semiestructurada a cada uno de los casos. La recogida de datos se llevó a cabo entre julio y diciembre de 2019.

\section{Calidades democráticas de las plataformas digitales}

El marco de las calidades de sostenibilidad de la economía de plataforma (figura 1) se compone de seis dimensiones que permiten un análisis holístico de los modelos de plataforma. La dimensión de gobernanza evalúa la gobernanza en cuanto a la provisión de plataformas (transparencia, políticas de participación y constitución legal) y la gobernanza en cuanto a la interacción de la plataforma (haciendo coincidir las funcionalidades de la plataforma con el grado en que los usuarios pueden participar). La dimensión del modelo económico estudia la relación entre los beneficios económicos (distribución y destino) y su impacto social (condiciones y derechos laborales, tipos de crecimiento) y el modelo de sostenibilidad económica del proyecto. Las políticas tecnológicas hacen referencia a la arquitectura y el software tecnológico teniendo en cuenta el grado de reproductibilidad, determinado por el tipo de licencia. Se consideran dos elementos de las políticas de conocimiento: el acceso a los datos generados y la licencia del contenido. Finalmente, la dimensión de responsabilidad social e impacto evalúa las implicaciones generadas por la actividad de la plataforma (exclusión, desigualdad de género, impacto ambiental, etc.).

Figura 1. Marco de calidades democráticas de la economía de plataforma

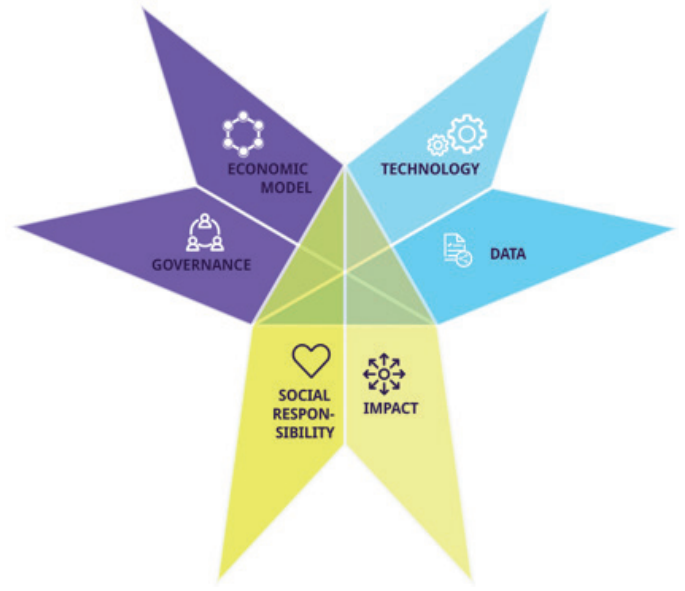

\section{Modelos de economía de plataforma}

El marco de las calidades democráticas de las plataformas digitales parte de la hipótesis de que es posible distinguir entre tres modelos de plataforma diferentes: unicornios, open commons y platform coops. En esta sección, se presentan y analizan los tres modelos y se relacionan con el marco de calidades democráticas presentado en la sección previa.

La producción entre iguales basada en los comunes (Benkler, 2006) es un concepto utilizado para describir formas de producción caracterizadas por la apertura a la participación (Fuster Morell, 2010), una fuerte igualdad en la distribución de las contribuciones a la comunidad (Ortega, 2009), descentralización (Crowston y Howison, 2006; Lanzara y Morner, 2004), modularidad y granularidad (Benkler, 2006), no coercitividad y una coordinación basada en la estigmergia (Siefkes, 2010), procesos transparentes (Bauwens, 2007), propiedad intelectual comunitaria (Wark, 2004) y las dimensiones del valor más allá de las concepciones monetarias (Fuster Morell et al., 2016). 
Las plataformas open commons son generalmente promovidas por fundaciones de gobierno comunitarias. Este modelo de plataforma utiliza el software libre de código abierto (FLOSS) y licencias abiertas que abren datos y conocimientos, lo que favorece la economía circular, atiende al impacto ambiental y se orienta al valor social.

Las unicornio hacen referencia a las startups de plataformas promovidas por empresas tecnológicas con una alta capitalización del mercado. El término «unicornio» fue utilizado por primera vez por Aileen Lee (2013) en una publicación en TechCrunch que hacía referencia a empresas nacidas después del 2003 y que se habían valorado en hasta 1.000 millones de dólares de capitalización bursátil en algún momento de su ciclo de vida. Las unicornio son empresas multinacionales orientadas exclusivamente al beneficio económico y que restringen enormemente su gobernanza. Normalmente se desarrollan con software propietario y datos cerrados. Las unicornio producen impactos disruptivos sobre la soberanía de las ciudades, el medio ambiente, la inclusión y el género.

Scholz y Schneider popularizaron el término "cooperativismo de plataforma» (Scholz, 2016; Scholz y Schneider, 2017). Según Scholz (2016), las plataformas se tienen que basar en los valores del cooperativismo y las herramientas digitales tienen que aumentar la escalabilidad de las plataformas y su impacto social y económico. Al mismo tiempo, Fuster Morell (2017) afirmó que las cooperativas de plataforma tendrían que adoptar programas y licencias abiertas teniendo en cuenta la importancia de su arquitectura tecnológica.

\section{Cuatro plataformas democráticas de ámbito europeo}

A partir del marco analítico presentado en la sección 2, procedemos al estudio de cuatro casos de plataformas democráticas de entrega de alimentos con presencia en la Unión Europea, para analizar su caracterización.

\subsection{CoopCycle}

CoopCycle es una federación de cooperativas creada el 2017 en París con el objetivo de reducir los gastos gracias a la agrupación de recursos y, al mismo tiempo, fortalecer el poder de negociación de los derechos de los trabajadores. A pesar de que el grosor de actividad está en Francia, también tiene entidades en Canadá, Reino Unido, Alemania, Bélgica, Italia, Suecia, Polonia y España y está desarrollando nuevos nodos en Sudamérica y al este de Europa.

- Gobernanza: para asegurar una base democrática, todos los miembros locales de la federación de CoopCycle tienen que ofrecer contratos asalariados a sus mensajeros tan pronto como puedan y organizar democráticamente la distribución de los ingresos. A nivel federativo, las cooperativas locales deciden juntas, en base a una cooperativa, una voz, sobre cuestiones clave como el nivel de contribución de cada miembro al fondo mutuo según sus ingresos, el destino de este fondo o el régimen salarial por los servicios prestados.

- Modelo económico: todavía no se ha conseguido un modelo de sostenibilidad económica, pero, cuando se alcance, los beneficios se quieren reinvertir en el proyecto. CoopCycle tiene un modelo de crecimiento federado y con una descentralización progresiva de la gobernanza de la plataforma. Actualmente, cada cooperativa local mutualiza según sus ingresos/recursos ( $2 \%$ de su valor añadido) y se puede beneficiar de todos los servicios de CoopCycle.

- Políticas de conocimiento y datos: CoopCycle permite el acceso libre al código de la plataforma a las empresas con una base ética sólida a través de una licencia copyleft. Es decir, entidades que tienen como principio garantizar los derechos de los trabajadores y la gestión democrática interna. En cuanto a los datos, la plataforma solo recopila la información necesaria para completar la entrega (nombre, correo electrónico y teléfono).

- Responsabilidad social: solo pueden adherirse a la federación las cooperativas que tengan un gasto carbono cero (a través del uso de bicicletas mecánicas o eléctricas) y que tengan previsto un modelo de empleo de mensajeros asalariado. 


\subsection{La Cour Cyclette (CILFé)}

El servicio de entrega de bicicletas de La Cour Cyclette es una empresa cooperativa que opera en la Val de Marne, al sudeste de la ciudad de París. El servicio de entrega de bicicletas de La Cour Cyclette tiene como objetivo promover el desarrollo de empresas locales combatiendo la degradación de las condiciones laborales.

- Gobernanza: la organización cooperativa promueve que cada miembro tenga derecho a voto en la toma de decisiones. La remuneración y las condiciones laborales son acordadas conjuntamente por los socios cooperativos. A nivel tecnológico, La Cour Cyclette no utiliza sistemas de gestión algorítmica de control de los trabajadores.

- Modelo económico: como plataforma cooperativa, los beneficios se reinvierten en el proyecto. La Cour Cyclette es la única entidad de este estudio que ha logrado un modelo de sostenibilidad económica sólido, a través de colaboraciones con la administración pública y cuotas de socio.

- Política tecnológica: uso del software CoopCycle.

- Políticas de conocimiento y datos: no se pueden acceder a los datos generados en ningún formato.

- Responsabilidad social: La Cour Cyclette sitúa los valores de la economía circular en el centro de su estrategia. Aparte de reducir las emisiones en la entrega de la última milla, proporcionan materiales educativos para concienciar sobre el consumo sostenible.

\subsection{Crow Cycle Courier Collective (Crow)}

Crow es una cooperativa de mensajería de bicicletas independiente que opera en Berlín y se basa en la autogestión y la economía circular.

- Gobernanza: organización cooperativa democrática de quince miembros, diez hombres y cinco mujeres. A pesar de que actualmente los mensajeros de la plataforma son autónomos, la empresa tiene un plan para evitar la degradación de las condiciones laborales. De hecho, el reconocimiento jurídico de autónomo se acordó entre los miembros, valorando su situación económica y sus necesidades.

- Modelo económico: cada trabajador recibe un mínimo garantizado por hora. Esto hace que a menudo los sueldos sean mejores que cualquier otra empresa de mensajería de Berlín. El modelo de crecimiento se basa en aumentar el número de miembros de la cooperativa sin modificar la estructura de gobierno.

- Política tecnológica: uso del software de CoopCycle.

- Políticas de conocimiento y datos: no es posible exportar, copiar ni acceder a los datos.

- Responsabilidad social: Crow promueve el reciclaje y la circularidad de los materiales ofreciendo un tipo de servicio que mejora la eficiencia energética. También dan prioridad a la responsabilidad social cuando escogen los proveedores de los servicios que requieren.

\subsection{Mensakas}

Mensakas fue fundada en 2018 en Barcelona por exmensajeros de Glovo y Deliveroo. Su misión es demostrar que es posible crear una plataforma de distribución responsable.

- Gobernanza: cooperativa democrática formada por ocho trabajadores, cinco hombres y tres mujeres. Todas las personas son empleados directos y ganan el salario mínimo. Por decisión de la cooperativa, las mujeres tienen un $5 \%$ más de salario que los hombres.

- Modelo económico: los beneficios de la entidad se reinvierten en el proyecto. Su modelo de crecimiento se basa en la reproducción del proyecto y la descentralización progresiva de la gobernanza de la plataforma. De hecho, ayudan a iniciativas de otras ciudades que tienen como objetivo ofrecer una alternativa a las grandes plataformas globales como Deliveroo o Glovo. Mensakas ha logrado la sostenibilidad económica durante el 2020, a través de fondos públicos, las cuotas obligatorias de los miembros y los beneficios de su propia actividad. 
- Política tecnológica: actualmente utilizan el software de CoopCycle, pero tienen previsto desarrollar su propia aplicación que incorpore algunas necesidades específicas.

- Políticas de conocimiento y datos: no es posible exportar, copiar ni acceder a los datos.

- Responsabilidad social: Mensakas promueve el reciclaje y la circularidad de los materiales. Cuando hayan desarrollado su propia aplicación tienen previsto alojarla en servidores de energía verde. La entidad da prioridad a la responsabilidad social cuando eligen los proveedores de servicios. También tienen un plan de formación interno que permite fomentar el conocimiento compartido.

La tabla comparativa de los cuatro casos (tabla 1) permite observar que, a pesar de que no hay ningún caso que cumpla al 100\% las calidades democráticas en las cinco dimensiones definidas, todas las plataformas tienen un buen nivel de desempeño.

Tabla 1. Tabla comparativa entre casos analizados. Verde: desempeño; naranja: desempeño parcial; rojo: no desempeño.

\begin{tabular}{|l|l|l|l|l|l|}
\hline \multicolumn{1}{|c|}{ Dimensiones } & \multicolumn{1}{|c|}{ Subdimensiones } & CoopCycle & CILFé & Crow & Mensakas \\
\hline Gobernanza & Formato jurídico & & & \\
\hline & Participación & & & \\
\hline Modelo económico & Misión & & & \\
\hline & Modelo de crecimiento & & & & \\
\hline & Sostenibilidad & & & \\
\hline & Financiación no lucrativa & & & & \\
\hline Políticas tecnológicas & Software abierto & & & & \\
\hline & Descentralización & & & \\
\hline Políticas de conocimiento & Licencia copyleft & & & \\
\hline & Datos abiertos & & & \\
\hline Responsabilidad social & Inclusión socioeconómica & & & & \\
\hline & Sensibilidad ambiental & & & & \\
\hline
\end{tabular}

\section{Conclusiones}

Las condiciones laborales vinculadas a la economía de plataforma son vanguardia del debate público y la agenda de investigación porque empresas como Glovo, Deliveroo y UberEats provocan una degradación de las condiciones laborales y vulneran los derechos de sus trabajadores (Tassinari y Maccarrone, 2020; Wood et al., 2019). En paralelo y a pesar de tener menos atención mediática y de investigación, la economía de plataforma también ofrece diversidad de modelos de negocio que son afines a las calidades democráticas que emergen de los principios de la economía social y solidaria y los comunes digitales (Fuster Morell, 2018). Este 
artículo se centra en el estudio de cuatro plataformas alternativas del ámbito de la entrega a domicilio con sede en Europa que se analizan a través del marco de calidades democráticas de las plataformas digitales (Fuster Morell y Espelt, 2019).

El resultado del análisis señala que las cuatro plataformas estudiadas (CoopCycle, CILFé, Crow, Mensakas) se muestran como una alternativa al capitalismo de plataforma (Srnicek, 2016) y fomentan alternativas democráticas de economía de plataforma. Sin embargo, el estudio detallado de estas iniciativas muestra que tienen retos importantes.

La gobernanza es el elemento más destacado de todas ellas. No solo porque las cuatro entidades estudiadas tienen forma jurídica cooperativa, sino porque fomentan la participación horizontal y democrática de sus miembros. Respecto al modelo económico, todas las organizaciones estudiadas tienen un enfoque sin ánimo de lucro. De hecho, la mayoría reinvierten o tienen la intención de reinvertir beneficios en su proyecto. Además, el modelo de crecimiento se basa en la reproductibilidad y el crecimiento sin cambios en la misión del proyecto. Es decir, evitando modelos económicos especulativos. Aun así, el reto más importante de estas cuatro organizaciones es la sostenibilidad económica. A pesar de que La Cour Cyclette (CILFé) y, recientemente, Mensakas han llegado a un punto de equilibrio entre ganancias y gastos, se evidencia que la sostenibilidad económica es uno de los principales retos del cooperativismo de plataforma y de los proyectos open commons.

En términos de políticas tecnológicas, todos los casos promueven software abierto y arquitecturas tecnológicas descentralizadas. En cambio, las políticas de conocimiento y datos no contemplan los datos abiertos. Por lo tanto, a pesar de que el software sea libre y con licencia copyleft, no es posible descargar los datos generados por los usuarios.

Finalmente, la práctica totalidad de los proyectos cuidan su responsabilidad social y medioambiental, priorizando los proveedores de Economía Social y Solidaria y promoviendo un consumo responsable, y son conscientes del impacto ambiental de la infraestructura de la plataforma, aunque todavía no utilicen servidores ecológicos eficientes.

Estos hallazgos contribuyen al conocimiento emergente de literatura académica y divulgativa destinada a comprender estas alternativas de economía de plataforma, especialmente a través del análisis empírico de casos. Así mismo, esta investigación demuestra que están surgiendo organizaciones democráticas alternativas a las plataformas unicornio y, a pesar de que presentan retos importantes en cuanto a la sostenibilidad y la escalabilidad económica, prevén un futuro alternativo en que la tecnología no se utiliza como excusa para un mayor control del puesto de trabajo, sino como una herramienta para promover organizaciones más horizontales, democráticas y que protegen los derechos laborales de sus trabajadores.

\section{Bibliografía}

ALTENRIED, Moritz. On the last mile: Logistical urbanism and the transformation of labour. En: Work Organisation, Labour \& Globalisation, 2019. Vol. 13, núm. 1, págs. 114-129. DOl: https://doi.org/10.13169/workorgalaboglob.13.1.0114.

BALL, James. Deliveroo was the poster child for venture capitalism. It's not looking so good now. En: The Guardian, 2 de mayo de 2020 [en línea]. Disponible en: https://www.theguardian.com/commentisfree/2020/ may/02/deliveroo-venture-capitalism-food-delivery-business-model.

BAUWENS, Michel. Peer-to-Peer Governance, Production and Property: P2P as a Way of Living. Part 1. En: Master New Media, 20 de octubre de 2007 [en línea]. Disponible en: https://communities-dominate.blogs.com/ brands/2007/10/peer-to-peer-go.html.

BENKLER, Yochai. The wealth of networks: How social production transforms markets and freedom. Yale University Press, 2006.

CHARLES, Julien, FERRERAS, Isabelle y LAMINE, Auriane. A freelancers' cooperative as a case of democratic institutional experimentation for better work: A case study of SMart-Belgium. En: Transfer: European Review of Labour and Research, 2020. Vol. 26, núm. 2, págs. 157-174. DOl: https://doi.org/10.1177/1024258920919686. 
CROWSTON, Kevin y HOWISON, James. Hierarchy and centralization in free and open source software team communications. En: Knowledge, Technology \& Policy, 2006. Vol. 18, núm. 4, págs. 65-85. DOI: https://doi.org/10.1007/s12130-006-1004-8.

FORAMITTI, Joël, VARVAROUSIS, Angelos y KALLIS, Giorgos. Transition within a transition: How cooperative platforms want to change the sharing economy. En: Sustainability Science, 2020. Vol. 15, núm. 4, págs. 1185-1197. DOI: https://doi.org/10.1007/s11625-020-00804-y.

FORDE, Chris et al. The Social Protection of Workers in the Platform Economy. Policy Department A: Economic and Scientific Policy - European Parliament, 2017. Pág. 128 [en línea]. Disponible en: https://www.europarl. europa.eu/thinktank/en/document.html?reference=IPOL_STU(2017)614184.

FUSTER MORELL, Mayo. Participation in online creation communities: Ecosystemic participation? En: Conference Proceedings of JITP 2010: The Politics of Open Source, 2010. Vol. 1, págs. 270-295. Disponible en: https://scholarworks.umass.edu/jitpc2010/1/.

FUSTER MORELL, Mayo. Towards a Theory of Value of Platform Cooperativism. En: Scholz Trebor y Schneider Nathan (eds.), Ours to hack and to own: The rise of platform cooperativism, a new vision for the future of work and a fairer internet. OR Books, 2017.

FUSTER MORELL, Mayo (ed.). Sharing cities: A worldwide cities overview on platform economy policies with a focus on Barcelona. Sehen, Editorial UOC, 2018. Disponible en: http://www.sharingcitiesaction.net/wp-content/ uploads/2018/11/SharingCities_book.pdf.

FUSTER MORELL, Mayo y ESPELT, Ricart. A Framework to Assess the Sustainability of Platform Economy: The Case of Barcelona Ecosystem. En: Sustainability, 2019. Vol. 11, núm. 22, págs. 6450. DOI: https://doi.org/10.3390/su11226450.

FUSTER MORELL, Mayo, SALCEDO, Jorge y BERLINGUER, Marco. Debate About the Concept of Value in Commons-Based Peer Production. En: BAGNOLI, Franco et al. (eds.), Internet Science, vol. 9934, págs. 27-41. Springer International Publishing, 2016. DOI: https://doi.org/10.1007/978-3-319-45982-0_3.

IVANOVA, Mirela et al. The App as a Boss? Control and Autonomy in Application-Based Management. EuropaUniversität Viadrina, 2018. Pág. 27. Disponible en: https://opus4.kobv.de/opus4-euv/frontdoor/index/index/ docld/388.

JARRAHI, Mohammad y SUTHERLAND, Will. Algorithmic Management and Algorithmic Competencies: Understanding and Appropriating Algorithms in Gig Work. En: TAYLOR, C. et al. (eds.), Information in Contemporary Society, vol. 11420, págs. 578-589. Springer International Publishing, 2019. DOI: https://doi.org/10.1007/9783-030-15742-5_55.

KILHOFFER, Zachary et al. Study to gather evidence on the working conditions of platform workers. Luxemburgo, Publications Office of the European Union, 2019. Disponible en: https://ec.europa.eu/social/main.jsp?catld=8 9\&furtherNews=yes\&langld=en\&newsld=9582.

LANZARA, G. y MORNER, Michèle. Making and sharing knowledge at electronic crossroads: The evolutionary ecology of open source. Fifth European Conference on Organizational Knowledge, Learning and Capabilities, Innsbruck, Austria, 2004.

LEE, Min Kyung et al. Working with Machines: The Impact of Algorithmic and Data-Driven Management on Human Workers. En: Proceedings of the 33rd Annual ACM Conference on Human Factors in Computing Systems CHI '15, 2015. Págs. 1603-1612. DOI: https://doi.org/10.1145/2702123.2702548.

LEE, Aileen. Welcome To the unicorn club: Learning from billion-dollar startups. En: Techcrunch, 2 de noviembre de 2013 [en línea]. Disponible en: https://techcrunch.com/2013/11/02/welcome-to-the-unicorn-club/.

MARTINELLI, Francesca. Platform Cooperativism in Italy and in Europe. CIRIEC International, 2019.

MCGAUGHEY, Ewan. Taylorooism: When network technology meets corporate power: Technology meets corporate power. En: Industrial Relations Journal, 2018. Vol. 49, núm. 5-6, págs. 459-472. DOI: https://doi. org/10.1111/irj.12228.

ORTEGA, Felipe. Wikipedia: A Quantitative Analysis. Universidad Rey Juan Carlos, 2009.

PARENT-THIRION, Agnès. et al. 6th European Working Conditions Survey: Overview report (2017 update). Luxemburgo, Publications Office of the European Union, 2017. 
PESOLE, A. et al. Platform workers in Europe evidence from the COLLEEM survey. Luxemburgo, Publications Office of the European Union, 2018. Pág. 65.

PETRUZZI, Marina A., SHEPPARD, Valerie y MARQUES, Catarina. Positioning Airbnb and Fairbnb in the sharing-exchange continuum. En: Current Issues in Tourism, 2019. DOl: https://doi.org/10.1080/13683500.2019.1697650.

ROSENBLAT, A. y STARK, L. Uber's Drivers: Information Asymmetries and Control in Dynamic Work. SSRN Electronic Journal, 2015. DOl: https://doi.org/10.2139/ssrn.2686227.

SCHLOZ, Trebor. Platform cooperativism. Challenging the Corporate Sharing Economy. En: Rosa Luxemburg Stiftung, 2016 [en línea]. Disponible en: http://www.rosalux-nyc.org/platform-cooperativism-2/.

SCHOLZ, Trebor y SCHNEIDER, Nathan (eds.). Ours to hack and to own: The rise of platform cooperativism, a new vision for the future of work and a fairer internet. OR Books, 2017.

SIEFKES, Christian. Self-organized Plenty. En: Keimform. Auf Der Suche Nach Dem Neuen Im Alten, 23 de noviembre de 2010 [en línea]. Disponible en: https://keimform.de/2010/self-organized-plenty/.

SRNICEK, Nick. Platform capitalism. Polity Press, 2016.

TASSINARI, Arianna y MACCARRONE, Vicenzo. Riders on the Storm: Workplace Solidarity among Gig Economy Couriers in Italy and the UK. En: Work, Employment and Society, 2020. Vol. 34, núm. 1, págs. 35-54. https://doi.org/10.1177/0950017019862954.

TAYLOR, Frederik. The Principles of Scientific Management. Cosimo, Inc, 2006.

URZI BRANCATI, M.C., PESOLE, A., FERNÁNDEZ-MACÍAS, E. New evidence on platform workers in Europe results from the second COLLEEM survey. Luxemburgo, Publications Office of the European Union, 2020. DOI: https://doi.org/10.2760/459278.

VEEN, Alex, BARRATT, Tom y GOODS, Caleb. Platform-Capital's 'App-etite' for Control: A Labour Process Analysis of Food-Delivery Work in Australia. En: Work, Employment and Society, 2020. Vol. 34, núm. 3, págs. 388-406. DOI: https://doi.org/10.1177/0950017019836911.

WARK, McKenzie. A hacker manifesto. Harvard University Press, 2004.

WOOD, Alex et al. Good Gig, Bad Gig: Autonomy and Algorithmic Control in the Global Gig Economy. En: Work, Employment and Society, 2019. Vol. 33, núm. 1, págs. 56-75. DOl: https://doi.org/10.1177/0950017018785616.

Cita recomendada: RENAU*, Melissa; FUSTER, Mayo; ESPELT, Ricard. Alternativas al capitalismo de plataforma. Democratizando la economía de plataforma. Oikonomics [en línea]. Mayo 2021, n. 15. ISSN: 2339-9546. DOI: https://doi.org/10.7238/o.n15.2102

Los textos publicados en esta revista están sujetos -si no se indica lo contrario- a una licencia de Reconocimiento 4.0 Internacional de Creative Commons. Puede copiarlos, distribuirlos, comunicarlos públicamente, hacer obras derivadas siempre que reconozca los créditos de las obras (autoría, nombre de la revista, institución editora) de la manera especificada por los autores o por la revista. La licencia completa se puede consultar en https://creativecommons.org/licenses/by/4.0/deed.es_ES.

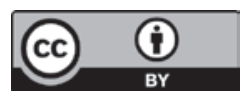




\section{Melissa Renau Gano \\ mrenauc@uoc.edu \\ Universitat Oberta de Catalunya}

Melissa Renau es doctoranda en Dimmons en el Internet Interdisciplinary Institute de

la Universitat Oberta de Catalunya. Actualmente desarrolla su tesis doctoral en Dimmons como parte del proyecto europeo Platform Labour in Urban Spaces sobre la flexibilidad y las condiciones laborales en la economía de plataformas. Tiene un máster en Sociología por la Universitat de Barcelona y una licenciatura en Administración de Empresas por la Universitat Pompeu Fabra.

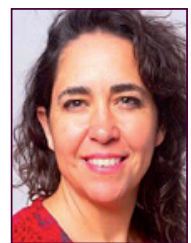

\section{Mayo Fuster Morell}

mfuster@uoc.edu

\section{Universitat Oberta de Catalunya y Berkman Center}

Mayo Fuster Morell es investigadora principal de Dimmons en el Internet Interdisciplinary Institute de la Universitat Oberta de Catalunya. Profesora afiliada al Berkman Klein Center for Internet and Society de la Universidad de Harvard. Es directora de la Cátedra Barcelona UOC en Economía Digital: para una economía colaborativa centrada en el bienestar de las personas y el derecho a la ciudad, de la UOC junto al Ayuntamiento de Barcelona y Barcelona Activa. Ha sido la investigadora principal de la UOC para los proyectos europeos DECODE: Decentralised Citizens Owned Data Ecosystem y PLUS: Platform Labor in Urban Spaces. Fue la investigadora principal del proyecto europeo P2Pvalue: Techno-social platform for sustainable models and value generation in commons-based peer production in the Future Internet. El 2010, concluyó su tesis doctoral en el Instituto Universitario Europeo de Florencia sobre la gobernanza de la producción procomún entre iguales y cuenta con numerosas publicaciones en este campo.

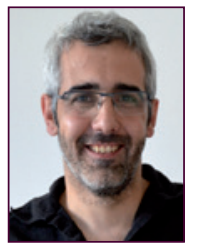

\section{Ricard Fspelt ricardespelt@uoc.edu Universitat Oberta de Catalunya}

Investigador senior y coordinador del equipo de investigación Dimmons en el Internet Interdisciplinary Institute de la Universitat Oberta de Catalunya. Centró su tesis doctoral en estudiar el impacto de Internet en el ámbito del cooperativismo agroecológico y ha desarrollado su línea de investigación en torno al cooperativismo de plataforma. Es licenciado en Bellas Artes y tiene una larga trayectoria en el eje que interrelaciona la educación y el arte. Es investigador posdoctoral y coordinador del proyecto europeo PLUS: Platform Labor in Urban Spaces y fue coordinador del proyecto DECODE: Decentralised Citizens Owned Data Ecosystem en Dimmons. 


\section{OTIOLIOMTS}

Revista de economía, empresa y sociedad

Dosier sobre economía colaborativa (y II)

Nuevas estrategias y dimensiones alternativas de la economía de plataforma

Coordinador: Lluís Alfons Garay Tamajón

NUEVAS FORMAS DE TRABAJO

\section{H futuro es colectivo y los colectivos son el futuro}

\section{Albert Gañigueral Bagó}

Ouishare

RESUMEN La evolución hacia la empresa-red y la fragmentación del trabajo que se deriva incrementa el número de personas trabajadoras autónomas con relaciones intermitentes entre varios empleadores y con sus posibles compañeros de trabajo. En este contexto emergen los «colectivos de autónomos" o "colectivos de independientes» en contraposición a la narrativa de que los trabajadores autónomos están aislados entre sí. Estos colectivos organizan luchas contra los algoritmos, luchas por los derechos laborales, mutualizan recursos materiales y digitales e incluso se presentan al mercado bajo una marca unificada sin ser una empresa. Al ser formas emergentes de organización, se enfrentan a retos acerca de su reconocimiento como actores en el diálogo social e incluso se les acusa de actuar como cárteles bajo el prisma de la libre competencia. Si bien sus formas actuales es probable que no sean las formas definitivas, podemos intuir que los "colectivos de autónomos» tienen y tendrán un papel relevante para definir las formas de trabajar y de vivir en el futuro.

PALABRAS CLAVE plataformas digitales; trabajadores de plataforma; economía gig; colectivos; autónomos 


\title{
The future is collective and the collectives are the future
}

\begin{abstract}
The evolution towards the network company and the resulting fragmentation of work increases the number of self-employed persons with intermittent relationships between various employers and with their potential co-workers. In this context, "collectives of the self-employed" emerge in contrast to the narrative that self-employed workers are isolated from each other. These collectives organise fights against algorithms, fights for labour rights, pool material and digital resources and even present themselves to the market under a unified brand without being a company. As emerging forms of organisation, they face challenges regarding their recognition as actors in social dialogue and are even accused of acting as cartels under the prism of free competition. Although their current forms are probably not the definitive forms, we can intuit that the "collectives of the self-employed" have and will have a relevant role in defining the ways of working and living in the future.
\end{abstract}

KEYWORDS digital platforms; platform workers; gig economy; collectives; self-employed

\section{Introducción}

Desde las últimas décadas del siglo XX, la «empresa-red» (Artiles, 1994) se ha convertido en el modelo paradigmático de organización productiva empresarial, fomentando la externalización de todo aquello que no se considera el centro del negocio (core business). Esto ha derivado en una mayor temporalidad en el empleo. Millones de personas ya no configuran sus vidas laborales alrededor de un empleo tradicional de 9 a 5 en un único empleador durante un período prolongado de tiempo (ver imagen 1). La irrupción de las plataformas digitales laborales (Cañigueral, 2020), que reducen los costes de transacción y coordinación para encontrar el talento que las organizaciones necesitan (Moore, 2014), ha acelerado aún más las tendencias de externalización preexistentes. Con ello la vida y la carrera laboral de un número creciente de personas trabajadoras se ha fragmentado (Bersin, 2019) y las fronteras del tiempo y el espacio de trabajo se han difuminado. En este artículo se explora cómo estas personas trabajadoras, con vidas laborales fragmentadas, se unen para cubrir sus necesidades laborales y vitales a la vez que defienden sus derechos laborales en un entorno narrativo y normativo que no les favorece.

\section{Imagen 1. El trabajo ya no es lo que era}

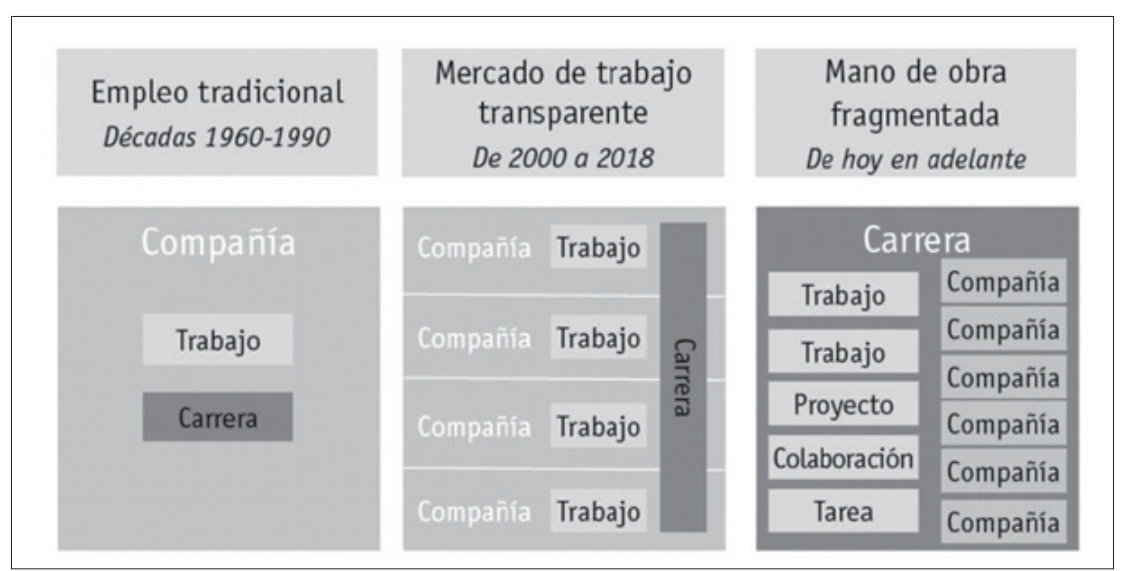

Fuente: adaptación de Josh Bersin 


\section{Trabajadores fragmentados del mundo, juníos!}

«iProletarios de todos los países, uníos!» es un lema político incluido en el Manifiesto del Partido Comunista, escrito por Karl Marx y Friedrich Engels, y una de las consignas más famosas y representativas de la causa del comunismo a nivel internacional. Si lo adaptamos al nuevo paradigma laboral, podríamos decir algo como: «iTrabajadores fragmentados del mundo, uníos!». Tras el estudio de las nuevas formas laborales durante unos años, una de las conclusiones imprevistas a las que he llegado es que el protagonista del futuro del trabajo no es el trabajador individual (fragmentado, autónomo o independiente), sino que son los «colectivos de autónomos» o "colectivos de independientes". La calidad de la experiencia laboral es muy diferente para el trabajador autónomo aislado, que es menos productivo y tiene problemas de salud más a menudo, que para los trabajadores autónomos agrupados. Así como las tecnologías digitales facilitan la fragmentación del trabajo, son estas mismas tecnologías las que facilitan la unión (Heimans y Timms, 2018) de los trabajadores autónomos en colectivos. Para aclarar lo comentado, se presentan en la tabla 1 varios ejemplos de cómo estas personas trabajadoras se unen mediante diversidad de formatos por diversos intereses.

\section{Tabla 1. Resumen de colectivos de trabajadores autónomos}

\begin{tabular}{|c|c|c|}
\hline Función principal & Descripción & Ejemplos \\
\hline Resistencia algorítmica & $\begin{array}{l}\text { Coordinarse para forzar un comportamiento concreto } \\
\text { de los algoritmos de la plataforma. }\end{array}$ & $\begin{array}{l}\text { Uber Surge Club, } \\
\text { Instagram Engagement Pods }\end{array}$ \\
\hline Sindical & $\begin{array}{l}\text { Defensa de los derechos laborales de las personas } \\
\text { trabajadoras en un sector de actividad concreto. } \\
\text { Operan a nivel local o nacional y se coordinan a nivel } \\
\text { supranacional. }\end{array}$ & $\begin{array}{l}\text { RidersXDerechos, Acua Chile, } \\
\text { Independants.co }\end{array}$ \\
\hline Mutualismo & $\begin{array}{l}\text { Mutualizar servicios compartidos (gestoría, seguros, } \\
\text { acceso a formación especializada, etc.). A menudo en } \\
\text { forma cooperativa. }\end{array}$ & Smart, Coopaname, CoopArt \\
\hline Espacio físico & $\begin{array}{l}\text { Espacios de trabajo compartido para una actividad } \\
\text { sectorial. Coworking de nicho. Comunidad. }\end{array}$ & $\begin{array}{l}\text { The Wing, The Writers Room, } \\
\text { The Qube, Nest City Lab }\end{array}$ \\
\hline Aprendizaje & $\begin{array}{l}\text { Compartir dudas y conocimiento en espacios mayo- } \\
\text { ritariamente digitales. Existen en diversos grados de } \\
\text { formalidad. }\end{array}$ & $\begin{array}{l}\text { SinOficina, StackOverflow, Meetups, } \\
\text { Grupos de Facebook, etc. }\end{array}$ \\
\hline Acceso al mercado & $\begin{array}{l}\text { Agrupación de trabajadores autónomos bajo una mis- } \\
\text { ma marca, sector de actividad, valores, etc. Aportan } \\
\text { continuidad al entorno laboral fragmentado. }\end{array}$ & $\begin{array}{l}\text { Ouishare, Happy-Dev, MyWaySpain, } \\
\text { Hoxby }\end{array}$ \\
\hline $\begin{array}{l}\text { Propiedad de los medios } \\
\text { de trabajo }\end{array}$ & $\begin{array}{l}\text { Plataformas cooperativas donde los trabajadores } \\
\text { son propietarios del código y de la gobernanza del } \\
\text { proyecto. }\end{array}$ & $\begin{array}{l}\text { CoopCycle, Mensakas, Up\&Go, } \\
\text { Stocksy, Eva }\end{array}$ \\
\hline
\end{tabular}




\subsection{Cuatro ámbitos de unión en mayor profundidad}

\section{Colectivos para la resistencia algorítmica}

Hecho el algoritmo, hecha la trampa. Mediante estrategias suficientemente elaboradas, mediante un trabajo colectivo, es posible hackear el algoritmo de la plataforma. Por ejemplo, en Instagram existen los grupos de compromiso (engagement pods) de influencers como una forma emergente de resistencia (O'Meara, 2019). Los grupos acuerdan comentar, compartir o interactuar entre sí, sin importar el contenido. De esta manera, el algoritmo de Instagram prioriza el contenido de los participantes y lo muestra a un público más amplio. Por otro lado, las estrategias de los conductores de Uber para disparar de manera artificial el surge pricing («multiplicador de precio») han sido bastante comentadas en los medios americanos. El incremento de precios se activa cuando hay una gran demanda de viajes, como cerca de un aeropuerto o después de un concierto o un partido de fútbol, y poca oferta. Los conductores pueden activar el surge pricing al apagar y encender sus aplicaciones de manera coordinada. Por ejemplo, se acercan a la zona del estadio y cinco minutos antes del final de un partido apagan las apps. En ese momento los espectadores empezaran a pedir viajes y al no existir oferta suficiente sube el precio. Cinco minutos más tarde vuelven a activar la aplicación y pueden ganar más dinero por el mismo trabajo que iban a realizar. En canales de YouTube de conductores para aplicaciones hablan del «Surge Club» (Hamilton, 2019), en referencia al Fight Club (El club de la lucha), y a la vez piden que Uber reflexione acerca de su política de remuneración.

\section{Colectivos de carácter sindical o neosindical}

Históricamente, uno de los elementos clave para la mejora de las condiciones de los trabajadores ha sido su organización colectiva y la acción sindical. En el caso de muchos de los trabajadores atípicos (ej.: Las Kellys de los hoteles) y de los trabajadores de plataforma, que no comparten ni espacio ni tiempo de trabajo, resulta algo más difícil, pero no imposible. Hoy en día la coordinación puede materializarse mediante la creación de un grupo de WhatsApp, mediante el que se puede proponer una huelga 2.0 (Shenker, 2019). En el ámbito de los trabajadores de plataforma, los primeros en organizarse fueron los trabajadores de las plataformas bajo demanda, contribuyendo al incremento de su visibilidad respecto a otros colectivos. En España, a mitades de 2017, los repartidores de Deliveroo convocaron la primera huelga de trabajadores de una plataforma digital. Los riders de Deliveroo crearon Ridersxderechos como plataforma para agrupar a los trabajadores que se sumaron a la huelga.

Fue también Ridersxderechos quien lideró el segundo encuentro mundial de asociaciones de riders en Barcelona en abril de 2019. Hubo participación de otras asociaciones como la argentina APP Sindical (Asociación de Personal de Plataformas), la inglesa IWW Couriers Network o la francesa CLAP. Todas ellas se unen bajo la Transnational Courier Federation para defender sus derechos local y globalmente. Colectivos similares han emergido allá donde las plataformas de trabajo bajo demanda han empezado a funcionar. Debido a la heterogeneidad de los trabajadores de plataforma (Cañigueral, 2020) (incluso dentro de una misma plataforma o sector) emergen diversidad de grupos que representan a mensajeros con objetivos y puntos de vista diversos. Además de Ridersxderechos y SindicatoRiders, colectivos que denuncian la relación de falsos autónomos con las plataformas y piden una relación de empleo por cuenta ajena, existen otras asociaciones, como AsoRiders, Asociación Profesional de Riders Autónomos (APRA) y AutoRiders, que se posicionan a favor de seguir siendo autónomos y centran su actividad en mejoras operativas de las plataformas y de protección de los trabajadores autónomos. El conflicto entre los diversos colectivos es visible en los medios de comunicación (Cózar, 2020).

Otro de los colectivos que más y mejor se han organizado han sido los conductores de Uber y similares, con agrupaciones de trabajadores como United Private Hire Drivers, Independent Drivers Guild, Drivers United, Gig Workers Rising o AcuaChile, por mencionar algunos de los más activos. A finales de enero de 2020, representantes de conductores de 23 países se reunieron en Londres para crear la International Alliance of App-based Transport Workers (IAATW) y así llevar su lucha colectiva a una escala global (Varghese, 2020), a la misma escala que muchas de estas plataformas. El mapa "Leeds Index of Platform Labour Protest» 
(Trappmann et al., 2020) recopila y analiza más de 300 protestas y conflictos de los trabajadores de plataformas bajo demanda a escala global. En la mayoría de las instancias, los cambios en el sistema de pagos han sido la causa principal.

Los medios y la literatura se centran mucho en los ejemplos en riders y conductores por ser los más mediáticos, pero el fenómeno de los neosindicatos abarca todos los sectores de actividad. Nunca fue ni tan fácil ni tan necesario organizarse entre los trabajadores. La National Domestic Workers Alliance es un gran grupo de trabajadoras del hogar en Estados Unidos. En España las camareras de hotel, conocidas como kellys, tienen grupos locales en las principales ciudades turísticas. También hay grupos para redactores en medios digitales (Digital Writers Union) o youtubers (FairTube). Otro tipo de trabajadores de plataforma que se ha organizado de manera más visible han sido los freelancers mediante colectivos como Freelancers Union (Estados Unidos) o Independants.co (Francia). Todos se han organizado colectivamente para mejorar sus condiciones de trabajo.

\section{Colectivos de carácter mutualista}

Los trabajadores independientes también se han unido para mutualizar riesgos y repartir gastos en grupos de intereses similares. En algunos casos acaban desarrollando unos servicios WorkerTech (Cañigueral, 2019) de carácter más cooperativo. En Reino Unido el caso de Breadfunds fue de los pioneros. Se trata de un grupo de 25 a 50 personas que contribuyen con algo de dinero cada mes a un fondo para poder apoyar a cualquiera de estos miembros cuando no pueden trabajar por una enfermedad o lesión. En Francia WeMind y OtherWise siguen la misma lógica. También en Francia la ley de las CAE (coopératives d'activités et d'emploi) ha permitido el nacimiento de proyectos como Port Parallèle, Coopaname u Oxalis; donde uno se hace socio y trabajador asalariado de la cooperativa. El «salario» y el volumen de cotizaciones dependerá de los proyectos facturados como trabajador independiente, pero es un trabajador asalariado a ojos de la administración, bancos, etc. En España existen CoopArt o Smart Iberia que, amparadas bajo la ley de cooperativas de Andalucía, actúan de manera similar a una CAE. Smart Iberia forma parte del grupo europeo Smart con sede central en Bélgica y con más de 120.000 socios en toda Europa. Las cooperativas se encargan de la administración y se llevan un $\%$ por todo ello.

\section{Colectivos para acceder al mercado}

Mi propia vida laboral es fragmentada haciendo de consultor, divulgador, formador, escritor, etc. a lo largo del año para varios clientes en Europa y América principalmente. En este "caos», lo que me aporta continuidad, sentido de pertenencia e identidad laboral es el colectivo Ouishare. Son mis compañeros/as de aventuras y de cuando en cuando también mis compañeros/as de trabajo en diversos proyectos.

Estar acompañado de esta manera permite aprender más rápido, mutualizar algunos temas comunes (espacio de coworking, gestoría, herramientas informáticas, etc.). Nos pasamos trabajos los unos a los otros y cuidamos colectivamente la marca y la reputación de manera que es más fácil para todos conseguir otros trabajos individuales o colectivos. La última evolución con la que se está experimentando son los «PODS» (Basterfield, 2018) y los «TetraPod» (Trepat, 2021). Existen otros grupos similares a Ouishare. Happy Dev (desarrolladores por toda Francia), Collectif Cosme (en Burdeos como agrupación de freelancers de la comunicación), Enspiral (Nueva Zelanda) o Colab.coop (Estados Unidos), por mencionar algunos. Estos colectivos no suelen ser muy grandes ni tienen ambición de crecer. Es gente que se une por afinidad en valores y por tener habilidades complementarias en un ámbito profesional concreto. Luego existen colectivos de mayor escala y menor foco en los valores, más cercanos a una red de expertos que a una comunidad. Destaco Hoxby, Moonlightwork, Contra, MyWaySpain o Communo. Estas agrupaciones ofrecen a las empresas su grupo de freelancers altamente seleccionados. Algo similar a una agencia o un bufete, pero sin empleados y con capacidad de acceder a talento muy diverso en todo el mundo. 


\subsection{Observaciones adicionales}

A la luz de los ejemplos, algunas observaciones adicionales:

- Este tipo de agrupaciones son un fenómeno relativamente reciente en el ámbito de los trabajadores de plataforma. Hay otros sectores, como el ámbito creativo y artístico, donde los trabajadores han vivido con relaciones laborales fragmentadas desde hace muchos años. Estudiar en mayor profundidad estos sectores puede ser relevante para anticipar la evolución y los retos que se van a presentar en los colectivos de trabajadores de plataforma.

- Los colectivos de carácter sindical y de acceso al mercado, al no encajar legalmente en un formato de sindicato tradicional al no ser asalariados, se enfrentan a varios retos. Por un lado, su nivel de reconocimiento como interlocutores en el diálogo social no es siempre el que sería deseable (Gyulavári, 2020). Por otro lado, con una interpretación estrecha de las leyes de competencia, se les está acusando de tener comportamientos de tipo cártel (ej.: fijación de precios mínimos) (DCCA, 2020). Recientemente la Comisión Europea ha emitido una iniciativa para permitir a los trabajadores autónomos negociar colectivamente sin ser obstaculizados por la ley de competencia. Este trabajo deberá ser seguido de cerca.

- Las plataformas digitales laborales (UpWork/Freelancer.com) están empezando a aceptar no solo individuos, sino también grupos de freelancers y agencias. Las empresas también deberán empezar a incluir la contratación de colectivos, no solo de personas, en su gestión de talento. Como dice Xavier Damman de Open Collective: «Cuando contratas a alguien de una comunidad, estás contratando a mucho más que al individuo en particular. También te beneficias de la inteligencia colectiva de la(s) comunidad(es) a la(s) que pertenece» (Damman, 2017).

\section{Conclusiones}

Como ha quedado demostrado con la revisión de iniciativas, la colectivización de las personas trabajadoras con vidas y carreras laborales fragmentadas es un fenómeno emergente, en crecimiento y en movimiento. No creo que la forma actual de relación entre empleadores, plataformas y trabajadores independientes sea la forma final en la que se configurará el futuro del trabajo. En algunos aspectos estos colectivos se podrían comparar con los colectivos comerciales de la Edad Media que eran los gremios: compañeros de profesión que se unen para aprender, organizarse y defenderse. Del mismo modo que han surgido los neosindicatos, en próximas iteraciones pueden emerger «neogremios digitales" y tener un rol importante en el futuro del trabajo de los trabajadores autónomos. El estratega John Hagel lo ha resumido con un «From the Gig Economy to the Guild Economy» (Hagel, 2020), que no tiene una traducción simple al castellano. Sin duda los "colectivos de autónomos» tienen y tendrán un papel relevante para definir las formas de trabajar y de vivir en el futuro. Será recomendable seguir de cerca su evolución.

\section{Bibliografía}

ARTILES, A. (1994). «La empresa red: un modelo de división del trabajo entre empresas». Papers, vol. 44, pág. 87. DOI: https://doi.org/10.5565/rev/papers.1747

BASTERFIELD, S. (2018). «P's in a pod: Purpose, Proximity \& Product - the journey of the Golden Pandas». Enspiral Tales [en línea] [fecha de consulta: 28 de enero de 2021]. Disponible en: https://medium.com/enspiraltales/ps-in-a-pod-purpose-proximity-product-the-journey-of-the-golden-pandas-ab3c77e29abf

BERSIN, J. (2019). «The Pixelated Workforce: A Job For Almost Everyone». Josh Bersin [en línea] [fecha de consulta: 28 de enero de 2021]. Disponible en: https://joshbersin.com/2019/06/the-pixelated-workforce-a-jobfor-almost-everyone/. 
CAÑIGUERAL, A. (2019). El mercado digital a debate: Plataformas, trabajadores, derechos y WorkerTech. Fundación COTEC. ISBN: 978-84-92933-42-6

CAÑIGUERAL, A. (2020). El trabajo ya no es lo que era: Nuevas formas de trabajar, otras maneras de vivir. Penguin Random House Grupo Editorial, España. ISBN: 9788417992057

DCCA (2020). «Commitment decision on the use of a minimum hourly fee». DCCA [en línea] [fecha de consulta: 28 de enero de 2021]. Disponible en: https://www.en.kfst.dk/nyheder/kfst/english/decisions/20200826-commitment-decision-on-the-use-of-a-minimum-hourly-fee-hilfr/

CÓZAR, C. (2020). "La guerra de 'riders': quién es quién en la batalla por los derechos de los repartidores de Glovo». Economía Digital [en línea] [fecha de consulta: 28 de enero de 2021]. Disponible en: https://www. economiadigital.es/finanzas/la-guerra-de-riders-quien-es-quien-en-la-batalla-por-los-derechos-de-los-repartidores-de-glovo_20113708_102.html

DAMMAN, X. (2017). «From firms to collectives». Open Collective [en línea] [fecha de consulta: 28 de enero de 2021]. Disponible en: https://medium.com/open-collective/from-firms-to-collectives-c139ae27a4ee

MOORE, G. (2014). «La naturaleza de la empresa (75 años después)». Reinventar la empresa en la era digital. Alianza Editorial, pág. 51-62.

GYULAVÁRI, T. (2020). "Collective rights of platform workers: The role of EU law». Maastricht journal of European and comparative law, vol. 27, núm. 4, pág. 406-424. DOI: https://doi.org/10.1177/1023263X20932070

HAGEL, J. (2020). «From the Gig Economy to the Guild Economy». John Hagel [en línea] [fecha de consulta: 28 de enero de 2021]. Disponible en: https://www.johnhagel.com/from-the-gig-economy-to-the-guild-economy/

HAMILTON, I. A. (2019). «Uber drivers are reportedly colluding to trigger «surge» prices because they say the company is not paying them enough». Business Insider [en línea] [fecha de consulta: 28 de enero de 2021]. Disponible en: https://www.businessinsider.com/uber-drivers-artificially-triggering-surge-prices-reports-abc7-2019-6

HEIMANS, J.; TIMMS, H. (2018). New Power: How Power Works in Our Hyperconnected World --and how to Make it Work for You. Doubleday. ISBN: 9780385541114

O'MEARA, V. (2019). «Weapons of the chic: Instagram influencer engagement pods as practices of resistance to Instagram platform labor». Social media + society, vol. 5, núm. 4, págs. 205630511987967. DOI: https://doi. org/10.1177/2056305119879671

SHENKER, J. (2019). "Strike 2.0: how gig economy workers are using tech to fight back». The Guardian [en línea] [fecha de consulta: 28 de enero de 2021]. Disponible en: http://www.theguardian.com/books/2019/aug/31/ the-new-resistance-how-gig-economy-workers-are-fighting-back

TRAPPMANN, V. et al. (2020). «Trends in Collective Action, Organising and Mobilisations in the Platform Economy». 32nd Annual Meeting [en línea]. SASE. Disponible en: https://sase.confex.com/sase/2020/meetingapp.cgi/Paper/15890

TREPAT, A. (2021). «High-trust teams to navigate the futureS of work». Medium, 2021 [en línea] [fecha de consulta: 28 de enero de 2021]. Disponible en: https://aliciatrepatpont.medium.com/high-trust-teams-to-survivethe-future-of-work-d807e3949ea6

VARGHESE, S. (2020). «Gig economy workers have a new weapon in the fight against Uber». WIRED UK [en línea] [fecha de consulta: 28 de enero de 2021]. Disponible en: https://www.wired.co.uk/article/gig-economy-uberunions

Citación recomendada: CAÑIGUERAL BAGÓ, Albert. El futuro es colectivo y los colectivos son el futuro. Oikonomics [en línea]. Mayo 2021, no. 15, pp. 1-8. ISSN: 2339-9546. DOI: https://doi. org/10.7238/o.n15.2101 


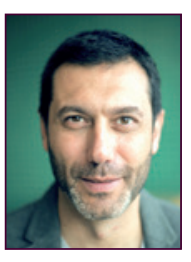

\section{Albert Cañigueral} albert@ouishare.net Ouishare

Albert Cañigueral es el Connector Ouishare para España y América Latina. En 2011 fundó el blog Consumo Colaborativo y, desde entonces, es considerado uno de los mayores referentes de la economía de plataforma en español. Ha publicado recientemente el libro El trabajo ya no es lo que era: nuevas formas de trabajar, otras maneras de vivir (Conecta, 2020). Trabaja como explorador, consultor y divulgador en el ámbito de la economía de plataforma y actualmente se ha centrado sobre todo en el futuro del trabajo, el impacto de las plataformas digitales en las ciudades y las innovaciones regulatorias.

Los textos publicados en esta revista están sujetos -si no se indica lo contrario- a una licencia de Reconocimiento 4.0 Internacional de Creative Commons. Puede copiarlos, distribuirlos, comunicarlos públicamente, hacer obras derivadas siempre que reconozca los créditos de las obras (autoría, nombre de la revista, institución editora) de la manera especificada por los autores o por la revista. La licencia completa se puede consultar en https://creativecommons.org/licenses/by/4.0/deed.es_ES.

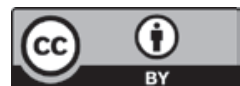




\section{OTIOLTOMTS}

Revista de economía, empresa y sociedad

Dosier sobre economía colaborativa (y II)

Nuevas estrategias y dimensiones alternativas de la economía de plataforma

Coordinador: Lluís Alfons Garay Tamajón

NUEVAS FORMAS DE EMPLEO

\section{Fconomía colaborativa \\ y regulación laboral}

\section{Miguel Rodríguez-Piñero Royo1}

Catedrático de Derecho del Trabajo (Universidad de Sevilla). Senior Counsellor, PwC

RESUMEN La regulación del trabajo se ha construido sobre una dicotomía asalariado-autónomo que está siendo superada por el desarrollo de nuevas formas de empleo. Entre estas destacan las vinculadas con nuevos modelos económicos, como la economía colaborativa, en la que personas se prestan servicios con un valor económico, pero al margen de los mercados y de los modelos contractuales tradicionales. Estas modalidades de prestación de servicios encuentran un encaje defectuoso en este modelo binario, demandando un marco regulatorio propio. El objetivo de este trabajo es delimitar este pro-blema y plantear algunas posibles alternativas de intervención para resolverlo.

PALABRAS CLAVE trabajo en plataformas; trabajo cooperativo; trabajo voluntario; economía circular; economía colaborativa; mercado de trabajo.

1. Grupo de Investigación PAIDI SEJ-322. Es un resultado científico del proyecto de investigación "Nuevas dinámicas y riesgos sociales en el mercado de trabajo del siglo XXI: desigualdad, precariedad y exclusión social", de la convocatoria 2018 de "Proyectos de I+D Retos Investigación", con referencia RTI2018-098794-B-C31. También lo es del proyecto FEDER18-1264479 "Nuevas Causas y Perfiles de Discriminación e Instrumentos para la Tutela Antidiscriminatoria en el Nuevo Contexto Tecnológico Social". 


\title{
Circular economy and the regulation of labour
}

\begin{abstract}
The regulation of work has been built on a dependent/self-employed dichotomy, which is being overcome by the development of new forms of employment. Among these, those linked to new economic models, such as the collaborative economy, are becoming very relevant. In these forms of work people provide services with an economic value, but outside traditional markets and contractual schemes. These provisions of services find a faulty fit in this binary model, demanding their own regulatory framework. The objective of this work is to define this problem, and to propose some alternatives to solve it.
\end{abstract}

KEYWORDS platform work; cooperatives; voluntary work; circular economy; collaborative economy; labour market

\section{Introducción: el triskelion regulativo laboral}

La afamada serie alemana Dark ha puesto de moda un símbolo, el triskelion o triqueta, una figura con tres partes idénticas que salen de un núcleo, cuyos bordes forman una línea continua. El símbolo es sugerente, y me gustaría utilizarlo para explicar lo que considero es el modelo de regulación del trabajo que se está generando en el siglo xxl, el segundo siglo en el que contamos con un derecho del trabajo propio de tal nombre.

Este se ha construido a partir de una decisión básica, la de delimitar qué tipo de «trabajos» regulaba. Porque nunca se diseñó para regular todos los presentes en el mercado, nunca pretendió ser un verdadero «Derecho del trabajo» en su totalidad, de todo trabajo. Lo que siempre fue, y sigue siendo, es el erecho del trabajo subordinado, de un sector del mercado caracterizado por el mecanismo a través del cual se articula el intercambio de servicios profesionales, el contrato de trabajo. Que este haya crecido hasta convertirse en el modelo de referencia explica que esta rama del derecho se haya desarrollado hasta sus niveles actuales. Este es uno de los tres elementos del triskelion: el trabajo por cuenta ajena, que incluye también a los funcionarios públicos, materialmente subordinados aunque vinculados con su empleador mediante un instrumento jurídico diferente.

El segundo elemento es el trabajo autónomo, la forma no asalariada con mayor presencia en el mercado y mayor grado de regulación, hasta convertirse en el modelo alternativo de ordenación del trabajo. Definido de manera especular con el trabajo asalariado, lo más que se puede decir es que le faltan las notas que definen este, la ajenidad y la dependencia, siendo, en consecuencia, por cuenta propia y autónomo; por encima de todas las cosas, trabajo no asalariado.

La regulación del mercado de trabajo se basaba en esta dicotomía tradicional, y fueron estas dos modalidades las que guiaron la construcción de su regulación. Existía entre ellas una frontera rígida y poco permeable, dado que cada una se definía con elementos opuestos a los de la otra; aunque a la vez controvertida y difícil de delimitar, por las presiones de los operadores del mercado de ubicarse en el territorio que les resultaba más favorable a sus intereses, y por la propia indeterminación de los elementos definitorios.

Esta dicotomía se extendía también al ámbito de la Seguridad Social, que en la mayor parte de los casos se construyó dividiendo su protección en dos grandes sistemas, uno para cada tipo de trabajo, adaptándose a la mayor diferencia entre ambos, la existencia o no de un empleador.

La consolidación del modelo dual supuso una tendencia expansiva de ambas áreas. Al definirse las dos grandes áreas por exclusión mutua, lo que no era una cosa era necesariamente la otra; y si no encajaba bien en ninguna, se le buscaba un acomodo más o menos forzado. Seguramente es en el ámbito de la Seguridad Social donde mejor se percibe este efecto, mediante figuras como la asimilación al alta, que hace que personas 
que materialmente no sean autónomos ni asalariados puedan integrarse en alguno de estos dos regímenes del sistema público.

Lo que no encajaba en ninguna de las dos categorías quedaba fuera de la atención del regulador, que las consideraba poco relevantes, por su escasa presencia, por su poca importancia económica y, también, por el desprecio hacia actividades predominantemente femeninas (como ocurre con los cuidados).

En el siglo XXI este tercer espacio demanda tanta atención como los otros dos. Lo forman figuras de las prestaciones de servicios que no encajan en estos dos modelos tradicionales por algún elemento relevante: la finalidad del intercambio, la falta de empleador por trabajarse para la propia economía doméstica (trabajo familiar y doméstico), la presencia de un marco jurídico alternativo para el intercambio (el trabajo cooperativo), etc. Esta sería el tercer, y emergente, sector del triskelion.

El ordenamiento ha ido respondiendo de manera puntual, proporcionando un marco normativo a algunas de las alternativas más extendidas y cercanas a los mercados tradicionales. Así ha ocurrido con la economía social, el modelo más presente y regulado, hasta llegar a presentarse como una especie de tercera vía. Esto ya no es suficiente, y otros modelos de prestación de servicios demandan una habitación propia en el Derecho de los trabajos. Dos tendencias confluyen en esto: la expansión y diversificación de estas formas, hasta alcanzar una dimensión económica considerable; y la voluntad del Estado para ocupar todos los espacios sociales en los que se producen relaciones económicas, integrándolos en su sistema fiscal y de protección social. Cada vez más, quien trabaja debe tributar e integrarse en la Seguridad Social, si lo que hace tiene un impacto económico. Los servicios excluidos están viendo reducido su espacio. La Seguridad Social lidera el camino, integrando en su protección situaciones originalmente no contempladas (como las prácticas o los cuidadores no profesionales); las normas laborales no van muy detrás.

Entre las nuevas formas destacan las vinculadas con modelos económicos alternativos. En estas el objetivo que mueve a las partes es peculiar, puesto que no buscan cambiarse unos servicios por una retribución o precio, sino obtener otras satisfacciones por lo que hacen, o cumplir otro tipo de obligaciones, o simplemente buscar alternativas a los mercados tradicionales. No hay un mercado de trabajo ni de servicios, sino otra forma de entender las relaciones entre las personas. Las situaciones son distintas, y también las retribuciones. En este trabajo me referiré a ellas, con todas las reservas, como "economía circular» o "economía colaborativa», aun siendo consciente de las grandes diferencias entre ambas.

¿Cómo integrar estas formas de intercambio en un modelo dual? ¿Cómo lograr una respuesta regulatoria adecuada para el tercer elemento del triskelion? Reflexionar sobre esto es el objetivo de este trabajo.

\section{2. ¿Cómo ubicar la economía colaborativa en la regulación laboral?}

El ordenamiento jurídico no está preparado para regular adecuadamente un panorama como el descrito. Su solución por defecto pasa por integrar el trabajo en la economía colaborativa en alguno de los dos grandes sistemas, el asalariado y el autónomo. Mantenerlo como un sector autorregulado y ajeno al Estado tampoco es sostenible cuando se alcanzan ciertas dimensiones.

La aplicación del derecho del trabajo a las actividades por cuenta ajena es automática, basta con la presencia de las notas de la laboralidad definidas por el legislador: ajenidad y dependencia, fundamentalmente. Estando ambas presentes, no hay forma de excluir esta aplicación, si no es por la propia voluntad del legislador laboral. Su ausencia determina la aplicación del modelo por cuenta propia, activado por la ausencia de subordinación.

Por ello la respuesta a esta pregunta debe hacerse mediante un análisis de los elementos característicos de estos intercambios; de aquello que el legislador considera identificador del tipo de trabajo. Debemos ver si hay ajenidad, si se trabaja en interés y beneficio de otro, y subordinación, si existe el compromiso de someterse a la dirección, al control y al poder disciplinario de este. Así analizada, gran parte de la economía colaborativa encajaría en el modelo por cuenta propia, por faltar dichos elementos. Tendríamos a autónomos intercambiando sus servicios por otros. 
Ahora bien, no se puede olvidar que la economía colaborativa genera un mercado: interno y autorregulado, pero mercado al fin, con unas disposiciones internas que determinan aspectos fundamentales del intercambio, a las que tienen que someterse los participantes. También es importante que en muchas ocasiones estos no operan profesionalmente, de manera organizada y continuada, un requisito para la calificación como trabajador autónomo. Esta conclusión tiene, pues, sus carencias.

Lo paradójico es que el elemento identitario de la economía circular, la finalidad perseguida por las partes que colaboran en estas experiencias, no encaja en este análisis. Estas resultan poco relevantes jurídicamente, dado lo difícil que resulta identificarlas y acreditarlas. Solo existe una excepción, la de los servicios que se prestan con una finalidad no lucrativa, que en el Derecho del trabajo español se califican como realizados «por amistad, benevolencia y buena vecindad", y a los que el Estatuto de los Trabajadores excluye de su ámbito de aplicación; y al hacerlo, los saca también del ámbito de la Seguridad Social.

Se ha intentado dirigir la economía colaborativa hacia este espacio, el de los trabajos benevolentes y no lucrativos. Esta solución encuentra dos serios obstáculos: el primero es que su consecuencia es la desregulación, ya que no se ha dotado a este tipo de actividades de una ordenación jurídica (con alguna excepción como el voluntariado); esto supone excluirlo, por ejemplo, de los mecanismos de protección social y de tutela del prestador de servicios. La desregulación no siempre es una buena solución, especialmente si se quiere que esta economía tenga una presencia sustancial. El segundo obstáculo es que no encaja en este supuesto, ya que los participantes aspiran a obtener un beneficio de los servicios que prestan o tienen la expectativa de poder recibir los de otros, por lo que nos encontramos ante intercambios lucrativos, ajenos a la gratuidad que caracteriza los servicios benevolentes.

No tenemos manera de encajarlo en los esquemas tradicionales, diseñados para una realidad distinta, pero con la vocación de regular toda la realidad laboral. Este es el principal problema que afrontan hoy los servicios realizados en el marco de la economía colaborativa.

\section{Economía colaborativa y trabajo en plataformas}

El trabajo en plataformas tiene poco que ver con la economía colaborativa, a pesar de que en unos primeros momentos adoptara esta denominación y se apropiara de algunos elementos culturales de esta. El elemento en común era la idea de mercado digital, a través del que se hacen posibles intercambios impensables en formatos tradicionales; también, en un primer momento, la posibilidad de utilizar recursos ociosos, como ocurría en las primeras versiones de Uber. El resto era diferente, y el intento de camuflar un nuevo sector económico tras un movimiento social fue pronto desenmascarado. Lo paradójico ha sido el posterior crecimiento de las plataformas de servicios, que han superado en presencia e impacto económico a las formas de economía colaborativa que las precedieron.

Hoy el trabajo en plataformas es la primera línea del debate sobre la regulación de los servicios. Su preeminencia es buena y mala. Tiene aspectos positivos porque está llamando la atención sobre los modelos alternativos de prestación de servicios, poniendo el foco en la necesidad de desarrollar el tercer elemento del triskelion. Ha puesto de manifiesto la insostenibilidad del modelo dual, llevando a plantearse su superación o, al menos, un rediseño en profundidad. En este debate están apareciendo construcciones originales y sugerentes, que pueden llevar a una verdadera revolución regulatoria. También nos avisa del impacto de la tecnología en los mercados de servicios.

Los aspectos negativos están también ahí. Sus efectos de huida de la regulación y de precarización han generado una justificada desconfianza hacia esta vanguardia de las formas de trabajo hiperprecario. Lo que ha llevado a reacciones del Estado cuyos efectos sobre estas no siempre son positivos. En la práctica los legisladores están afrontando esta cuestión de una manera conservadora, haciendo lo que se ha hecho siempre, intentar encajarlas en alguna de las dos áreas conocidas, calificándolos como autónomos o asalariados. El caso español es quizás el mejor ejemplo, con una ley todavía en proyecto (seguramente aprobada para cuando esto salga publicado) dirigida a facilitar la calificación como asalariados de los trabajadores del reparto a domicilio de comida preparada. 
Una medida efectiva que mejorará la situación de estas personas. Aunque no deja de ser una respuesta tradicional a un problema nuevo.

Incluso aquellos que defienden posturas teóricamente más avanzadas, se han inclinado por buscar zonas de confluencia o de soberanía compartida entre ambas. Las propuestas de "tercera vía», en algunos casos ya implementadas en algunos ordenamientos (en España tenemos los TRADE del Estatuto del Trabajo Autónomo, que son una figura equívoca en cuanto son auténticos autónomos, y no una figura intermedia), no han sido una respuesta adecuada, sivviendo en ocasiones para regularizar prácticas fraudulentas, pero no siempre de una forma adecuada, y otras veces sirviendo de canal para el propio fraude.

Lo cierto es que una posible regulación de trabajo en plataformas no servirá para resolver la cuestión de la economía colaborativa. Esta, por el contrario, se verá perjudicada no solo por la desconfianza del legislador y por la aplicación de una normativa inadecuada, sino también por una mayor atención hacia las actividades económicas, buscando traer todas estas a los espacios regulados. Su estatus actual, resguardado en gran medida de las normas aplicables al trabajo, no será sostenible mucho tiempo.

\section{Algunas soluciones}

Ante las dificultades para integrar en el ordenamiento jurídico estas formas de trabajar, la realidad nos está poniendo de manifiesto algunas iniciativas destinadas precisamente a buscarle un acomodo. En ocasiones es la propia sociedad la que genera estas prácticas, aprovechando el marco normativo existente; el apoyo público que pueden llegar a encontrar no puede ocultar su carácter autónomo. Otras veces, en cambio, es el Estado el que diseña soluciones novedosas para afrontar necesidades nuevas. Hay casos, finalmente, en los que se reutilizan para fines diferentes figuras preexistentes.

\subsection{Las monedas sociales}

Las monedas sociales son una forma de facilitar los intercambios que caracterizan muchas modalidades de economía colaborativa, creando un medio de pago y de acumulación de créditos que sirve para adquirir bienes y servicios de otros participantes en la experiencia. Limitadas originalmente en su uso a los miembros del colectivo que las creaba, y ceñidas a los intercambios entre estos, posteriormente el modelo ha sido asumido por entidades públicas y autoridades locales como forma de fomentar estas prácticas. Son numerosos los ayuntamientos que han acuñado su propia moneda social y la han puesto en circulación para intercambios de prestaciones entre sus vecinos, con mayor seguridad jurídica y alcance.

Las monedas sociales son una forma de facilitar los intercambios que caracterizan muchas modalidades de economía colaborativa, creando un medio de pago y de acumulación de créditos que sirve para adquirir bienes y servicios de otros participantes en la experiencia. Limitadas originalmente en su uso a los miembros del colectivo que las creaba, y ceñidas a los intercambios entre estos, posteriormente el modelo ha sido asumido por entidades públicas y autoridades locales como forma de fomentar estas prácticas. Son numerosos los ayuntamientos que han acuñado su propia moneda social y la han puesto en circulación para intercambios de prestaciones entre sus vecinos, con mayor seguridad jurídica y alcance.

El pago de servicios mediante monedas sociales favorece indudablemente las iniciativas colaborativas, ya que evita los problemas de inmediatez y de identidad de partes en la contraprestación, permitiendo ampliar el abanico de sujetos potenciales en las operaciones. Facilita también la asignación de un valor a los servicios. Todo esto resulta básico para las transacciones.

Es una experiencia social que, de nuevo, ha sido oscurecida por otra más llamativa, la de las monedas virtuales. La reacción frente a los riesgos generados por estas puede llevar a la adopción de medidas que restrinjan la utilización de aquellas. 
Desde el punto de vista del Derecho del trabajo las monedas sociales resultan, sin embargo, de escasa ayuda. La forma en que se produce el pago no resulta especialmente relevante para calificar unos servicios. Es cierto que estos deben ser retribuidos; y que las leyes laborales obligan desde hace tiempo a que este pago se realice en moneda oficial. De hecho, entre las primeras normas laborales se encontraban las prohibiciones del truck system, de la retribución mediante vales o mercancías. El pago en dinero fue una conquista histórica, y las normas así lo reconocen. Pero el hecho de que no se haga así no es indicativo de que no estemos ante trabajo asalariado; más bien apunta a la existencia de un incumplimiento por parte del empleador, por lo que hay una verdadera obligación de pagar el salario en el medio adecuado.

La presencia de unos servicios prestados a cambio de una de estas monedas sociales indica que estamos ante un intercambio obligatorio, con valor económico y finalidad lucrativa. Elementos todos estos que afianzan más que debilitan su calificación como una actividad por cuenta propia o ajena.

\subsection{El trabajo con bonos}

El trabajo con bonos es una modalidad de servicios, que pueden ser tanto autónomos como asalariados. Con cierta tradición en algunos países, algunos organismos europeos la califican ya como una de las «nuevas formas de empleo» ante su extensión en otros ordenamientos. Consiste en el pago de los servicios prestados mediante un bono, intercambiable por dinero, pero una vez deducidos unos porcentajes a título de cotizaciones sociales y fiscalidad sobre esta renta. El bono sustituiría la retribución en dinero del salario, pero también la formalización del contrato de servicios, la cotización social y el pago de las obligaciones fiscales. El voucher work se presenta precisamente como una modalidad especial de trabajo precisamente por las grandes peculiaridades que presenta frente al estándar. Facilita mucho las cosas, pero también supone inaplicar, o aplicar de manera peculiar, numerosas normas de gran relevancia, con el peligro de incumplimiento de estas obligaciones. Por no hablar del riesgo de generar unos títulos al portador fácilmente convertibles, desde la perspectiva del blanqueo de capitales, la posibilidad de robos, etc.

En sus orígenes fue diseñado como respuesta a varias necesidades: por un lado, asegurar que determinadas ayudas sociales se destinaban a la finalidad para la que se diseñaron (los bonos solo podrían utilizarse para ciertos fines); por otro, regularizar actividades de escasa entidad (como el cuidado de menores o las labores auxiliares) para facilitar el cumplimiento de las formalidades laborales y fiscales.

Su aplicación a la economía circular se haría mediante el intercambio de servicios por bonos, que se cambiarían por dinero ordinario en los términos indicados. La diferencia frente a las monedas sociales consiste en que estas no pueden convertirse en moneda oficial. Y que los bonos tienen un alcance mucho más amplio, al no estar limitados a los mercados internos de las iniciativas que generan las monedas sociales. Presenta, ahora bien, el mismo problema que estas, que la forma de pago es un aspecto marginal dentro del marco general del intercambio de actividades económicas. Lo relevante seguirá siendo su impacto económico y la forma de prestación. No obstante, es indudable que pueden resultar muy útiles para formalizar y ordenar las experiencias de economía circular, facilitando el cumplimiento de las obligaciones vinculadas a las prestaciones mutuas que la caracterizan.

\subsection{Las plataformas cooperativas}

La extensión de las plataformas de servicios está llevando también, como una forma particular de resistencia a sus aspectos más nocivos, a la aparición de un sector de estas gestionado por los propios trabajadores. En esta modalidad de actuación el colectivo de trabajadores operaría en el mercado como una entidad, que ofrece sus servicios asociando a las personas que los prestan; no actuando como un intermediario, y en su propio interés, que es lo que hacen las plataformas. Así compensan desequilibrios contractuales frente a mercados digitales y clientes; mutualizan riesgos y costes; y obtienen visibilidad y representación, generando un potente factor de marketing social. Serían los propios prestadores los que establecerían las condiciones generales del servicio y 
fijarían sus precios, más benevolentes y equilibrados. Se construye un interlocutor propio para este colectivo, que no solo actúa frente a las plataformas tradicionales, sino que compite con ellas utilizando sus mismos medios, mediante plataformas sociales autogestionadas, verdaderas plataformas cooperativas.

En algunos casos la creación de una cooperativa ha sido una respuesta a las condiciones abusivas impuestas por determinadas empresas gestionadoras de plataformas, mimetizándose con ellas para poder disponer de un mismo soporte tecnológico sin sus costes e inconvenientes. Así ha pasado en España con cooperativas aparecidas en el sector de la ciclomensajería y el reparto de comida cocinada.

De un modo paradójico, estas experiencias acercan el trabajo en plataforma al modelo originario de economía colaborativa, la que generó esta denominación, incorporando el componente social, mutualista y cooperativo.

El desarrollo de estas plataformas cooperativas se ha visto beneficiado de algunas medidas de apoyo. Así, la Xarxa d'Economia Solidària (XES) de Cataluña ha puesto en marcha Pam a Pam, ("palmo a palmo»), una iniciativa para mapear proyectos de economía solidaria en el territorio catalán para visibilizarlas. Por su parte, la Corporación Mondragón, en cooperación con su universidad (Mondragon Unibertsitatea) y otras entidades, ha puesto en marcha un programa formativo para impulsar la promoción del cooperativismo digital a escala mundial y promover el emprendimiento de cooperativas a través de plataformas digitales. Se trata del programa Cooperativas de Plataforma ¡YA!

Para la economía colaborativa real, las ventajas de esta alternativa son evidentes al dotarla de un marco jurídico concreto, seguro y regular, que es el de la economía social. Las obligaciones mutuas con el Estado y con terceros quedarían aclaradas, en un modelo que es además democrático e igualitario. Esta regulación, sin embargo, se diseñó pensando en actividades económicas relevantes para sus prestadores, como formas de autoempleo. Se basa en la creación de personas jurídicas estables, con pretensiones de continuidad. Esto no ocurre en todos los casos en la economía colaborativa, por lo que en ocasiones puede resultar una solución excesiva, un cierto «ensañamiento jurídico» para lo que se pretende.

\subsection{Las nuevas formas de empleo}

El fenómeno de la economía colaborativa y circular se produce en un momento muy peculiar del mercado de trabajo, que está experimentando una marcada tendencia a la diversificación. El modelo dual tradicional está siendo superado, como se vio; pero es que además las dos áreas tradicionales están sufriendo importantes transformaciones. En el ámbito del trabajo autónomo son llamativas la generalización, precarización y diversificación, en el marco de la conocida como «revolución freelance» que lo ha extendido, pero a la vez lo ha empobrecido. En el campo del trabajo asalariado el fenómeno más llamativo es el de las nuevas formas de empleo. Entre ambos, la frontera se resquebraja, con flujos de instituciones y de colectivos, mayor permeabilidad y crecimiento de las zonas comunes o superpuestas.

El fenómeno de las nuevas formas de empleo supone la aparición en el mercado de trabajo de formas originales de articular la relación laboral, a veces con reconocimiento legal. Son muchas, por lo que han aparecido nuevas clasificaciones y categorías, entre las que podemos citar las de «trabajo muy atípico» (contratos laborales de duración determinada muy breves, de menos de seis meses de duración; el trabajo a tiempo parcial de menos de 10 horas a la semana; los contratos verbales, y el trabajo «cero horas» 0 «puntual»), las «formas de empleo casual» (contratos de cero horas, trabajo a llamada, freelances, trabajo en plataformas on-line), las «formas no estándares de trabajo» (trabajo muy atípico y casual, falsos autónomos, trabajadores de contratas, trabajadores en misión, trabajo pagado con bonos, trabajo no retribuido, etc.), y las «nuevas formas de empleo» (trabajo casual, trabajo por bonos, empleo colaborativo, trabajadores compartidos, trabajo por portafolio, interim management, trabajo compartido, trabajo móvil basado en tecnologías de la infocomunicación, y trabajo en plataformas), y así.

Las instituciones de la Unión Europea han adoptado diversas iniciativas al respecto, entre las que está la Directiva (UE) 2019/1152, del Parlamento Europeo y del Consejo, de 20 de junio de 2019, relativa a unas condiciones laborales transparentes y previsibles en la Unión Europea. Otra directiva sobre trabajo en plataformas se encuentra en sus primeras fases de discusión en el Parlamento Europeo. 
En España hemos contemplado recientemente una nueva regulación del trabajo a distancia y del teletrabajo, así como la introducción de una nueva modalidad contractual, el contrato para la formación dual universitaria, por la disposición final 36.1 de la Ley 11/2020, de 30 de diciembre, de Presupuestos Generales del Estado para el año 2021. Previstas están una importante reforma para reducir la tipología contractual y una ley sobre trabajo en plataformas que se encuentra en plena discusión en el diálogo social. Acompañan a estas reformas un fortalecido activismo de la Inspección de Trabajo, y una reconstrucción de la jurisprudencia sobre contratación temporal que está restringiendo su espacio. En el marco de estos tiempos de cambio bien podría plantearse una modalidad contractual que pudiera servir para algunas manifestaciones de la economía colaborativa. No para todas, obviamente, pero sí para algunas, asegurándoles la protección de la ley y la cobertura del régimen general de la Seguridad Social.

Varias son las alternativas que tenemos en el derecho español para construir una nueva forma de empleo: como modalidad contractual, un tipo de contrato adaptado para una relación laboral por lo demás ordinaria; o como relación laboral especial, con un marco normativo completamente adaptado. El principal problema que tendríamos que afrontar es la dificultad de articular una relación bilateral, con un empleador único al que atribuirle los poderes y las responsabilidades de esta condición. Habría que pensar en un esquema innovativo, seguramente triangular, en el cual una entidad emplearía a las personas que desarrollan la actividad y las pondría en contacto con las que los reciben; solo que unas mismas personas estarían sucesivamente en dos extremos del triángulo, como trabajadores y como usuarios, según correspondiera. La Ley 14/1994, por la que se regulan las empresas de trabajo temporal, ya preveía la posibilidad de que estas adoptaran la forma de cooperativas, acercándolas al modelo de autoempleo colectivo.

Las relaciones triangulares tienen ventajas evidentes cuando se trata de articular relaciones esporádicas. Es uno de los modelos regulatorios, de hecho, que se ha propuesto para la ordenación del trabajo en plataformas. Podría servir también para la economía colaborativa, o para una parte de esta, con las debidas adaptaciones

\section{Economía circular y Estatuto de los Trabajadores para el Siglo xxI}

Nos encontramos en mitad de un período de activismo legislativo con pocos precedentes. No me refiero a la emergencia COVID, que ha generado por sí misma su propio «Derecho», conformado por una sucesión de normas de urgencia y de duración limitada a la de la crisis sanitaria (se supone). Lo que quiero decir es que en los últimos años hemos contemplado un volumen de producción de normas laborales muy anormal, sin que hayamos tenido una «reforma laboral» como las que acostumbramos a sufrir cada vez que hay una crisis económica.

Es otra cosa. Hay una voluntad de cambiar el modelo laboral que tenemos en España. Si hacemos abstracción del Derecho COVID, se está avanzado considerablemente en la mejora de los derechos de los trabajadores, tras décadas de erosión como consecuencia de las presiones deudocráticas. Aun sin haber desandado el camino de la reforma laboral de 2012, algo improbable en este contexto, los últimos cambios legislativos coinciden en esta dirección en al menos tres áreas, un nuevo triskelion de avances en la tutela de las personas trabajadoras.

La primera línea de progresión es la de los derechos digitales, que se refleja en la Ley Orgánica 3/2018, de 5 de diciembre, de Protección de Datos Personales y garantía de los derechos digitales y en el Real Decreto-Ley 28/2020, de 22 de septiembre, de trabajo a distancia; y que se verá completada por la Carta de Derechos Digitales y la «ley rider», cuando se aprueben.

La segunda la conforman las medidas para luchar por la igualdad y la no discriminación, principalmente por motivos de género. La producción legislativa se inicia con el Real Decreto-ley 9/2018, de 3 de agosto, de medidas urgentes para el desarrollo del Pacto de Estado contra la violencia de género; seguido del Real Decreto-ley 6/2019, de 1 de marzo, de medidas urgentes para garantía de la igualdad de trato y de oportunidades entre mujeres y hombres en el empleo y la ocupación; y del Real Decreto-ley 3/2021, de 2 de febrero, por el que se adoptan medidas para la reducción de la brecha de género y otras materias en los ámbitos de la Seguridad Social y económico. En el nivel reglamentario se han aprobado los importantes Reales Decretos 901/2020, de 13 de octubre, por el que se regulan los planes de igualdad y su registro, y se modifica el Real Decreto 713/2010, de 28 
de mayo, sobre registro y depósito de convenios y acuerdos colectivos de trabajo, y 902/2020, de 13 de octubre, de igualdad retributiva entre mujeres y hombres.

La tercera línea la forman medidas en materia de tiempo de trabajo y permisos, establecidas por el ya citado Real Decreto-ley 6/2019, de 1 de marzo, de medidas urgentes para garantía de la igualdad de trato y de oportunidades entre mujeres y hombres en el empleo y la ocupación; y por el Real Decreto-ley 8/2019, de 8 de marzo, de medidas urgentes de protección social y de lucha contra la precariedad laboral en la jornada de trabajo.

En conjunto, las personas trabajadoras empiezan esta década con derechos de los que carecían pocos años antes: desconexión digital, registro de jornada, intimidad informática, adaptación de jornada... También con instrumentos de tutela más potentes, como los planes de igualdad y las auditorias retributivas. Hay un modelo diferente, y un objetivo a medio plazo: el Estatuto de los Trabajadores para el Siglo XXI, previsto en el programa de gobierno de coalición con el objetivo de garantizar la «protección de los trabajadores y trabajadoras frente a los desafíos sociales, tecnológicos y ecológicos del siglo xxl», así como «el reconocimiento de nuevos derechos de los trabajadores propios de la realidad económica, social y laboral actual».

Este estatuto, destinado a regular el mercado de trabajo de las próximas décadas, puede servir para introducir un enfoque diferente en la regulación laboral, superando la original que ya ha puesto de manifiesto sus carencias. Debe contener, sin duda, la ordenación del trabajo asalariado. Pero esto debe ser solo una de sus partes. Otra debe incluir un verdadero "estatuto de las personas que trabajan», con independencia del modelo jurídico que asuma su prestación, que actúe como fundamento para los tres estatutos hoy existentes, el del trabajo asalariado, el del autónomo y el del empleo público. Una verdadera carta de derechos de las personas en el mercado de trabajo y en la prestación de servicios. En esta nueva norma debe haber también un espacio para las formas alternativas de intercambio de regulación y servicios, como la economía colaborativa, reconociendo su papel en la sociedad y en el mercado, proveyéndola de un marco adecuado y de seguridad jurídica en sus operaciones.

Debe producirse en paralelo una reforma de los mecanismos de protección social, un proceso con otros ritmos pero que ya está en marcha con la introducción de nuevos elementos que completan el modelo contributivo y profesional vigente; la dependencia y el ingreso mínimo vital, básicamente, que demuestran que podemos proteger a las personas al margen de que sean autónomos o asalariados.

Este es el momento. Debemos aprovechar este proceso de transformación para ampliar el foco e incluir así otras modalidades de prestación de servicios, hoy necesitadas de una ordenación jurídica adecuada. Si estamos de acuerdo en su relevancia y en la importancia de su promoción, debemos encontrarle su lugar no solo en el mercado y en la sociedad, sino también en el derecho. Solo así podrán desarrollarse, con seguridad y con justicia, en beneficio de todos.

\section{Referencias bibliográficas}

ALFONSO SÁNCHEZ, R. (2016). «Economía colaborativa: un nuevo mercado para la economía social». CIRIECEspaña, revista jurídica de economía social y cooperativa, núm. 88, pág. 231. DOl: https://doi.org/10.7203/ CIRIEC-E.88.9255

ALTÉS TÁRREGA, J.A. (2018). «Análisis legal de las cooperativas de facturación y las cooperativas de impulso empresarial». En HERNÁNDEZ-BEJARANO, M.; TODOLÍ SIGNES, A. (coords.): Trabajo en plataformas digitales: innovación, derecho y mercado. Pamplona, Aranzadi, pág. 387.

BELDA MIQUEL, S.; PELLICER SIFRES, V. (eds.) (2019). Innovación social colectiva. Experiencias para la transición a la sostenibilidad desde la ciudadanía organizada. Barcelona, Icaria.

CALVO GALLEGO, F.J. (2017). «UBERPOP como servicio de la sociedad de la información o como empresa de transporte: su importancia para y desde el derecho del trabajo». En HERNÁNDEZ-BEJARANO, M.; RODRÍGUEZ-PIÑERO ROYO, M. (dirs.): Economía colaborativa y trabajo en plataforma: realidades y desafíos. Albacete, Bomarzo, pág. 331 
FALCÓN-PÉREZ, C.E.; FUENTES-PERDOMO, J. (2019). «Mejorando el bienestar de la sociedad a través del cooperativismo de plataforma». CIRIEC-España, revista de economía pública, social y cooperativa, núm. 95, pág. 61. DOI: https://doi.org/10.7203/CIRIEC-E.95.12655

FERNÁNDEZ-TRUJILLO MOARES, F. (2019). «Delivery Cooperatives. An Alternative to the Great Platforms of the Digital Economy». En TEJERINA, B.; MIRANDA DE ALMEIDA, C.; PERUGORRÍA, I. (coords.): Sharing Society: The Impact of Collaborative Collective Actions in the Transformation of Contemporary Societies, Universidad del País Vasco.

HERNÁNDEZ-BEJARANO, M.; GARCÍA MANDALONIZ, M. (2020). «El rol de la moneda y criptomoneda social en el nuevo contexto económico social y digital». CIRIEC-España, revista jurídica de economía social y cooperativa, núm. 37, pág. 283. DOI: https://doi.org/10.7203/CIRIEC-JUR.37.15791

HERNÁNDEZ-BEJARANO, M.; TODOLÍ SIGNES, A.; RODRÍGUEZ-PIÑERO ROYO, M.C (dirs.) (2020). Cambiando la forma de trabajar y de vivir: de las plataformas a la economía colaborativa real. Valencia, Tirant lo Blanch.

HERNÁNDEZ-BEJARANO, M.; TODOLÍ SIGNES, A. (coord.) (2018). Trabajo en plataformas digitales: innovación, derecho y mercado. Pamplona, Aranzadi.

HERNÁNDEZ-BEJARANO, M.; RODRÍGUEZ-PIÑERO ROYO, M.C. (dirs.) (2017). Economía colaborativa y trabajo en plataforma: realidades y desafíos. Albacete, Bomarzo.

HERNÁNDEZ-BEJARANO, M. (2017). «Nuevos modelos de cooperativas de trabajadores autónomos: un análisis de las cooperativas de impulso empresarial y las cooperativas de facturación». En HERNÁNDEZ-BEJARANO, M.; RODRÍGUEZ-PIÑERO ROYO (dirs.): Economía colaborativa y trabajo en plataforma: realidades y desafíos. Albacete, Bomarzo, pág. 145.

RODRÍGUEZ-PIÑERO ROYO, M.C. (2017) «La agenda reguladora de la economía colaborativa: aspectos laborales y de Seguridad Social», Temas Laborales, núm. 138, pág. 125.

RODRÍGUEZ-PIÑERO ROYO, M.C. (2017). «Todos eran mis hijos: el Derecho del Trabajo y las nuevas formas de empleo». Derecho y Sociedad, núm. 49, pág. 185.

Citación recomendada: RODRÍGUEZ-PIÑERO ROYO, Miguel. Nuevas formas de empleo. Economía colaborativa y regulación laboral. Oikonomics [en línea]. Mayo 2021, no. 15, pp. 1-11. ISSN: 2339-9546. DOI: https://doi.org/10.7238/o.n15.2103

Los textos publicados en esta revista están sujetos -si no se indica lo contrario- a una licencia de Reconocimiento 4.0 Internacional de Creative Commons. Puede copiarlos, distribuirlos, comunicarlos públicamente, hacer obras derivadas siempre que reconozca los créditos de las obras (autoría, nombre de la revista, institución editora) de la manera especificada por los autores o por la revista. La licencia completa se puede consultar en https://creativecommons.org/licenses/by/4.0/deed.es_ES.

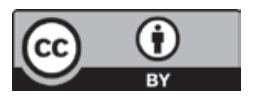




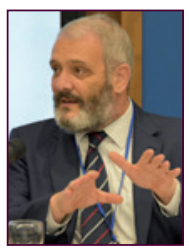

Miguel Rodríguez-Piñero Royo

mrodriguez7@us.es

Catedrático de Derecho del Trabajo y de la Seguridad Social,

Universidad de Sevilla

ORCID 0000-0001-7926-6175

Compagina su cátedra con la colaboración con la firma PwC como senior counsellor, y con la condición de secretario general de la Universidad Internacional de Andalucía. Sus principales líneas de investigación son la regulación del mercado de trabajo, el impacto de los cambios tecnológicos en las relaciones laborales y la dimensión transnacional y de la Unión Europea del Derecho del Trabajo. Últimamente está desarrollando proyectos de investigación sobre nuevas formas de empleo, nuevas causas de discriminación y trabajo en plataformas. 


\section{OTIOLTOMTS}

Revista de economía, empresa y sociedad

Dosier sobre economía colaborativa (y II)

Nuevas estrategias y dimensiones alternativas de la economía de plataforma

Coordinador: Lluís Alfons Garay Tamajón

SUB IUDICE

\section{Plataformas digitales en el sector de los VTG}

\section{Gabriel Doménech Pascual}

Universitat de València

RESUMEN El del transporte urbano de pasajeros con vehículos turismo (taxi y VTC) es, seguramente, el sector donde la irrupción de la economía colaborativa -o, si se prefiere decir así, las plataformas digitales- ha dado lugar a controversias más encendidas, medidas regulatorias más cuestionables y un mayor número de pleitos. En el presente trabajo se hace un breve repaso de las cuestiones regulatorias más candentes que se han planteado, haciendo hincapié en las que todavía están pendientes de resolución en un sentido que no parece fácil avizorar.

PALABRAS CLAVE economía colaborativa; plataformas digitales; taxi; transporte urbano de pasajeros.

\section{Digital platforms in the vehicle for hire sector}

ABSTRACT The sector of urban passenger transport with tourism vehicles (taxis and vehicles for hire) is, surely, the one where the appearance of the sharing economy-or, we can choose to say, the digital platforms- has given rise to more heated controversies, more questionable regulatory measures and a greater number of disputes. In the work presented herein, a brief review is set out of the latest regulatory issues which have been outlined here, highlighting those which are still awaiting resolution, in a sense which is seemingly not easy to perceive..

KEYWORDS sharing economy; digital platforms; taxis; urban passenger transport 


\section{La irrupción de las plataformas digitales en el sector de los VTC}

Durante los últimos años, varios sectores de la economía han experimentado una fuerte sacudida como consecuencia de la aparición de plataformas digitales (v. gr., Uber, Cabify, BlaBlaCar, Deliveroo, Glovo y AirBnB). En algunos de estos sectores, dicha aparición se ha visto envuelta en una intensa polémica, que ha tenido su reflejo jurídico en forma de un alud de medidas regulatorias y pleitos. Las disputas han sido especialmente fuertes allí donde existía una densa regulación y las autoridades reguladoras estaban en buena medida capturadas por los operadores ya establecidos.

El sector del transporte urbano de pasajeros con turismos es un buen ejemplo. Los taxis y los llamados vehículos turismo con conductor (VTC) se reparten este mercado. Ambos han estado sometidos a numerosas restricciones regulatorias, entre las cuales destacan las siguientes:

1) Para realizar esta actividad se requiere la obtención de una autorización administrativa previa, cuyo número -y, a la postre, el de los vehículos con los que se puede prestar el servicio- ha sido «artificialmente» limitado por las autoridades reguladoras.

2) Este mercado está fragmentado territorialmente. Los servicios de taxi solo pueden iniciarse en el término del municipio que haya otorgado la correspondiente licencia, salvo excepciones. Los VTC, por su parte, solo pueden prestar servicios habitualmente dentro del territorio de la comunidad autónoma en que se encuentre domiciliada la autorización en que se amparan.

Las diferencias regulatorias más significativas entre ambos tipos de vehículos son las siguientes:

- Los precios y otras condiciones (v. gr., horarios y calendarios) de los servicios prestados por los taxis están regulados.

- El número de autorizaciones de taxi de las que una misma persona puede ser titular suele limitarse.

- Los taxis pueden tomar pasajeros en paradas, directamente en la calle a solicitud de estos, o contratar sus servicios con antelación. Los VTC, en cambio, únicamente pueden prestar servicios previamente contratados.

- Durante el periodo que medió entre la Ley 25/2009 y el Real Decreto 1057/2015 no existieron restricciones cuantitativas para solicitar licencias de VTC. Esta ventana temporal de libertad de entrada propició un considerable incremento de la flota de VTC. Si en 2010 había casi 3.000 licencias, en 2021 hay 16.911 licencias en España (frente a las 64.315 de taxi).

En este contexto normativo, la irrupción de plataformas como Uber y Cabify ha hecho posible: 1) reducir drásticamente las asimetrías informativas y los costes de transacción que conlleva precontratar un VTC; 2) generar considerables economías de escala y de red; y 3) aprovechar el enorme incremento de licencias VTC para prestar de manera muy eficiente y rentable un gran volumen de servicios de transporte.

De resultas de ello, muchas de las regulaciones arriba descritas se han vuelto desproporcionadas, por cuanto los fallos del mercado que trataban de combatir pueden ser eliminados o paliados ahora de manera mucho más eficiente a través de las referidas plataformas digitales. La experiencia de otros países, donde se ha liberalizado el sector, permite estimar que la eliminación de varias de esas restricciones incrementaría el bienestar social, especialmente de los usuarios.

Sirvan dos ejemplos. El primero es el de la limitación del número de vehículos. El principal argumento aducido para establecerla es el de las externalidades -polución ambiental y congestión del tráfico- que estos generan. Pero este argumento no es atendible, por varias razones.

a) Si se quiere combatir esos efectos negativos, lo que habría que hacer es reducir el número global de turismos que circulan por nuestras ciudades, y no solo el de taxis o VTC en particular.

b) Aquella limitación puede resultar inútil o incluso contraproducente para alcanzar dicha reducción. No está en absoluto claro que una restricción tal de la oferta de taxis y VTC vaya a repercutir positivamente sobre el medio ambiente y la fluidez del tráfico. Es posible que algunos individuos que viajarían en ellos si la oferta fuese mayor recurran a vehículos privados y que, por ende, tales externalidades acaben agravándose. 
c) Abundantes estudios han puesto de manifiesto que el establecimiento de un impuesto que grave el acceso al centro urbano permite lograr dichos objetivos de manera mucho más eficiente. Esta alternativa es, desde luego, mucho más respetuosa con la libertad y la igualdad, ya que deja a todos los ciudadanos la posibilidad de transitar por allí y, en principio, se aplica igualmente a todos los que desarrollan esta actividad.

El segundo es el de la propia dualidad regulatoria existente entre taxis y VTC. A la vista de que hoy en día precontratar un VTC a través de una plataforma digital resulta más fácil y eficiente que tomar un taxi en una parada o «levantando una mano", ¿qué sentido tiene seguir manteniendo esa dualidad? ¿Qué se gana con ella?

\section{Resistencia al cambio}

Uno podría pensar que lo que deberían hacer las autoridades competentes es revisar esas restricciones regulatorias, eliminar las que se hayan vuelto obsoletas y permitir que las plataformas digitales operen en este sector sin más limitaciones que las estrictamente necesarias y no excesivas para corregir los fallos del mercado todavía subsistentes.

Sin embargo, no es eso lo que ha ocurrido. Más bien, todo lo contrario. En líneas generales, tales autoridades han adoptado toda una batería de medidas dirigidas a intensificar dichas restricciones y proteger a los taxis frente a la competencia que suponen los VTC.

Esa reacción se explica en gran medida por dos factores. El primero -y, probablemente, más determinante- es que esas autoridades llevan décadas capturadas por el gremio de los taxistas, que ha logrado ejercer sobre ellas una enorme presión, con resultados muy exitosos. El segundo factor es que, en la mayoría de las comunidades autónomas, la presencia de los VTC es todavía muy escasa, lo que hace que los titulares de sus licencias, sus trabajadores y sus usuarios tengan una capacidad muy reducida de influir sobre las autoridades y contrarrestar las presiones del lobby del taxi. Resulta muy significativo que en ninguna de las cuatro comunidades autónomas donde la ratio VTC/taxis es mayor (Madrid, La Rioja, Cantabria y Andalucía) se hayan adoptado «medidas hostiles» contra los primeros. ${ }^{1}$

\section{La reacción de las autoridades reguladoras}

\subsection{Reacción inicial: contención}

En líneas generales, esta reacción inicial consistió en frenar y contener la expansión de los VTC, así como proteger a los taxistas frente a la creciente competencia que los primeros representaban.

En efecto, por de pronto, prácticamente todas las comunidades autónomas denegaron sistemáticamente las licencias VTC solicitadas durante el periodo de liberalización, 2009-2015, lo que obligó a los solicitantes a acudir a los tribunales para que estos les reconocieran su derecho a obtenerlas.

En segundo lugar, tanto las comunidades autónomas como el Estado aprobaron varias medidas encaminadas a entorpecer la actividad de los VTC, algunas de las cuales fueron consideradas contrarias a derecho por los tribunales. Por ejemplo, el Decreto Ley catalán 5/2017, entre otras cosas, impuso una moratoria de dos años para la transmisión de autorizaciones de VTC y creó un registro electrónico de comunicaciones de los servicios de VTC con el fin de someter a control administrativo cada uno de los prestados por los mismos. La referida moratoria

1. Según datos del Ministerio de Fomento, a 1 de marzo de 2021, en Andalucía había 9.195 taxis y 2.900 VTC. En Madrid, 15.714 taxis y 8.023 VTC. En Cantabria, 512 taxis y 143 VTC. Y, en La Rioja, 166 taxis y 83 VTC. 
fue declarada inconstitucional por la Sentencia del Tribunal Constitucional 105/2018. El Gobierno central, por su parte, estableció, en virtud del Real Decreto 1076/2017, una moratoria y un registro electrónico prácticamente idénticos, medidas que fueron consideradas ilegales y anuladas por la Sentencia del Tribunal Supremo de 10 de marzo de 2020 (ECLI:ES:TS:2020:732).

Aquí pueden mencionarse, también, las prohibiciones o limitaciones de la posibilidad de circular (v. gr., por el centro urbano) que algunos ayuntamientos (v. gr., de Madrid, Córdoba y Granada) han impuesto solo a los VTC, pero no a los taxis, y que varios juzgados han considerado discriminatorias.

Finalmente, se han otorgado beneficios cuestionables a los taxistas. Aquí destacan los programas de rescate de licencias. En lugar de incrementar la oferta, a fin de intensificar la competencia y mejorar los servicios en beneficio de los usuarios, algunos ayuntamientos (v. gr., los de Sevilla y Santa Cruz de Tenerife) han optado por restringirla todavía más, pagando cantidades considerables a los taxistas que voluntariamente deciden extinguir sus licencias.

\subsection{Reacción posterior: penalty y expulsión}

En una segunda fase, y como respuesta a la creciente presión del lobby del taxi, se ha tratado de expulsar a los VTC del mercado.

\subsubsection{La ordenanza de la Área Metropolitana de Barcelona de 2018}

El primer hito en este sentido lo constituye la ordenanza de la Área Metropolitana de Barcelona (AMB) de 26 de junio de 2018, que vino a dejar sin efectos en su territorio las autorizaciones de VTC otorgadas después de 2009, lo cual suponía de facto expropiarlas. Esta ordenanza incurría en varias ilegalidades flagrantes y, por esta razón, fue suspendida cautelarmente por el Auto del Tribunal Superior de Justicia de Cataluña de 26 de julio de 2018.

\subsubsection{El Real Decreto Ley $13 / 2018$}

En virtud de esta norma, el Gobierno central dispone que las licencias VTC «habilitarán exclusivamente para realizar transporte interurbano de viajeros», entendiéndose por tal aquel cuyo «recorrido rebase el territorio de un único término municipal o zona de prestación conjunta de servicios de transporte público urbano». Es decir, estas licencias ya no permiten realizar transportes urbanos, lo que prácticamente les priva de cualquier utilidad, puesto que la abrumadora mayoría de las carreras que actualmente hacen los VTC transcurren íntegramente por un único término municipal o zona de prestación conjunta de servicios de transporte público urbano.

Adicionalmente, se restringe también la prestación de servicios interurbanos, pues se establece, como regla general, que estos «deberán iniciarse en el territorio de la comunidad autónoma en que se encuentre domiciliada la correspondiente autorización».

Estas restricciones son tan intensas que abocan a la desaparición a la práctica totalidad de los VTC. Consciente de que esta regulación constituye una expropiación de las correspondientes licencias, el Gobierno prevé como «indemnización» que, durante los cuatro años posteriores a la entrada en vigor del Real Decreto Ley 13/2018, sus titulares «podrán continuar prestando servicios de ámbito urbano», plazo que puede extenderse hasta los seis años, si concurren determinadas circunstancias. Cabe poner en duda, obviamente, que esta compensación baste para dejar «indemnes» a los expropiados.

El decreto ley también «habilita» a las comunidades autónomas para regular las condiciones de explotación de los servicios "cuyo itinerario se desarrolle íntegramente en su respectivo ámbito territorial», con arreglo a ciertos límites.

Además, establece que «los servicios de transporte prestados en el ámbito urbano por los titulares de dichas autorizaciones quedarán sujetos a todas las determinaciones y limitaciones que establezca el órgano competente en materia de transporte urbano en el ejercicio de sus competencias sobre utilización del dominio público 
viario, gestión del tráfico urbano, protección del medio ambiente y prevención de la contaminación atmosférica; especialmente en materia de estacionamiento, horarios y calendarios de servicio o restricciones a la circulación por razones de contaminación atmosférica». Parece, pues, que se permite a las administraciones autonómicas y locales imponer a los VTC condiciones de prestación de servicio hasta ahora inexistentes, lo que, obviamente, disminuiría todavía más la rentabilidad de su actividad y haría aún más cuestionable la compensación de 4-6 años prevista.

Este real decreto ley incurre, en nuestra opinión, en varias infracciones de la Constitución española. ${ }^{2}$ No sería de extrañar, por ello, que el Tribunal Constitucional acabara pronunciándose al respecto.

\subsubsection{Disposiciones autonómicas}

Varias comunidades autónomas han publicado sendas disposiciones por las cuales imponen a los VTC, principalmente, tres restricciones, que prácticamente les impiden seguir operando como lo venían haciendo: 1) la necesidad de que entre la contratación del servicio y su prestación transcurra un periodo mínimo de tiempo (que oscila entre los 15 y los 30 minutos); 2) la prohibición de mostrar a los potenciales usuarios la geolocalización de los vehículos; y 3) la obligación de que los vehículos permanezcan estacionados fuera de las vías públicas cuando no estén prestando el servicio, o la prohibición de circular por estas vías para propiciar la captación de clientes, o incluso la prohibición de captar clientela en zonas de concentración de la demanda. ${ }^{3}$

La conformidad a derecho de estas restricciones es ciertamente dudosa. El Consell de Garanties Estatutàries de la Generalitat de Catalunya ha considerado que el referido periodo de contratación supone una restricción desproporcionada y, por lo tanto, ilícita, de la libertad de empresa reconocida en el artículo 38 de la Constitución. ${ }^{4}$ Por una razón análoga, el Tribunal Superior de Justicia de Cataluña ha suspendido cautelarmente dos disposiciones de una nueva ordenanza de la AMB, que elevaban el periodo mínimo de contratación hasta los 60 minutos y obligaban a los VTC a inscribirse en un registro municipal. ${ }^{5} \mathrm{El}$ Tribunal Superior de Justicia del País Vasco, por su parte, ha suspendido cautelarmente las disposiciones relativas al periodo mínimo de precontratación y a la geolocalización de los vehículos contenidas en el correspondiente decreto del Gobierno Vasco. ${ }^{6}$

\subsection{Comunidades autónomas no hostiles}

Como ya hemos señalado, las comunidades autónomas donde mayor es la ratio de VTC/taxis (Madrid, La Rioja, Cantabria y Andalucía) se han abstenido de adoptar medidas significativamente «hostiles» contra los primeros. Es más, los partidos políticos gobernantes en las comunidades donde más VTC hay en términos absolutos (Madrid y Andalucía) han manifestado públicamente su voluntad de establecer una regulación que garantice una cierta competencia entre ambos tipos de vehículos. La reciente convocatoria de elecciones a la Asamblea de Madrid, sin embargo, deja la referida regulación en el aire. Ya veremos cómo evolucionan los acontecimientos, pues los partidos de la oposición han sido los grandes impulsores de la solución consistente en «expulsar» a los VTC del mercado.

2. Véase Doménech Pascual (2019).

3. Véanse el Decreto Ley catalán 4/2019, de 29 de enero; el Decreto Ley balear 1/2019, de 22 de febrero; el Decreto Ley aragonés de 7/2019, de 12 de marzo; el Decreto Ley valenciano 4/2019, de 29 de marzo; y el Decreto vasco 200/2019, de 17 de diciembre.

4. Dictamen 2/2019, de 22 de febrero.

5. Auto de 9 de julio de 2019.

6. 6 Auto de 10 de febrero de 2020 (ECLI:ES:TSJPV:2020:60A). 


\section{El turno de los tribunales, perspectivas de futuro}

La aparición de plataformas digitales en este y otros sectores se ha visto envuelta en un reguero de pleitos, con resultados «mixtos». Los partidarios de liberalizar el sector han obtenido muchas victorias parciales -como las que se han ido reseñando a lo largo de este artículo-, pero también grandes derrotas, como la que supuso la Sentencia del Tribunal Supremo de 4 de junio de 2018 (ECLI:ES:TS:2018:1913), que avaló casi todas las restricciones existentes en el mercado de los VTC y, muy especialmente, las cuantitativas.

El futuro del sector depende en gran medida del resultado de numerosos pleitos que actualmente están pendientes de resolución y en los que los tribunales han de pronunciarse sobre algunas de las piezas clave de la regulación vigente, como la conformidad del Real Decreto Ley 13/2018 con la Constitución y el derecho de la Unión Europea.

Hay una gran incertidumbre acerca de cómo se van a resolver esos litigios. Por un lado, existen razones más que sobradas para considerar inconstitucionales muchas de las medidas adoptadas con el fin de dificultar o impedir la actividad de los VTC. Pero, por otro lado, hay que tener en cuenta que, tradicionalmente, nuestros tribunales han sido extremadamente deferentes con el legislador a la hora de enjuiciar restricciones de la libertad de empresa, hasta el punto de que nunca se ha declarado inconstitucional una norma con rango de ley por este motivo. Puede afirmarse que la libertad de empresa prevista en el artículo 38 de la Constitución no es en nuestro ordenamiento jurídico, de facto, un verdadero derecho constitucional, oponible frente al legislador.

Además, debe notarse que a los titulares de licencias VTC tampoco les interesa que se eliminen todas aquellas restricciones injustificadas y, en particular, la relativa al número de vehículos que en este sector puede operar, pues ello reduciría prácticamente a cero el valor de tales licencias. Lo que les interesa, sobre todo, es que se supriman otras limitaciones que entorpecen su libertad de prestación de servicios o, al menos, que se les permita seguir operando en este mercado como venían haciéndolo antes de la aprobación del Real Decreto Ley 13/2018.

En fin, resulta difícil avizorar cómo evolucionará este sector en el futuro. A la incerteza existente respecto del sentido en el que se van a resolver las dispuestas judiciales y políticas pendientes, se añade la posibilidad de que surjan innovaciones tecnológicas que transformen significativamente las condiciones de este mercado. Sea como fuere, cuesta imaginar que, por mor de una decisión política -económica y jurídicamente injustificada-, en dos años vaya a desaparecer un sistema productivo que ha acreditado sobradamente su eficiencia, que mueve muchos millones de euros y que da trabajo directo a unas 20.000 personas.

\section{Referencias bibliográficas}

AUTORITAT CATALANA DE LA COMPETĖNCIA (2018). Estudio sobre el sector del transporte de viajeros en vehículos de hasta nueve plazas: el taxi y los vehículos de alquiler con conductor (ES 15/2018).

DOMÉNECH PASCUAL, G. (2017). «La regulación de la economía colaborativa en el sector del taxi y los VTC». En MONTERO PASCUAL, J.J. (ed.): La regulación de la economía colaborativa. Airbnb, BlaBlaCar, Uber y otras plataformas. Valencia, Tirant lo Blanch, pág. 351-401.

DOMÉNECH PASCUAL, G. (2019). «Penalty y expulsión. La economía de las plataformas digitales en el sector de los taxis y los VTC». En ORTÍ VALLEJO, A.; RUBIO GIMENO, G. (eds.): Propuestas de regulación de las plataformas de economía colaborativa. Perspectivas general y sectoriales. Cizur Menor, Aranzadi.

GONZÁLEZ CABRERA, I. (2020). «Taxis y VTCS/PHVS (private hire vehicles) en España y en el Reino Unido. Una visión crítica de las regulaciones desarrolladas en las áreas metropolitanas de Barcelona y de Londres». Revista General de Derecho de los Sectores Regulados, núm. 5.

GÓRRIZ LÓPEZ, C. (2019). "Taxi vs. Uber: de la competencia desleal al arrendamiento de vehículo con conductor». Revista de Derecho Mercantil, núm. 311.

TORNOS MAS, J. (2019). Dret i innovación tecnológica. El cas Uber versus Taxi. Barcelona, Acadèmia de Jurisprudència i Legislació de Catalunya. 
Cita recomendada: DOMÉNECH, Gabriel. Plataformas digitales en el sector de los VTC. Oikonomics [en línea]. Mayo 2021, no. 15, pp. 1-7. ISSN: 2339-9546. DOI: https://doi.org/10.7238/o.n15.2106

Los textos publicados en esta revista están sujetos -si no se indica lo contrario- a una licencia de Reconocimiento 4.0 Internacional de Creative Commons. Puede copiarlos, distribuirlos, comunicarlos públicamente, hacer obras derivadas siempre que reconozca los créditos de las obras (autoría, nombre de la revista, institución editora) de la manera especificada por los autores o por la revista. La licencia completa se puede consultar en https://creativecommons.org/licenses/by/4.0/deed.es_ES.
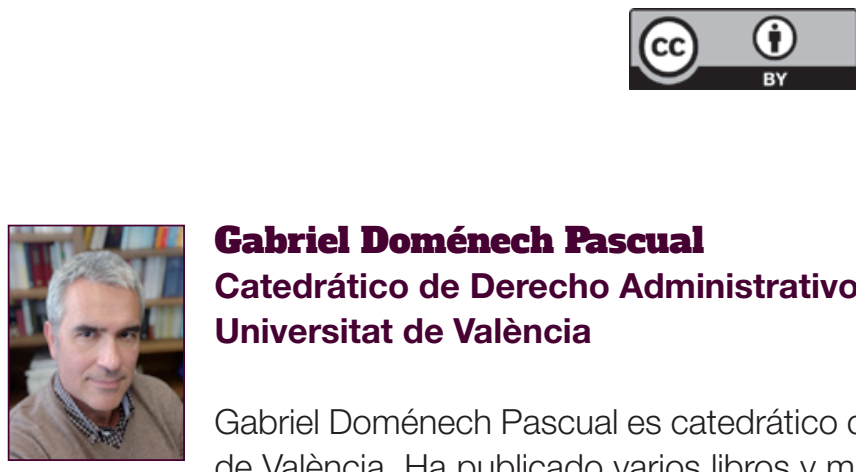

\section{Gabriel Doménech Pascual Catedrático de Derecho Administrativo Universitat de València}

Gabriel Doménech Pascual es catedrático de Derecho Administrativo en la Universitat de València. Ha publicado varios libros y más de cien artículos y capítulos sobre muy diversos temas: la invalidez de las normas jurídicas, las obligaciones positivas del Estado de proteger los derechos fundamentales, el régimen jurídico del bienestar animal, la responsabilidad civil del Estado, la llamada economía colaborativa (principalmente, en los sectores del transporte urbano y las viviendas de uso turístico), las tasas judiciales, los sistemas de retribuciones variables de los jueces, la especialización judicial, etc. Desde hace unos años viene orientando su actividad investigadora y docente principalmente hacia el análisis económico del derecho público. 


\section{OTIOLTOMTS}

Revista de economía, empresa y sociedad

Dosier sobre economía colaborativa (y II)

Nuevas estrategias y dimensiones alternativas de la economía de plataforma

Coordinador: Lluís Alfons Garay Tamajón

NUEVAS ESTRATEGIAS

\section{Alojamientos desinfectados y cuerpos sanos: reflexiones sobre la respuesta de Airbnb a la pandemia}

\section{Maartje Roelofsen}

Universitat Oberta de Catalunya (UOC)

\section{Glaudio Minca}

Universidad de Bolonia

RESUMEN El presente artículo examina algunos de los principales cambios registrados en la política de viajes, los estándares y los protocolos de Airbnb desde que se iniciara la pandemia de COVID-19. Constituye una reflexión sobre cómo el clima de incertidumbre instalado desde la crisis sanitaria mundial, ha llevado a Airbnb a fomentar entre sus usuarios nuevas actitudes y valores relacionados con la flexibilidad, la adaptabilidad, la responsabilidad y el compromiso de largo plazo. Se analizan, en particular, los nuevos protocolos y medidas que han dado origen a una política uniforme y de transparencia en las cuestiones relacionadas con la salud y la seguridad, pero también en las interacciones sociales y los modos de comunicación personal, el trabajo, así como en el comportamiento diario de los anfitriones y los huéspedes de Airbnb. También se pone en relieve la manera en que los cambios aplicados en la plataforma han sido objeto de cuestionamientos, expresados mediante algunas protestas en contra de las nuevas medidas, las cuales fueron recogidas en el Airbnb Community Center. Por último, se presentan algunas observaciones sobre el desarrollo futuro del sistema de hospitalidad de Airbnb y sus posibles consecuencias para los viajes y el turismo en escenarios postpandémicos.

PALABRAS CLAVE Airbnb; COVID-19; desinfección; alojamiento; hospitalidad/hospedaje 


\title{
Sanitised homes and healthy bodies: reflections on Airbnb's response to the pandemic
}

\begin{abstract}
This paper examines some key changes to Airbnb's travel philosophy, protocols and standards since the outbreak of the COVID-19 pandemic. It reflects on how the climate of uncertainty imposed by the global health crisis has induced Airbnb to promote among its users a new ethos of flexibility, adaptability, liability and long-term commitment. In particular, we discuss how new protocols and regulatory measures have engendered a culture of uniformity and transparency regarding issues of health and safety, but also concerning social interactions, personal communication, labour, and the conduct of everyday life of Airbnb's hosts and guests. The article also highlights that the changes implemented by the platform have not gone unchallenged and how some of the protests against the new measures and protocols were manifested via the Airbnb Community Center. We conclude with a few considerations about possible future directions of the Airbnb hospitality machinery and their potential consequences on the post-pandemic landscapes of travel and tourism.
\end{abstract}

KEYWORDS Airbnb; COVID-19; sanitization; home; hospitality

\section{Introducción}

El futuro de Airbnb ha estado en el centro de vigorosos debates públicos y académicos desde el comienzo de la pandemia de COVID-19 (véase, por ejemplo, Dolnicar y Zare 2020; Glusac 2020; Schaal 2020). Algunas plataformas, y en particular, las plataformas de servicios de entrega a demanda, han capitalizado la crisis sanitaria con el incremento expansivo en su volumen de usuarios (Bosma et al. 2020). Pero, en cambio, Airbnb se ha visto atrapada en esta crisis que ha afectado a la industria del turismo y de la hostelería en general. Este sector es uno de los más afectados por el virus (UNWTO 2020) y es considerado como uno de sus vectores de propagación (laquinto 2020). Los espacios cerrados en los aviones, los barcos de crucero y las diversas modalidades de alojamiento turístico, incluidos los «alojamientos compartidos", fueron sometidos a normas estrictas porque fueron identificados como los lugares en donde podrían producirse más contagios. Al igual que ocurrió con la mayoría de empresas turísticas desde que el virus empezara a extenderse por el mundo, Airbnb registró una anulación masiva de reservas debido a las restricciones a la movilidad individual, los confinamientos, el cierre de las fronteras y las reglas de distanciamiento social impuestas por las autoridades en los países afectados por la pandemia. Las enormes pérdidas en sus ingresos llevaron a la empresa a adoptar medidas de manejo de la crisis (véase Bosma 2020) tales como la suspensión de todas sus actividades de marketing, la aplicación de recortes salariales y el despido del 25 \% de su personal. Aun así, y a pesar del impacto de la pandemia en sus operaciones, la plataforma sigue siendo considerada como una de las empresas de hostelería de mayor valor a nivel mundial gracias a su capitalización en el mercado, un aspecto confirmado por el éxito de su salida en el mercado de valores en diciembre de 2020 (Allyn y Schneider 2020). Airbnb ha conseguido, en cierto modo, reinventarse a sí misma explorando nuevas maneras de capitalizar la vida diaria y los espacios íntimos de sus usuarios introduciendo algunos cambios en sus productos y servicios. Según ha observado Sarah Barns $(2020,101)$, es necesario mantenerse atentos a los cambios que las plataformas están efectuando, pues estos no son únicamente «una condición generalizada en el capitalismo de plataforma» sino un conjunto de intervenciones estratégicas de las compañías, cuyo fin es ejercer y mantener el control de sus mercados.

Basándonos en nuestros trabajos anteriores sobre Airbnb (Roelofsen 2018; Roelofsen y Minca 2018; Minca y Roelofsen 2019) y en otros estudios de plataformas turísticas, explicamos aquí brevemente la manera en que la 
pandemia ha puesto en cuestión la propia idea del «alojamiento compartido», lo cual ha dado lugar a una nueva "Cultura de la hospitalidad Airbnb» basada en la incertidumbre, el contagio y la desinfección. Para ello, hacemos un repaso de algunos de los principales cambios introducidos en el último año en la «política de viajes» de Airbnb, en sus protocolos y normas, sus términos y condiciones, y en su infraestructura digital. También hemos analizado 79 entradas de blog publicadas por la empresa en el Newsroom de Airbnb entre el 9 de octubre de 2019 y el 27 de enero de 2021, que explican en detalle los principales cambios realizados. A su vez, contraponemos a este análisis el examen de una selección de 31 comentarios de blog publicados por los anfitriones y usuarios de Airbnb en el Airbnb Community Center (en lo sucesivo, el ACC).

\section{Anfitriones responsables y flexibles y «alojamientos para estancias largas»}

El primer pronunciamiento oficial de Airbnb con motivo de la pandemia se dio a conocer a finales de febrero de 2020. En un anuncio aparecido en Airbnb News, la empresa anunció que seguía de cerca el brote de coronavirus y se concentró en ofrecer «ayuda de emergencia» como respuesta a las reservas que estaban siendo canceladas en forma masiva (Airbnb 2020). Con la activación de su «política de causas de fuerza mayor relativa al coronavirus», Airbnb permitió que tanto los anfitriones como los huéspedes cancelaran algunas reservas desde su plataforma sin que fueran aplicados los gastos ni las penalizaciones habituales. Esta medida tuvo un impacto adverso, particularmente en los anfitriones que antes estuvieron a favor de políticas estrictas o moderadas de cancelación y que, en circunstancias normales, habrían obtenido (parte) del importe pagado por el huésped sin importar que se hubiera producido o no su estancia.

El consecuente trastorno ocasionado a un número considerable de anfitriones llevó a estos a expresar su frustración por medio del ACC y de otros canales de comunicación. El ACC registró numerosas discusiones en las que el público se preguntaba si la compañía hubiera debido ser responsable, y de qué manera, del resarcimiento por las pérdidas ocasionadas. Una entrada que se hizo popular y generó un hilo con más de 600 respuestas, reclamaba que los costes de cancelación deberían ser al menos compartidos entre los anfitriones y los huéspedes. La discusión puso en evidencia que muchos anfitriones aprovecharon políticamente las circunstancias, y que utilizaron las redes sociales y el ACC de manera colectiva para poner el foco de atención en el funcionamiento y las responsabilidades de la plataforma. Esta estrategia (que tuvo un éxito moderado) ya había sido empleada anteriormente por los anfitriones para reclamar por la forma en que su trabajo estaba siendo configurado, regulado y organizado por el software de Airbnb (véase Minca y Roelofsen 2019; también Wilson et al. 2021). La principal crítica que se repetía en muchas de las entradas más recientes señalaba que Airbnb mantenía el derecho de control, redireccionamiento y capitalización del negocio del «alojamientos compartidos» que se generaba a través de su software, y al mismo tiempo, se exoneraba de toda responsabilidad en casos de fuerza mayor, absteniéndose de prestar a los anfitriones el apoyo o la protección que serían de esperar. Un grupo de anfitriones publicó peticiones para hacer responsable a la compañía, mientras que otros expresaron su intención de trasladar sus negocios de «alojamientos compartidos» a otras plataformas de alquiler por estancias cortas, animando a más miembros a hacer lo mismo. Sin proponérselo, los comentarios aparecidos en el ACC evidenciaron que la base de usuarios de Airbnb estaba conformada por personas que podían ser consideradas como «profesionales» con las más diversas aptitudes (Bosma 2021; Semi y Tonetta 2020). Basándose en estudios anteriormente encargados por la propia empresa, ésta a menudo ha señalado que sus usuarios son predominantemente «anfitriones que comparten la vivienda en la que viven» para así obtener unos ingresos suplementarios (por ejemplo, Airbnb 2017a; 2017b; 2018). Pero lo que en realidad emergía de los comentarios publicados en el blog es que existían numerosos miembros participantes en la discusión que dependían única o significativamente de sus ingresos en Airbnb para subsistir; y que algunas de estas personas administraban una oferta de alquiler variada y que alquilaban exclusivamente a turistas (véase Gil y Sequera 2020; Cocola-Gant y Gago 2019).

Sin duda, esta vibrante reacción hizo que Airbnb reconsiderase su estrategia de emergencia e ideara respuestas que fuesen mejor aceptadas por su base de usuarios. Pocas semanas después, y como pidiendo disculpas, la empresa estableció un fondo de ayuda de 250 millones de dólares a modo de compensación para los anfitrio- 
nes más afectados por la decisión de suspender la política de cancelaciones (Airbnb 2020a). Además, se creó un Fondo de Emergencia para los Superhosts que eran «especialmente dependientes» de los ingresos que obtienen en Airbnb para «llegar a fin de mes» (Ibid.) Finalmente, unas 8.700 personas recibieron financiación a través de este fondo y se publicaron en el Airbnb News los casos de algunas de las personas que fueron indemnizadas (Airbnb 2020b). En la misma noticia, el director ejecutivo de la compañía, Brian Chesky, reiteraba a los anfitriones que Airbnb se comprometía a «restaurar nuestra sociedad", poniendo el énfasis en la manera en que los alojamientos de Airbnb podían ser también muy útiles para dar respuesta a la crisis. De hecho, se alentó a los anfitriones a ofrecer sus viviendas de forma gratuita, o a bajo coste, para el personal sanitario de emergencias y de primera línea que trabajaba en la pandemia. Aunque todavía queda por investigar en qué medida ese gesto filantrópico ha sido puesto en práctica por los anfitriones, Airbnb se mostró como un símbolo de «institución urbana» que promovía el uso de las propiedades de sus usuarios y su hospitalidad, los cuales constituyen activos urbanos esenciales en tiempos de crisis (véase Van Doorn 2020). Al hacerlo, Airbnb pone implícitamente de manifiesto su vigoroso papel como actor social en la gobernanza de numerosas ciudades, también en tiempos de crisis como la que ha provocado la pandemia.

Tras la controversia creada, y con miras a operar en un nuevo escenario de riesgos ocasionados por la COVID, la empresa publicó en su blog varias piezas en las que aclaraba y reafirmaba cuáles eran sus responsabilidades con los usuarios. Se informaba que la plataforma de Airbnb promovía un modelo de negocio con «pocos activos" que tenía una «base comunitaria» y se apoyaba en el «impulso de las personas». Con ello se diferenciaban de los modelos de negocio tradicionales, que son jerárquicos y no admiten contrapartes, como ocurre en las «grandes corporaciones con muchos activos, que están verticalmente integradas y capturan la mayor parte de los beneficios económicos que se generan» (Airbnb 2020c). En sus publicaciones, Airbnb aclaraba que la empresa era fundamentalmente responsable de su infraestructura «digital». Por ser la proveedora del software que posibilita un «mercado de dos caras», la empresa señalaba su «compromiso en hacer todo lo posible por dar apoyo razonable a ambas partes, y siendo coherentes con el funcionamiento de este mercado» (Ibid.). La insistencia de Airbnb en puntualizar su exclusivo papel de proveedor del software, y su ambigüedad al expresarse acerca de la naturaleza del «apoyo» que presta a los usuarios, es similar a las estrategias adoptadas por otras plataformas a demanda. Dichas estrategias ya han sido antes empleadas para obligar a los usuarios a asumir los riesgos y responsabilidades que conlleva el trabajo con el que ellos hacen posible que las plataformas obtengan beneficios. (véase van Doorn 2017).

Desde el inicio de la pandemia, Airbnb ha efectuado cambios adicionales en su infraestructura digital que obligan al usuario a cumplir con unos niveles más altos de flexibilidad y «profesionalidad» mientras que la empresa se exonera nuevamente de cualquier responsabilidad. Por ejemplo, se han introducido una serie de herramientas y programas de «Reservas más flexibles», las cuales han sido desarrolladas para "asistir a los anfitriones y los huéspedes en tiempos de incertidumbre con el fin atender cualquier necesidad de cancelar o postergar sus ofertas de alojamiento o sus planes de viaje» (Airbnb 2020d). Airbnb ha ofrecido recompensas para los anfitriones que adopten las políticas de cancelación más «flexibles» en este programa, permitiendo que «sus ofertas sean más visibles para conseguir más reservas» (Ibid.). Por su parte, los huéspedes dispondrían de nuevos filtros de búsqueda de las ofertas que tengan las políticas de cancelación más flexibles; con ello, serán menos visibles en las búsquedas tanto las ofertas como los anfitriones que no quieran o puedan aceptar cancelaciones de última hora y pérdidas de la reserva. Con estas medidas, Airbnb empuja a los anfitriones a asumir más riesgos y responsabilidades en una nueva época marcada por la incertidumbre, ofreciendo a cambio que estos aparezcan mejor clasificados en los resultados de búsqueda.

La promoción de «alquileres de larga estancia» es otro de los cambios notables registrados en los materiales de marketing y comunicaciones de Airbnb. Anteriormente los huéspedes reservaban para poder conseguir su «inmersión en la nueva comunidad y poder explorar su cultura durante las vacaciones». Ahora la plataforma dice que los huéspedes están buscando alquilar por periodos más largos como «apoyo a sus planes de teletrabajo y de traslado temporal por motivos laborales. Así el trabajo desde casa se ha convertido en el trabajo desde cualquier casa (Airbnb 2020e, cursivas añadidas)». Es posible que las ofertas más populares en tiempos de la pandemia fueran las que estaban disponibles por períodos de tiempo más largos, así como aquellas que ofrecen «privacidad y distancia social» y que admiten mascotas. Con el fin de reducir los contactos personales, Airbnb 
ha recomendado a sus anfitriones que alarguen el tiempo de estancia de las reservas y ofrezcan a los huéspedes modalidades de «auto registro on-line». Sin embargo, los debates en el ACC revelan que hay anfitriones que quedan excluidos por no disponer de una propiedad que les permita optar por alinearse con el nuevo modelo. Los anfitriones que ofrecen una habitación o una cama en su propia vivienda no podrían cumplir con el requisito impuesto por Airbnb de distancia social o física permanente al alojar a los huéspedes; por tanto, estos no encajan en la nueva modalidad en la que se ofrece «trabajar desde cualquier casa». Y en muchos casos, tampoco los anfitriones están necesariamente dispuestos a alojar a personas por períodos prolongados, particularmente en las inciertas circunstancias creadas por la pandemia, tal como pudo leerse en muchos comentarios del blog del ACC. Quedan por estudiar las implicaciones de este cambio en la composición de la base de usuarios de Airbnb y en el tipo de ofertas publicitadas. Lo que sí puede señalarse con claridad en estos momentos, es que el interés de Airbnb por las «estancias prolongadas» está en línea con su reciente desarrollo de un «ecosistema centrado en las plataformas» que favorece a un grupo de anfitriones específico. Aquellos que sean capaces de capitalizar sus activos en vivienda propia para generar un flujo de ingresos más estable, serán también quienes contribuyan a incrementar la escala y las ganancias en las operaciones de Airbnb (van Doorn 2020, 13; para la «profesionalización privilegiada», véase también Bosma 2021).

\section{Desinfección de la vivienda y tratamiento de los casos de huéspedes infectados}

Las prácticas laborales de Airbnb también han registrado un cambio de enfoque fundamental en el último año. Hubo varios intentos de «profesionalizar» el trabajo doméstico y las interacciones entre usuarios aplicando nuevos protocolos y estándares, así como introduciendo cambios en la estructura de la plataforma. La «profesionalización» comporta la existencia de una estrategia implementada por Airbnb con el fin de redefinir y controlar las prácticas en el trabajo, como respuesta a diversas presiones sociales y económicas que se han hecho más evidentes durante la crisis sanitaria mundial ocasionada por la Covid-19. El 7 de abril de 2020, Airbnb anunció que aplicaría varios protocolos sanitarios y de seguridad en los meses subsiguientes y que, además, esperaba que sus usuarios cumplieran con las recomendaciones, leyes y políticas para viajeros emitidas por los gobiernos locales y nacionales (Airbnb 2020f). Para seguir haciendo uso de la plataforma, los anfitriones y los usuarios debían comprometerse a usar una mascarilla o cubierta facial y mantener en todo momento una distancia entre personas de 2 metros. Las nuevas normas generaron un considerable debate entre los anfitriones de los lugares en donde la prevalencia del virus no era extendida y cuyas medidas sanitarias y de seguridad eran más laxas (por ejemplo, en Nueva Zelanda).

Además, se recomendó a todos los anfitriones la adopción del «proceso de limpieza avanzada» en cinco pasos, que pasó a ser medida de obligado cumplimiento a partir del 20 de noviembre de 2020 (excepto para los anfitriones en China; respecto a Airbnb en China, véase Minca y Roelofsen 2019). Los anfitriones que no pudieran demostrar el cumplimiento de las medidas de seguridad (incluyendo el "proceso de limpieza avanzada») fueron informados de que sus reservas no serían aceptadas en lo sucesivo, quedando suspendida la publicación de sus ofertas, o retiradas éstas de Airbnb (Airbnb 2021). Los huéspedes que incumplieran (reiteradamente) las pautas de seguridad no tendrían derecho a un reembolso en el caso de que sus anfitriones cancelaran la reserva por dicho incumplimiento. Por último, se recomendó a los «anfitriones» que tanto el «equipo encargado del hospedaje» como los asociados en la limpieza siguieran los nuevos protocolos. Aquellos anfitriones que cumplieran el protocolo recibirían una estrella que aparece destacada junto al texto descriptivo de su oferta de alojamiento (Airbnb 2020g), de manera similar a los símbolos empleados en otros programas que indican "estatus", tales como las recompensas a los «Superhosts» (véase Roelofsen y Minca 2018). Por otro lado, los huéspedes estarían en condiciones de identificar y reservar los alojamientos incluidos en este programa tan pronto como los anfitriones se suscribieran. 
El control y la determinación de las modalidades de trabajo en el ecosistema de Airbnb es establecido a partir de la prescripción de un ámbito, una escala y unos límites para el trabajo doméstico y el hospedaje. Airbnb especifica qué cosas deben limpiarse, con qué frecuencia, por quién y con qué productos o materiales. También se dan instrucciones precisas sobre la interacción social entre anfitriones y huéspedes. Como ya ha sido mencionado, en todo momento el contacto físico o personal debe evitarse, al igual que debe mantenerse la distancia. Además, la compañía informó que se ha asociado con plataformas de servicios de limpieza con el fin de «facilitar una limpieza más rápida y mejorada». Es posible que muy pronto se ofrezcan «recompensas» para quienes externalicen esta clase de trabajo, como ya ocurre con los anfitriones que son «recompensados» si cumplen con los «protocolos de limpieza mejorada». Así, en las preferencias de búsqueda de los huéspedes podrían aparecer en los primeros lugares las ofertas del alojamiento que haya sido limpiado por los equipos «profesionalmente» certificados de Airbnb. Tal como ya lo publicitan Hyatt, Hilton y otras grandes cadenas hoteleras que aparecen en la web del Consejo Mundial de Viajes y de Turismo, Airbnb está comprometida con los estándares y protocolos de higiene y limpieza que le permitirán operar en las circunstancias actuales de «nueva normalidad» (WTTC 2021). La plataforma se ha asociado también con conocidas empresas de la industria química tales como Diversey, RB y Dettol, y recomienda a los anfitriones que adquieran sus productos y los utilicen en la limpieza de sus alojamientos (Airbnb 2020h; 2021a). Aun cuando asociarse con estas empresas y con su imagen pública podría ayudar a incrementar la confianza y la credibilidad en tiempos de la pandemia, la estrategia parece contradecirse con el modelo de negocio de Airbnb. Desde hace más de una década, éste se ha basado en preferir la experiencia idealizada de alojarse en las casas de personas desconocidas a la de hospedarse en una habitación de hotel corriente (y desinfectada) (Minca y Roelofsen 2019).

Existe un nivel aún más profundo para la desinfección del alojamiento en los casos en que el virus puede estar presente. Cuando los anfitriones o los huéspedes presentan síntomas o resultan positivos en una prueba de COVID-19, se les pide que sigan una serie de pasos establecidos por Airbnb (Airbnb 2021i). Estos incluyen diversos itinerarios en el caso de que los anfitriones y los huéspedes hayan tenido contacto estrecho o compartido el espacio de hospedaje. Cuando exista sospecha de infección o se obtenga un resultado de test positivo, se recomienda a ambos grupos de usuarios buscar atención médica, ponerse en contacto con las autoridades y también, informar a Airbnb de su estado de salud (lbid.). No es posible detallar aquí la extensa lista de pasos a seguir ante esta situación. Sin embargo, se han dado varios casos de suspensión de las cuentas de usuario de manera que los anfitriones o huéspedes quedan inhabilitados para reservar nuevas estancias en la plataforma de Airbnb durante un tiempo. Sus cuentas de usuario solo serán reactivadas cuando Airbnb reciba confirmación válida de que "se puede volver a hospedar o viajar». Asimismo, se aconseja a los anfitriones y a los huéspedes que «no envíen información sensible ni relacionada con cuestiones de salud (por ejemplo, certificados médicos)» (Ibid.). No obstante, la realización de estos trámites permite a Airbnb obtener y recoger datos sensibles acerca del historial sanitario de sus miembros.

La compañía ha anunciado recientemente que está preparando una Declaración de Seguridad Sanitaria que, por ahora, es una herramienta voluntaria que habilita al anfitrión a «solicitar al huésped que firme una declaración de no tener los síntomas comunes de COVID-19 y desconocer si han sido expuestos al virus» (Airbnb 2021b). La crisis sanitaria ha abierto la posibilidad de extraer y apropiarse de los datos (biométricos) de los anfitriones y los huéspedes conforme a unos principios de autodisciplina y autogestión de los cuerpos que ahora se están aplicando a los miembros de la plataforma (véase Roelofsen y Minca 2018). La retórica basada en la comunidad (de viajeros) que acogía la promesa de «vivir como la gente del lugar» ha sido reemplazada por una particular atención al saneamiento y el distanciamiento. A ello se suma la creciente estandarización de un conjunto de prácticas que han terminado por transformar una forma de inducción biopolítica a las espacialidades de la intimidad del hogar en una forma reguladora de la vida de las personas y de las relaciones sociales de huéspedes y anfitriones. 


\section{Observaciones finales}

En vista de lo aquí observado, tal vez sea procedente añadir algunas notas a modo de conclusión. La primera es que la situación de emergencia por efecto de la pandemia ha puesto en evidencia la manera en que Airbnb se ha eximido de responsabilidad al suspender las normas existentes respecto a las políticas de cancelación estrictas; por causa de esto, fueron los anfitriones los que se vieron más afectados por las consecuencias adversas de la pandemia. Ello les ocasionó un trastorno importante, razón por la cual reaccionaron de manera colectiva contra los cambios dispuestos, aunque con éxito relativo. Al mismo tiempo, la crisis ha permitido a la plataforma diseñar, implementar y facilitar una política de cancelación por motivos de emergencia, la cual se ha traducido en interminables exigencias de flexibilidad y responsabilidad para con los anfitriones. Además, con la modificación de las funciones de búsqueda y la manera en que éstas privilegian la aparición de las ofertas que sí cumplen con la nueva política, la compañía ha ejercido (de manera discreta) su poder sobre los anfitriones.

En segundo lugar, los conceptos de «alojamiento» y «hospedaje» (elementos identitarios tradicionalmente importantes en la política de viajes de Airbnb) están siendo interpretados desde la llegada de la pandemia. En sus orígenes, la compañía presentaba la experiencia de alojarse en casa de un anfitrión como algo original y auténtico, la hospitalidad en contraposición a lo que ofrecían los hoteles y otros establecimientos similares. Airbnb ponía el acento en las posibilidades de esa nueva manera de viajar, que permitía relacionarse con la población local y vivir como ellos. Sin embargo, con la imposición de los nuevos estándares de limpieza y desinfección del alojamiento, la intervención de personas ajenas a la vivienda (antes considerada como un atractivo) se somete ahora a una vigilancia más estricta. A todo ello se añade un mayor nivel de control que es, hasta cierto punto, comparable con el control que suele ejercerse en el ámbito de la hostelería comercial.

Los cambios recientemente operados en la infraestructura de la plataforma y en sus protocolos facilitan la exposición, extracción y apropiación de los datos relativos al «trabajo de hospedaje», particularmente de aquellos que tienen que ver con las operaciones de limpieza y las interacciones presenciales. La externalización de los trabajos de limpieza en servicios profesionales aprobados por Airbnb podría ir en contra de los anfitriones que (solo pueden permitirse) realizar su propia limpieza o encargar el trabajo a terceros. Es probable que esta política altere tanto las relaciones establecidas por contrato como la dinámica de poder entre Airbnb y las administradoras inmobiliarias o las empresas de limpieza, pues éstas habían convenido previamente sus términos y condiciones con los arrendadores de corta estancia. Todas estas son novedades que generan dudas acerca de la estandarización y la subcontratación laboral adoptada por Airbnb, en la medida en que ocasionarán problemas con la legislación vigente y otras directrices (nacionales) del derecho laboral referidas a la protección de los trabajadores en el sector turístico (véase también Roelofsen y Minca 2018; loannides et al. 2021). Es cierto que muchos trabajos académicos sobre Airbnb se centran a menudo en la creación de una política para los alquileres de corto plazo con el fin de proteger el mercado de la vivienda y velar por el cumplimiento de las normas de salud y seguridad, así como de la fiscalidad. Pero quisiéramos resaltar aquí que todavía queda mucho por estudiar acerca de las condiciones laborales y el cumplimiento de sus leyes, particularmente en contextos en los que «prevalecen los bajos salarios, la explotación y una insuficiente protección, como ocurre en las industrias del turismo y de la hostelería» (Bianchi and de Man 2021).

También merece investigarse la creciente tendencia, observada en Airbnb, a fomentar entre sus miembros la oferta de estancias de mediano y largo plazo para «huéspedes» que podrían ser residentes en las proximidades del alojamiento. Aun cuando siempre se ha presentado como una compañía que opera en el sector del turismo y la hostelería, ¿sería posible que Airbnb se esté transformando, a vista de todos, en una «inmobiliaria de plataforma» (Fields y Rogers 2019) que ofrece espacios de alquiler para los más diversos propósitos? ¿Y de qué manera ello podría afectar, en diferentes contextos, la oferta y el mercado de la vivienda, así como los precios de ésta? Por ejemplo, algunos agentes inmobiliarios escriben comentarios de blog sobre el incremento del valor de sus propiedades mientras especulan con las cinco estrellas que son como un «antecedente» de la valoración de los clientes de Airbnb. ¿Cuáles podrían ser las consecuencias de este cambio en comparación con el impacto que han tenido en las ciudades los alquileres de estancias cortas? ¿Y cuál será el perfil de los nuevos «anfitriones» de la plataforma en los próximos años? Los nuevos protocolos de Airbnb ¿serán insostenibles e insoportables para 
aquellos anfitriones cuyas viviendas no sean adecuadas o que no dispongan de tiempo ni dinero para invertir en los trabajos requeridos? Si volvemos a preguntarnos acerca del futuro de Airbnb, nuestro breve estudio pone en evidencia que, a pesar de todas las dificultades que comporta la restricción a la movilidad turística en tiempos de pandemia, están surgiendo nuevas oportunidades en los espacios vacíos que nos deja la crisis sanitaria. Será importante estar atentos al papel que tendrá que jugar la plataforma en la evolución de los conceptos de alojamiento y vida cotidiana, pero también del trabajo en el turismo y el mercado de la vivienda.

\section{Bibliografía}

AIRBNB (2016). Overview of the Airbnb Community in Berlin. [en línea]. Disponible en: https://www.airbnbcitizen. com/wp-content/uploads/2016/04/airbnb-community-berlin-en.pdf

AIRBNB (2017a). Read the report: Airbnb, Housing, and the City of Cambridge. [en línea]. Disponible en: https://news.airbnb.com/read-the-report-airbnb-housing-and-the-city-of-cambridge/

AIRBNB (2017b). The Positive Impacts of Home Sharing in Copenhagen. [en línea]. Disponible en: https://news. airbnb.com/the-positive-impacts-of-home-sharing-in-copenhagen/

AIRBNB (2020). Airbnb's Work to Protect its Community During the Coronavirus Outbreak. [en línea]. Disponible en: https://news.airbnb.com/update-on-extenuating-circumstances-policy-for-coronavirus/

AIRBNB (2020a). A letter to hosts. [en línea]. Disponible en: https://news.airbnb.com/a-letter-to-hosts/

AIRBNB (2020b). Superhost Relief Fund Provided Grants to 8,700 Homes and Experience Hosts. [en línea]. Disponible en: https://news.airbnb.com/superhost-relief-fund-provided-grants-to-8700-homes-and-experience-hosts/

AIRBNB (2020c). A People-to-People Marketplace. By Greg Greeley. [en línea]. Disponible en: https://news. airbnb.com/a-people-to-people-marketplace/

AIRBNB (2020d). More Flexible Reservations in Times of Uncertainty. [en línea]. Disponible en: https://news. airbnb.com/more-flexible-reservations-in-times-of-uncertainty/

AIRBNB (2020e). Work From Anywhere: How Airbnb \& Guests are Approaching Remote Working. [en línea]. Disponible en: https://news.airbnb.com/work-from-anywhere-how-airbnb-guests-are-approaching-remote-working/

AIRBNB (2020f). Airbnb's Enhanced Cleaning Initiative for the Future of Travel. [en línea]. Disponible en: https://news.airbnb.com/our-enhanced-cleaning-initiative-for-the-future-of-travel/

AIRBNB (2020g). Getting started with the 5-step enhanced cleaning process. [en línea]. Disponible en: https://www. airbnb.com/resources/hosting-homes/a/getting-started-with-the-5-step-enhanced-cleaning-process-186

AIRBNB (2020h). Introducing Airbnb Enhanced Clean. [en línea]. Disponible en: https://news.airbnb.com/introducing-airbnb-enhanced-clean/

AIRBNB (2020i). Your guest or host may have COVID-19. Now what? [en línea]. Disponible en: https://www. airbnb.com/resources/hosting-homes/a/your-guest-or-host-may-have-covid-19-now-what-168

AIRBNB (2021). What is Airbnb's 5-step enhanced cleaning process? [en línea]. Disponible en: https://www. airbnb.com/help/article/2809/what-is-airbnbs-5step-enhanced-cleaning-process

AIRBNB (2021a). Partnering with RB, the Makers of Lysol®, to Help Protect Hosts and Guests. [en línea]. Disponible en: https://news.airbnb.com/partnering-with-rb-the-makers-of-lysol-to-help-protect-hosts-and-guests/

AIRBNB (2021b). Airbnb Announces Health Safety Attestation to Support Responsible Travel. [en línea]. Disponible en: https://news.airbnb.com/airbnb-announces-health-safety-attestation-to-support-responsible-travel/

ALLYN, B.; SCHNEIDER, A. "Airbnb now a $\$ 100$ billion company after stock market debut sees stock price double". NPR, 2020 [artículo en línea]. [Fecha de consulta: 9 de febrero de 2021].

BARNS, S. Platform Urbanism. Singapore: Springer Singapore, 2020. DOI: https://doi.org/10.1007/978-981-329725-8

BIANCHI, R.V.; DE MAN, F. "Tourism, inclusive growth and decent work: a political economy critique". Journal of Sustainable Tourism, 2021, vol. 29, no. 2-3, págs. 353-371. DOI: https://doi.org/10.1080/09669582.2020.1 730862 
BOSMA, J. "Airbnb and Covid-19: Capturing the Value of the Crisis". Platform Labor, 2020 [artículo en línea]. [Fecha de consulta: 9 de febrero de 2021].

BOSMA, J. "Platformed professionalization: Labor, assets, and earning a livelihood through Airbnb". University of Amsterdam, Centre for Urban Studies Working Paper Series, 49, 2021.

BOSMA, J.; MOS, E.; DOORN, N. van, "Disrupting 'Business as Usual': COVID-19 and platform labour”. Futures of Work, 2021[artículo en línea]. №. 15. [Fecha de consulta: 9 de febrero de 2021].

COCOLA-GANT, A.; GAGO, A. "Airbnb, buy-to-let investment and tourism-driven displacement: A case study in Lisbon". Environment and Planning A: Economy and Space, 2019. DOl: https://doi. org/10.1177\%2F0308518X19869012.

DOLNICAR, S.; ZARE, S. "COVID19 and Airbnb - Disrupting the Disruptor". Annals of Tourism Research, 2020. DOI: https://doi.org/10.1016/j.annals.2020.102961.

FIELDS, D.; ROGERS, D. "Towards a Critical Housing Studies Research Agenda on Platform Real Estate". Housing, Theory and Society, 2021. vol. 38, no. 1, págs. 72-94. DOl: https://doi.org/10.1080/14036096.2019.1 670724

GIL, J.; SEQUERA, J. "The professionalization of Airbnb in Madrid: far from a collaborative economy". Current Issues in Tourism, 2020. DOI: https://doi.org/10.1080/13683500.2020.1757628.

GLUSAC, E. "In a Changed World for Travel, What Does Airbnb's Future Hold?" New York Times, 2020 [artículo en línea]. [Fecha de consulta: 9 de febrero de 2021].

IAQUINTO, B.L. "Tourist as vector: Viral mobilities of COVID-19". Dialogues in Human Geography, 2020. vol. 10, no. 2, págs. 174-177. DOI: https://doi.org/10.1177\%2F2043820620934250.

IOANNIDES, D.; GYIMÓTHY, S.; JAMES, L. "From liminal labor to decent work: A human-centered perspective on sustainable tourism employment". Sustainability, 2021. vol. 13, no. 2, págs. 1-15. DOl: https://doi. org/10.3390/su13020851.

MINCA, C.; ROELOFSEN, M. "Becoming Airbnbeings: on datafication and the quantified Self in tourism". Tourism Geographies, 2019. DOI: https://doi.org/10.1080/14616688.2019.1686767.

ROELOFSEN, M. "Performing 'home' in the sharing economies of tourism: The airbnb experience in Sofia, Bulgaria". Fennia, 2018. vol. 196, no. 1, págs. 24-42. DOl: https://doi.org/10.11143/fennia.66259.

ROELOFSEN, M.; MINCA, C. "The Superhost. Biopolitics, home and community in the Airbnb dream-world of global hospitality". Geoforum, 2018. vol. 91, págs. 170-181. DOl: https://doi.org/10.1016/j.geoforum.2018.02.021.

SCHAAL, D. "The Future of Short-Term Rentals After the Pandemic and an Airbnb IPO". Skift, 2020 [artículo en línea]. [Fecha de consulta: 9 de febrero de 2021].

SEMI, G.; TONETTA, M. "Marginal hosts: Short-term rental suppliers in Turin, Italy". Environment and Planning A, 2020. DOI: https://doi.org/10.1177\%2F0308518X20912435.

UNWTO, "How are countries supporting tourism recovery?" UNWTO Briefing Note - Tourism and COVID-19, 2020. $1^{\text {a }}$ ed., $n^{\circ}$ 2, págs. 1-28. DOI: https://doi.org/10.18111/9789284421893.

VAN DOORN, N. "A new institution on the block: On platform urbanism and Airbnb citizenship". New Media \& Society, 2020. vol. 22, no. 10, p. 1808-1826. https://doi.org/10.1177/1461444819884377

VAN DOORN, N. "Platform labor: on the gendered and racialized exploitation of low-income service work in the 'on-demand' economy". In: Information, Communication \& Society. 2017. Vol. 20, no. 6, pages 898-914. ISSN: 1461-4448. DOI: https://doi.org/10.1080/1369118X.2017.1294194.

WILSON, J.; GARAY-TAMAJON, L.; MORALES-PEREZ, S. "Politicising platform-mediated tourism rentals in the digital sphere: Airbnb in Madrid and Barcelona". Journal of Sustainable Tourism, 2021. DOI: https://doi.org/1 0.1080/09669582.2020.1866585.

WTTC, "Safe Travels: Global Protocols \& Stamp for the New Normal" World Travel and Tourism Council, 2020. [artículo en línea]. 
Citación recomendada: ROELOFSEN, Maartje; MINCA, Claudio. Alojamientos desinfectados y cuerpos sanos: reflexiones sobre la respuesta de Airbnb a la pandemia. Oikonomics [online]. Mayo 2021, no. 15, pp. 1-10. ISSN: 2339-9546. DOI: https://doi.org/10.7238/o.n15.2104

Los textos publicados en esta revista están sujetos -si no se indica lo contrario- a una licencia de Reconocimiento 4.0 Internacional de Creative Commons. Puede copiarlos, distribuirlos, comunicarlos públicamente, hacer obras derivadas siempre que reconozca los créditos de las obras (autoría, nombre de la revista, institución editora) de la manera especificada por los autores o por la revista. La licencia completa se puede consultar en https://creativecommons.org/licenses/by/4.0/deed.es_ES.
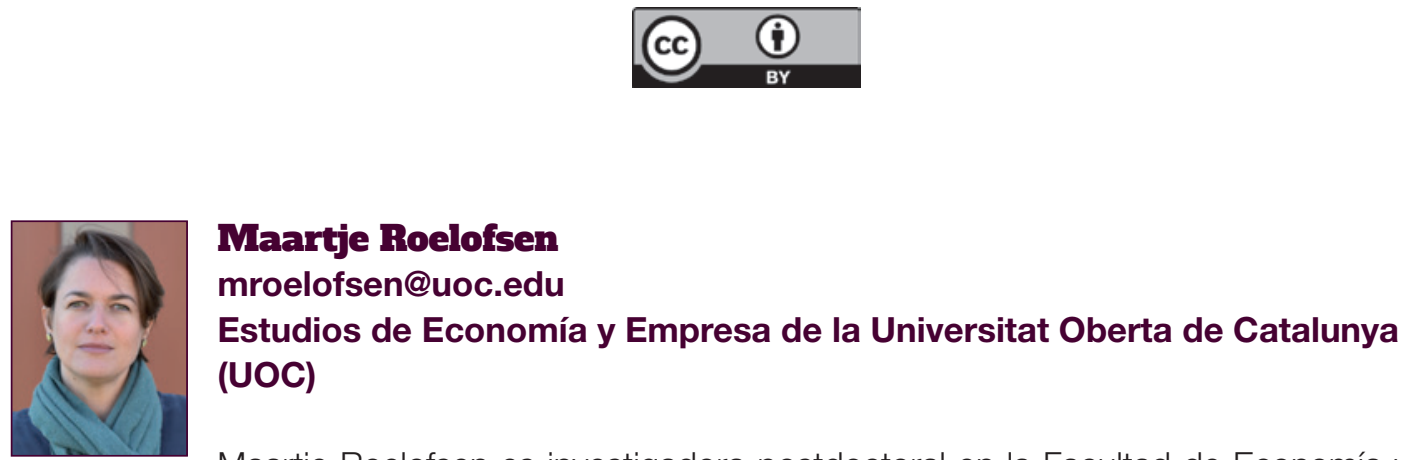

Maartje Roelofsen es investigadora postdoctoral en la Facultad de Economía y Empresa de la Universitat Oberta de Catalunya en España. Sus investigaciones versan sobre los impactos socioespaciales de las tecnologías digitales, específicamente en el ámbito del turismo. Tomando Airbnb como estudio de caso, ha indagado sobre el papel de la plataforma en la transformación de las ideas y las prácticas relacionadas con la noción del alojamiento. Su trabajo más reciente analiza la manera en que los usuarios de las plataformas se sirven de ellas para reforzar su capacidad de acción política con el fin de cuestionar y cambiar las modalidades de gobernanza de la empresa.

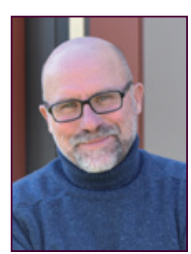

\section{Glaudio Minca claudio.minca@unibo.it \\ Departamento de Historia y Culturas - Unidad de Geografía Alma Mater Studiorum - Universidad de Bolonia}

Claudio Minca es profesor de Geografía en el Departamento de Historia y Culturas de la Universidad de Bolonia en Italia. Sus investigaciones se centran en tres grandes temas: la espacialización de la (bio)política, el turismo y las teorías sobre el viaje en la modernidad, y la relación entre el conocimiento moderno, el espacio y el paisaje en la geografía postcolonial. Recientemente, ha trabajado sobre las geografías de las prisiones, y en particular, en las de los campos de refugiados de Serbia y la región de los Balcanes. Actualmente es profesor visitante en la Facultad de Economía y Empresa de la Universitat Oberta de Catalunya. 


\section{OTIOLTOMTS}

Revista de economía, empresa y sociedad

Dosier sobre economía colaborativa (y II)

Nuevas estrategias y dimensiones alternativas de la economía de plataforma

Coordinador: Lluís Alfons Garay Tamajón

NUEVAS PERSPECTIVAS

\section{Gambios en la oferta de Airbnb durante la pandemia de COVID-19}

\section{Gzesław Adamiak}

Nicolaus Copernicus University de Toruń, Polonia

RESUMEN Airbnb se considera la empresa de turismo de mayor valor en la historia y es el epítome de la economía de plataforma en el turismo, un sector sumido en la crisis ocasionada por la pandemia de COVID-19. El presente artículo presenta el contexto actual de la investigación internacional centrada en Airbnb, describiendo para ello el origen, el estado actual y la posible evolución de la oferta de la plataforma durante y después de la pandemia. Los datos de la oferta mundial de Airbnb en 2018, 2019 y 2020 fueron obtenidos de la plataforma por el método de extracción de datos web (scraping); estos revelaron que el crecimiento dinámico de la oferta de alojamiento se detuvo en el último año. En el transcurso de la pandemia, la oferta de la plataforma ha seguido registrando una dispersión geográfica hacia mercados menos saturados y zonas rurales. Los pisos y los apartamentos enteros siguen siendo cada vez más predominantes en la estructura de las ofertas listadas en la plataforma, mientras que el descenso en el porcentaje de ofertas de anfitriones con ofertas múltiples indica una desaceleración en el proceso de profesionalización de la oferta.

PALABRAS CLAVE Airbnb; alojamiento entre pares; economía de plataforma; economía compartida 


\title{
Changes in the global Airbnb offer during the COVID-19 pandemic
}

\begin{abstract}
Airbnb is the most valuable tourism company in history and an epitome of the platform economy in tourism. Since 2020, together with the entire tourism sector, it has experienced the crisis caused by the COVID-19 pandemic. The paper presents the context for the current international research on Airbnb by describing the origin, current state, and possible developments of the platform offer during and after the pandemic. The data on the global Airbnb offer in 2018, 2019, and 2020 comes from web-scraping the platform website. It shows that the dynamic growth of accommodation supply stopped in the last year. The platform offer has continued to disperse geographically towards less saturated markets and rural areas during the pandemic period. Entire flats and apartments have been continuously growing in dominance in the structure of the listing, while the slower growth in the percentage of multihosts' listings indicates a slowdown in the process of the professionalisation of the platform offer.
\end{abstract}

KEYWORDS Airbnb; peer-to-peer accommodation; platform economy; sharing economy

\section{Introducción}

El 10 de diciembre de 2020, Airbnb presentó su primera oferta pública de acciones en la bolsa de valores NASDAQ. No obstante el devastador efecto que ha tenido la pandemia sobre el turismo, las acciones de Airbnb se duplicaron en el primer día de su salida en la bolsa, y el valor de la empresa superó los 100.000 millones de dólares USD (Schaal, 2020a). Apenas 12 años después de constituirse, Airbnb se convertía en la empresa de turismo más valiosa de la historia y el paradigma de la economía de plataforma en el sector turístico, siendo por ello objeto de atención pública y del mundo académico. Esto no solo ocurre por el tamaño del negocio y su éxito económico, sino también por los efectos perturbadores que ha tenido en la industria de la hostelería y del mercado de la vivienda, así como por su impacto transformador en los modelos de producción y consumo turístico (Guttentag, 2019).

El presente artículo se propone presentar el contexto actual de la investigación internacional centrada en Airbnb; para ello, describimos su origen, su estado actual y la posible evolución de la oferta de la plataforma. En la primera parte presentamos un esbozo del origen y los valores fundamentales que exhibe la compañía ante su base de usuarios. También ofrecemos una descripción de la situación de la plataforma en el actual mercado de intermediarios en el alojamiento. La segunda parte presenta datos de 2018, 2019 y 2020, extraídos de la web, que reflejan el estado actual y los cambios recientemente operados en la plataforma, así como su distribución geográfica y la estructura de sus alojamientos. En la última parte, hacemos uso de esos datos para contribuir al actual debate sobre el futuro de Airbnb y de la economía de plataforma durante y después de la pandemia. 


\section{Las raíces de Airbnb y sus competidores}

Airbnb es uno de los intermediarios on-line en alojamiento más grandes del mundo. Su oferta de 5,6 millones de viviendas, apartamentos y habitaciones se extiende por casi todos los países (Airbnb, 2021). En sus campañas de marketing, la compañía se esfuerza por presentarse como una forma cualitativamente novedosa de producción y consumo de servicios turísticos. Sin embargo, los fundadores de la plataforma no aportaron una idea completamente nueva al mercado; antes bien, estos aplicaron su creatividad sobre la base de tres modelos para el desarrollo de servicios turísticos que ya existían en el mercado:

- La explotación del modelo de mercado de dos caras, en el que la plataforma actúa como la intermediaria entre proveedores y consumidores que se encuentran geográficamente dispersos. El modelo ya había sido utilizado por agencias de viajes on-line como Booking y Expedia, si bien Airbnb desarrolló una plataforma que resultaba especialmente atractiva para los anfitriones a pequeña escala.

- Basándose en el dinámico mercado del alquiler de viviendas para las vacaciones, que suele relacionarse mejor con la tendencia, muy generalizada, de hacer uso de una vivienda sin residir en ella, (Doling, 2019), Airbnb contribuyó a extender hacia las grandes ciudades el alquiler de apartamentos turísticos, que es la forma habitual de alojamiento en los centros de ocio.

- La propuesta de Airbnb se inspiró en la difusión del concepto de la economía compartida y del consumo colaborativo (Dredge y Gyimóthy, 2015). Airbnb hace posible que los anfitriones utilicen un activo infrautilizado (apartamentos o habitaciones), mientras que la plataforma recurre al relato de la idea de compartir con el fin de publicitar su servicio como una forma de actividad económica novedosa y sostenible.

No es Airbnb la única plataforma que ofrece alojamiento en casas y habitaciones privadas de manera colaborativa y digital (peer-to-peer). La Tabla 1.1 muestra una relación de las plataformas más importantes que ofrecen servicios similares. Airbnb es la plataforma de más reciente creación (si excluimos a los competidores chinos), pero es la mayor red de alojamiento colaborativo y digital. 
Tabla 1.1. Selección de plataformas de alojamiento en vivienda compartida

\begin{tabular}{|c|c|c|c|c|c|}
\hline Plataforma & Año de fundación & Sede & $\begin{array}{l}\text { Modelo de arren- } \\
\text { damiento }\end{array}$ & $\begin{array}{l}\text { Ingresos de la } \\
\text { plataforma }\end{array}$ & $\begin{array}{l}\text { Tamaño de la } \\
\text { plataforma }\end{array}$ \\
\hline HomeExchange & $\begin{array}{l}1992 \text { HomeExchange, } \\
2011 \text { GuestToGuest }\end{array}$ & París, Francia & $\begin{array}{l}\text { Puntos obtenidos } \\
\text { por los huéspedes } \\
\text { al pagar por su } \\
\text { estancia }\end{array}$ & $\begin{array}{l}\text { Cuota de socio } \\
\text { pagada por los } \\
\text { usuarios }\end{array}$ & $\begin{array}{l}450 \text { mil viviendas en } \\
187 \text { países }\end{array}$ \\
\hline Vrbo & $\begin{array}{l}1995 \text { VRBO, } \\
2005 \text { HomeAway }\end{array}$ & Austin, EE.UU. & De pago & $\begin{array}{l}\text { Suscripción paga- } \\
\text { da por los anfitrio- } \\
\text { nes o comisiones } \\
\text { por las reservas }\end{array}$ & $\begin{array}{l}>2 \text { millones de } \\
\text { ofertas }\end{array}$ \\
\hline Booking.com & 1996 & $\begin{array}{l}\text { Amsterdam, } \\
\text { Países Bajos }\end{array}$ & $\begin{array}{l}\text { Pago en hoteles } \\
\text { (principalmente), } \\
\text { viviendas y aparta- } \\
\text { mentos }\end{array}$ & $\begin{array}{l}\text { Comisiones por las } \\
\text { reservas }\end{array}$ & $\begin{array}{l}2,4 \text { millones de } \\
\text { ofertas de vivien- } \\
\text { das, apartamentos, } \\
\text { estancias en hoga- } \\
\text { res, etc. }\end{array}$ \\
\hline TripAdvisor Rentals & $\begin{array}{l}1999 \text { HolidayLettings, } \\
2004 \text { VacationHome- } \\
\text { Rentals } \\
2005 \text { Niumba } \\
2007 \text { FlipKey } \\
2009 \text { HouseTrip }\end{array}$ & $\begin{array}{l}\text { Needham, } \\
\text { EE.UU. }\end{array}$ & De pago & $\begin{array}{l}\text { Suscripción paga- } \\
\text { da por los anfitrio- } \\
\text { nes o comisiones } \\
\text { por las reservas }\end{array}$ & $\begin{array}{l}\text { > } 830 \text { mil propieda- } \\
\text { des en } 190 \text { países }\end{array}$ \\
\hline Couchsurfing & 2004 & $\begin{array}{l}\text { San Francisco, } \\
\text { EE.UU. }\end{array}$ & Gratuita & $\begin{array}{l}\text { Cuota de socios } \\
\text { en ciertos países; } \\
\text { cuota de verifica- } \\
\text { ción opcional }\end{array}$ & $\begin{array}{l}14 \text { millones de } \\
\text { socios }\end{array}$ \\
\hline Airbnb & 2008 & $\begin{array}{l}\text { San Francisco, } \\
\text { EE.UU. }\end{array}$ & De pago & $\begin{array}{l}\text { Comisiones por las } \\
\text { reservas }\end{array}$ & $\begin{array}{l}4 \text { millones de anfi- } \\
\text { triones, } 5,6 \text { millones } \\
\text { de ofertas en más } \\
\text { de } 220 \text { países y } \\
\text { regiones }\end{array}$ \\
\hline Wimdu & 2011 & $\begin{array}{l}\text { Berlin, } \\
\text { Alemania }\end{array}$ & De pago & $\begin{array}{l}\text { Comisiones por las } \\
\text { reservas }\end{array}$ & $>350$ mil ofertas \\
\hline Tujia & 2011 & Beijing, China & $\begin{array}{l}\text { De pago (también } \\
\text { en hoteles) }\end{array}$ & $\begin{array}{l}\text { Comisiones por } \\
\text { reservas }\end{array}$ & $\begin{array}{l}\text { > Un millón de ofer- } \\
\text { tas, principalmente } \\
\text { en China }\end{array}$ \\
\hline Xiaozhu & 2012 & Beijing, China & De pago & $\begin{array}{l}\text { Comisiones por las } \\
\text { reservas }\end{array}$ & $\begin{array}{l}>500 \text { mil ofertas, } \\
\text { principalmente en } \\
\text { China }\end{array}$ \\
\hline
\end{tabular}

Fuente: elaboración propia basada en Hajibaba y Dolnicar, 2018; Feng, 2019; webs de las plataformas 


\section{Oferta de Airbnb antes y después de la pandemia de COVID-19}

Airbnb no publica datos detallados datos sobre su estructura, la distribución geográfica y el uso de las ofertas de alojamiento disponibles en su plataforma. Sin embargo, desde la página web de la plataforma es posible obtener indirectamente dicha información mediante la extracción automática de datos web (web-scrapers). Los datos extraídos suelen ser empleados, por ejemplo, para investigar sobre el comportamiento de los anfitriones y los huéspedes y, asimismo, sobre cómo repercuten los alquileres de Airbnb en el mercado de la vivienda. La mayoría de los investigadores utiliza unos datasets que se compilan, archivan y publican en las webs AirDNA (comercial) e InsideAirbnb (no comercial). En la mayoría de casos, el alcance geográfico de sus análisis se limita a ciudades específicas. Los casos poco frecuentes de estudios sobre la escala espacial a nivel mundial presentan grandes variaciones geográficas en términos de dimensión, estructura e intensidad en el uso de Airbnb (Adamiak, 2019; Ke 2017).

En los siguientes apartados de este artículo, presentamos información general acerca del tamaño, la distribución y la estructura de las ofertas de Airbnb en los tres últimos años. Para ello nos basamos en tres sesiones de extracción de datos web realizadas entre setiembre y octubre de 2018; en setiembre de 2019 y en noviembre de 2020. Se utilizó el script de extracción de datos web de Slee (2018). Este no garantiza la inclusión de todas las ofertas ocurridas en un momento dado. Con el fin de filtrar ofertas inactivas, publicadas por error o duplicadas, en los conjuntos de datos (datasets) se incluyeron solo las ofertas que obtuvieron al menos un comentario. La Figura 1.1 muestra que el número de arrendamientos disponibles siguió incrementándose hasta alcanzar cerca de 4 millones de ofertas en 2019, y luego cayó un 6,5 \% hasta noviembre de 2020, por efecto de la pandemia de COVID-19.

Figura 2.1. Número de ofertas de Airbnb con comentarios en los periodos correspondientes a septiembre-octubre 2018, septiembre 2019 y noviembre 2020

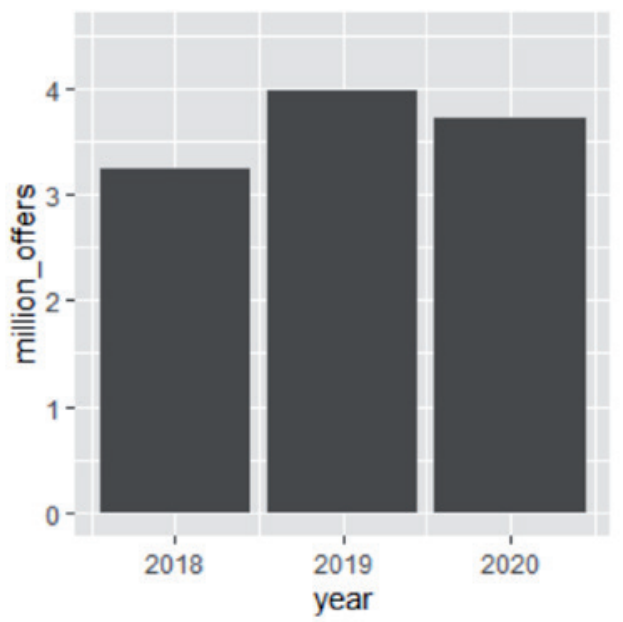

\subsection{Distribución geográfica de las ofertas}

Las mayores ofertas de Airbnb se concentran en América del norte y del sur, Europa y Asia oriental (Fig. 2.2). Una sexta parte del suministro mundial de alojamientos está localizada en los EE.UU., el país de nacimiento de la plataforma. En Europa, los mercados más grandes están en Francia, Italia, España, Reino Unido y Alemania. La lista de los diez países con mayor mercado la completan China, Brasil, México y Australia. También existen otros mercados grandes para Airbnb en algunos países pequeños de Europa, al igual que en otros países de América 
(norte y sur) y del Sudeste Asiático. El menor número de ofertas es típico de los países de África (exceptuando Sudáfrica) y de Asia central y sud-occidental. La oferta de alquileres siguió creciendo en todos los países hasta el año 2019. Se observaron tendencias distintas en cada país al registrarse caídas durante la pandemia. Al final de 2020, hubo un descenso en las ofertas de países de Europa del sur como España e Italia, llegando a niveles más bajos que en el año 2018. La mayoría de países registró un descenso en la oferta con respecto a 2019, aunque no mayor con respecto a 2018. Algunos países (por ejemplo, Brasil y Rusia) vieron un incremento continuado de su oferta de alquileres en 2020, aun con la pandemia.

Figura 2.2. Número de ofertas de Airbnb que obtuvieron comentarios en los 20 primeros países de la lista

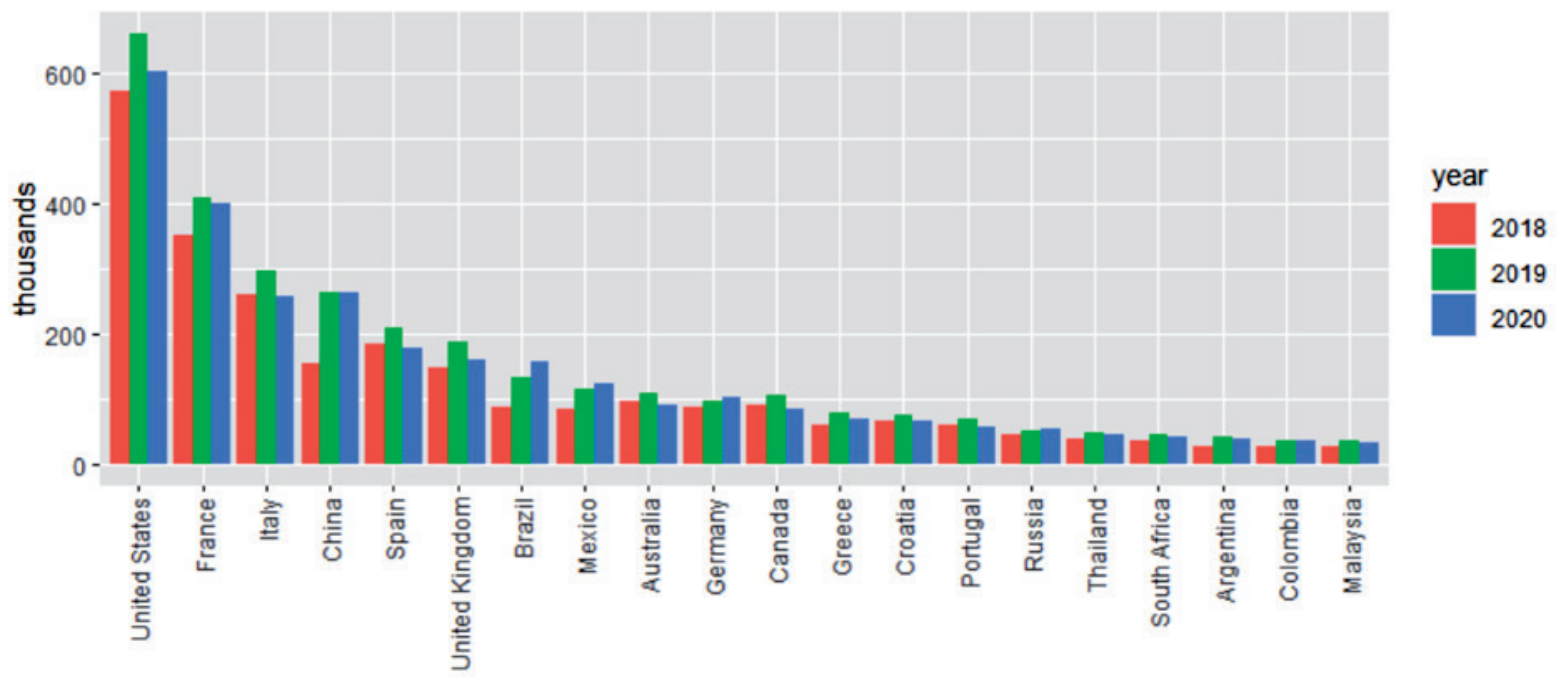

La figura 2.3 muestra el número de ofertas situadas en los mayores destinos de Airbnb. Estos lugares no son delimitados según el criterio administrativo que emplea la mayor parte de las publicaciones; en este caso, la delimitación responde a un análisis de los datos. Así, cada destino representa la concentración de ofertas de Airbnb en una zona pequeña. Los destinos fueron delimitados con DBSCAN, un método de agrupamiento por densidades (Hahsler et al., 2019) que empleó los parámetros eps=1 km y minPts=3. Los destinos de Airbnb más destacados se sitúan en las ciudades de Europa occidental (con París y Londres encabezando las ofertas), América del norte y del sur y Asia oriental. Además de las grandes ciudades, integran la lista las ciudades de Niza, Denpasar y Marbella, cuyos destinos de ocio están situados en sus respectivas periferias. 
Figura 2.3. Número de ofertas de Airbnb que obtuvieron comentarios en los 30 primeros destinos de la lista

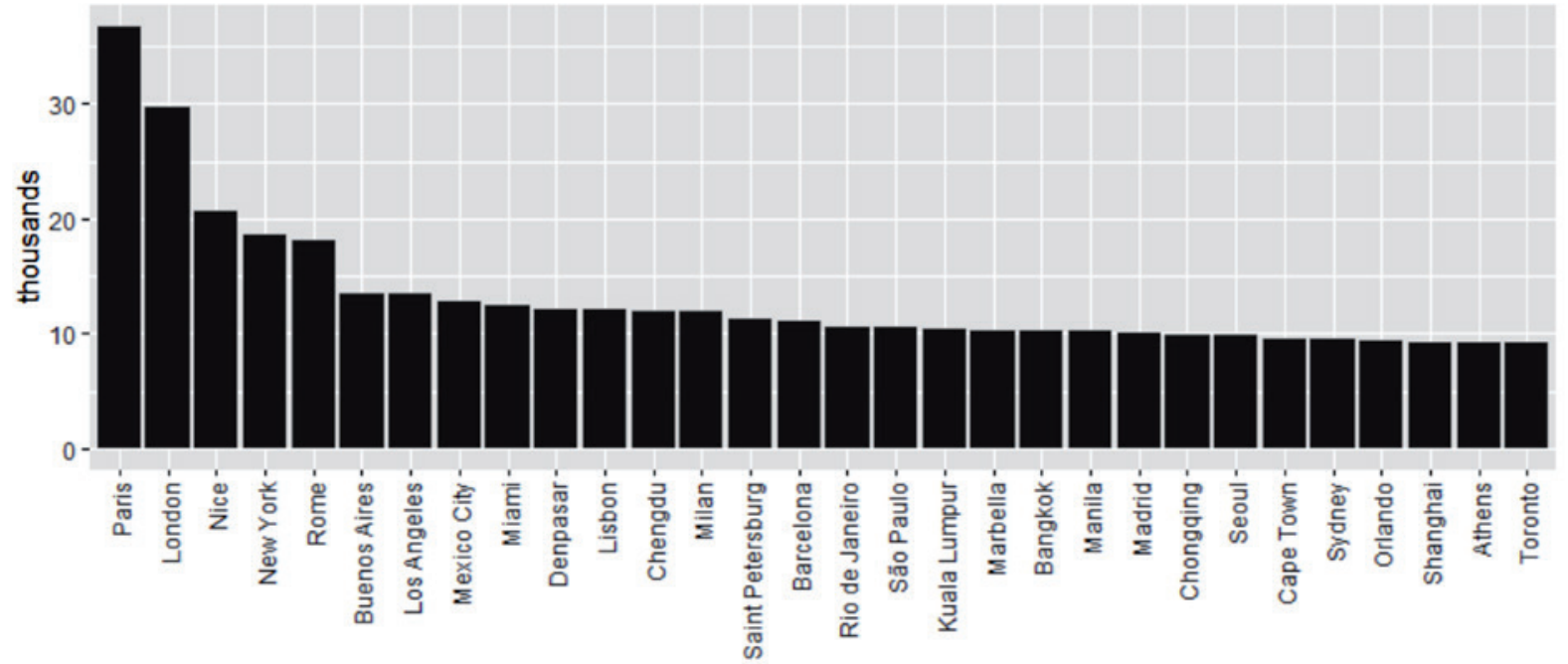

Las publicaciones suelen describir a Airbnb como un fenómeno urbano. Sin embargo, solo la mitad de las ofertas en el mundo está situada en zonas urbanizadas, siguiendo para ello la definición empleada en la base de datos geográfica de Natural Earth (2021). El resto de la oferta está situada en poblaciones pequeñas, centros de ocio y zonas rurales. En la comparativa entre países según el tamaño de sus ofertas urbanas, las ofertas de la plataforma se concentran principalmente en las ciudades de Europa oriental y de los países asiáticos. En cambio, los países de Europa meridional registran el mayor número de ofertas rurales, al ser éstas ubicadas con frecuencia en zonas costeras (Figura 2.4). En los últimos tres años, la proporción de ofertas urbanas ha descendido del 53,6\% en 2018 al 49,1\% en 2021, una tendencia que se ha vista acelerada durante la pandemia.

Figura 2.4. Porcentaje de ofertas de Airbnb situadas dentro de las zonas urbanas de los 20 primeros países de la lista

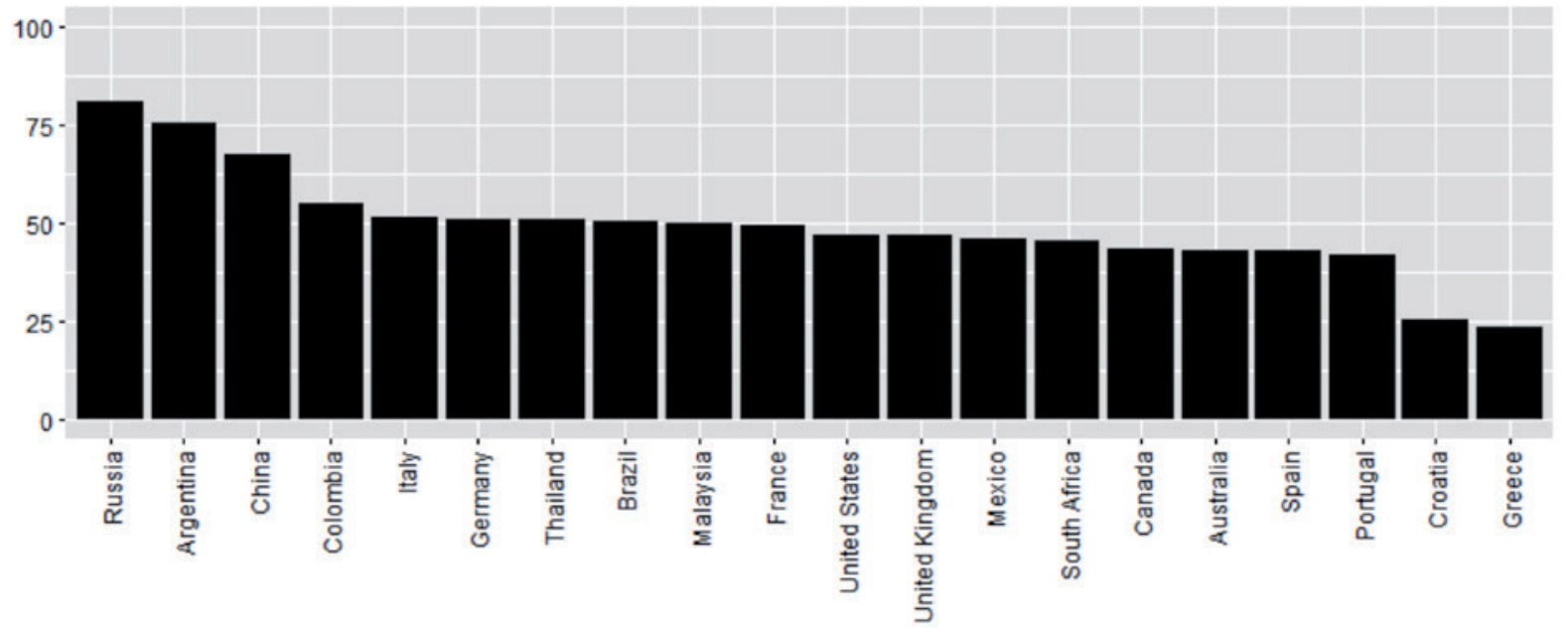




\subsection{Tipología de las ofertas de alojamiento}

Las ofertas de Airbnb tienen un uso, un valor y unas repercusiones variables según sea el tipo de oferta de alojamiento. Cuando se discute el impacto y la normativa del alquiler para estancias cortas, se suele distinguir entre anfitriones no profesionales (mamá y papá, o de par a par) y anfitriones profesionales (comerciales, con fines de lucro) (Dolnicar, 2019; Wegmann y Jiao, 2017). Los primeros arriendan una habitación en su vivienda o la casa entera cuando ellos se van de vacaciones; pero también pueden alquilar su segunda residencia. Por su parte, los apartamentos y viviendas de los anfitriones profesionales son utilizados exclusivamente para el arrendamiento, pudiendo ser ellos mismos o bien sus propietarios o bien los administradores de las propiedades de otros (Oskam, 2019). Airbnb también es utilizado como canal de distribución por los proveedores de servicios de alojamiento, los hoteles y otros lugares de pernoctación y desayuno (como el bed \& breakfast). Las normativas legales y los estudios sobre la materia distinguen entre las ofertas profesionales y las no profesionales según:

- la presencia o no del anfitrión en el apartamento

- el máximo permitido en días de alquiler anual

- el tipo de oferta (habitación o vivienda entera)

- el número de ofertas a cargo de un único anfitrión (Adamiak, 2019; Dolnicar, 2019; Oskam, 2019; Wegmann y Jiao, 2017)

En la base de datos de este estudio, se consideraron las dos últimas características arriba citadas. El tipo de oferta que predomina en Airbnb es la de viviendas o apartamentos enteros (Fig. 2.5). La proporción de este tipo de ofertas ha ido creciendo antes de la pandemia (del 72,6\% en 2018 al 74,1\% en 2019) y durante la pandemia (76,2\% en 2020). La proporción de habitaciones privadas ha descendido del 26,2\% en 2018 al 21,6\% en 2020. Las habitaciones de hotel (que son una categoría aparte desde 2019) y las habitaciones compartidas representan proporciones mínimas en el conjunto de ofertas.

Figura 2.5. Tipología de las ofertas de Airbnb que obtuvieron comentarios

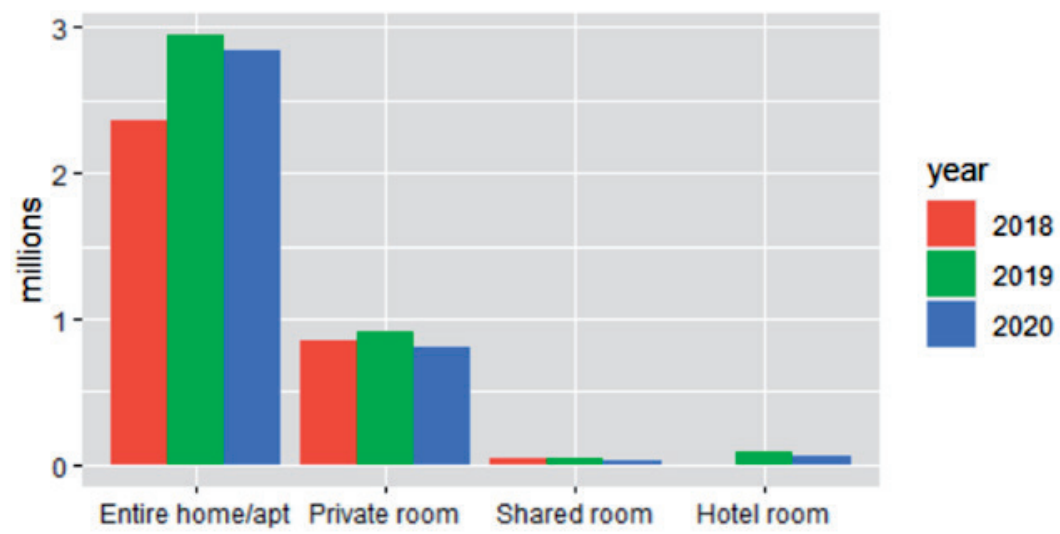

Los anfitriones con múltiples ofertas representan el 59,8\% del total de ofertas. Esta proporción representa un incremento respecto al 56,6\% registrado en 2018, aun cuando este registró una desaceleración el pasado año. El 15,1\% de las ofertas provienen de anfitriones que publicaron más de 10 ofertas, y el 5,2\% corresponde a anfitriones con más de 50 ofertas. El récord en número de ofertas publicadas por un único anfitrión es de 2.649. La Figura 2.6 muestra las diferencias entre países en relación con la cantidad de ofertas múltiples. En general, la mayor proporción de anfitriones que publican ofertas múltiples se encuentra en los mercados de Asia y Europa oriental, mientras que los anfitriones con una sola oferta son más habituales en Europa occidental y en Sudamérica. Aun así, entre los 20 primeros mercados de Airbnb, solo Francia registra una proporción mayoritaria de anfitriones con una sola oferta. 


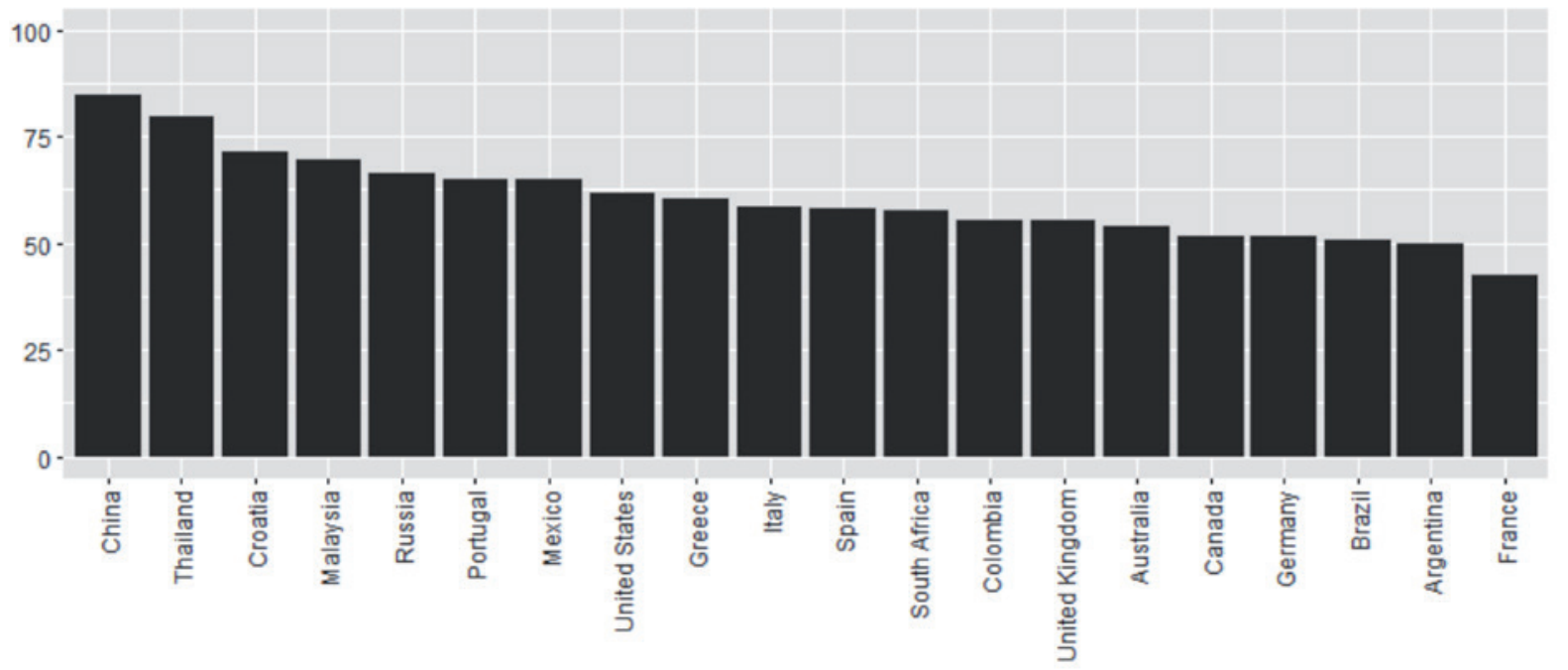

\section{Discusión sobre Airbnb y su futuro}

Antes de la pandemia, Airbnb estaba interesada en desarrollar la oferta de hoteles y anfitriones profesionales como una manera de incursionar en los viajes de lujo o de negocios por ser estos los segmentos más rentables (Dogru, Mody y Suess, 2019). La compañía adquirió otras plataformas, creó marcas para segmentos específicos (por ejemplo, Airbnb for Work y Airbnb Plus) y modificó ciertos mecanismos de la plataforma de modo que ésta fuese más conveniente para el usuario profesional. La tendencia al crecimiento rápido y desproporcionado de las ofertas de anfitriones profesionales quedó confirmada con la extracción de datos web. La estrategia de largo plazo de la compañía consistía en ampliar su oferta para los servicios turísticos más allá del alojamiento y construir una «plataforma de viajes integral», lo que fue solo en parte conseguido al añadirse productos en los apartados de «Restaurantes» $y$ «Experiencias».

La pandemia afectó a las industrias relacionadas con los viajes, de la cual Airbnb forma parte. La empresa registró una caída del 30\% en su recaudación anual y unas pérdidas netas de 459.000 millones en 2020 (Jelski, 2021) La crisis ha llevado a las plataformas a perder interés en ampliar la oferta de nuevos servicios turísticos. Por ello, la estrategia de director ejecutivo de Airbnb ha vuelto a poner el foco en los alojamientos y anfitriones microemprendedores (con múltiples ofertas), así como en las estancias de mayor duración (Schaal, 2020b). Existen estudios que pronostican futuros posibles para Airbnb tras la crisis de la industria turística. Para muchos, es posible que la oferta de alojamientos deje de crecer, principalmente por el éxito que los anfitriones profesionales están experimentando en la plataforma (Dolnicar y Zare, 2020; Zhang et al., 2020) y por el retorno parcial de la vivienda actualmente ofertada en Airbnb al mercado de la vivienda permanente (Farmaki et al., 2020; Kadi et al., 2020). Pero otros se inclinan por avizorar una renovación fortuita de la plataforma como algo que estaría ocurriendo en tiempos que requieren la distancia social: la preferencia de los clientes por alquilar pisos enteros en lugar de habitaciones de hotel (Bresciani et al., 2021).

La evidencia que ofrecen los datos revela que algunos procesos observados en la oferta de la plataforma con anterioridad a la pandemia se hicieron más visibles aún durante la crisis. Ello incluye la descentralización geográfica desde los EE.UU. y Europa sud-occidental a unos mercados nacionales menos saturados, y desde las zonas urbanas a las zonas rurales. Por lo que respecta al tipo de alojamiento, se ha registrado un mayor predominio de 
los apartamentos y viviendas en la estructura de las ofertas, mientras que los anfitriones con ofertas múltiples han dejado de crecer, lo cual confirma que la profesionalización de la oferta de la plataforma está perdiendo ritmo. Estos procesos podrían ser interpretados como una señal de que la plataforma está evolucionando más lentamente, pero también renovándose. El éxito de la salida en bolsa de la compañía parece indicar que la pandemia de COVID-19 no ha supuesto el fin del modelo de vivienda compartida sino que este seguirá redefiniendo la economía de la experiencia turística en el futuro.

\section{Referencias}

ADAMIAK, Czeslaw. "Current state and development of Airbnb accommodation offer in 167 countries". Current Issues in Tourism, 2019. DOI: https://doi.org/10.1080/13683500.2019.1696758

AIRBNB, About us, <https://press.airbnb.com/about-us/>, 2021 Disponible en: https://press.airbnb.com/about-us/ BRESCIANI, Stefano, FERRARIS, Alberto, SANTORO, Gabriele, PREMAZZI, Katia, QUAGLIA, Roberto, YAHIAOUI, Dorra y VIGLIA, Giampaolo. "The seven lives of Airbnb. The role of accommodation types". Annals of Tourism Research, 88, 103170, 2021. DOI: https://doi.org/10.1016/j.annals.2021.103170

DOGRU, Tarik and Mody, Makarand y SUESS, Courtney. "Adding evidence to the debate: Quantifying Airbnb's disruptive impact on ten key hotel markets". Tourism Management, 72, pp. 27-38, 2019. DOl: https://doi. org/10.1016/j.tourman.2018.11.008

DOLING, John. "'Not for housing' housing: Widening the scope of housing studies". Critical Housing Analysis, 6(1), pp. 22-31, 2019. DOI: http://dx.doi.org/10.13060/23362839.2019.6.1.450

DOLNICAR, Sara. "A review of research into paid online peer-to-peer accommodation". Annals of Tourism Research, 75, pp. 248-264, 2019. DOI: https://doi.org/10.1016/j.annals.2019.02.003

DOLNICAR, Sara and ZARE, Samira. "COVID19 and Airbnb - Disrupting the disruptor". Annals of Tourism Research, 83, 102961, 2020. DOI: http://dx.doi.org/10.1016/j.annals.2020.102961

DREDGE, Dianne and GYIMÓTHY, Szilvia. "The collaborative economy and tourism: Critical perspectives, questionable claims and silenced voices". Tourism Recreation Research, 40, pp. 286-302, 2015. DOI: http://dx.doi. org/10.1080/02508281.2015.1086076

FARMAKI, Anna, MIGUEL, Cristina, DROTAROVA, Maria H, ALEKSIĆ, Anna, ČASNI, ANITA Č. y EFTHYMIADOU, Fani. "Impacts of Covid-19 on peer-to-peer accommodation platforms: Host perceptions and responses". International Journal of Hospitality Management, 91(61), 102663, 2020. DOI: https://dx.doi.org/10.1016\%2Fj. ijhm.2020.102663

FENG, Linyan. "A scorecard breaking down everyone from Xiaozhu, Tujia to Airbnb". EqualOcean. < https://equalocean.com/analysis/201902091384 >, 2019

GUTTENTAG, Daniel. (2019). "Progress on Airbnb: a literature review". Journal of Hospitality and Tourism Technology, 10(4), 814-844. DOI: http://dx.doi.org/10.1108/JHTT-08-2018-0075

HAHSLER, Michael, PIEKENBROCK, Matthew and DORAN, Derek. "dbscan: Fast density-based clustering with R". Journal of Statistical Software, 91(1), pp. 1-30, 2019. DOl: http://dx.doi.org/10.18637/jss.v091.i01

HAJIBABA, Homa and DOLNICAR, Sara. "Airbnb and its competitors". In: Dolnicar S. (ed.). Peer-to-peer accommodation networks: Pushing the boundaries. Oxford: Goodfellow Publishers, 2018. DOl: http://dx.doi. org/10.23912/9781911396512-3604

JELSKI, Christina. "Airbnb says it beat its revenue projections for 2020". Travel Weekly. < https://www.travelweekly.com/Travel-News/Hotel-News/Airbnb-says-it-beat-its-revenue-projections-for-2020 >, 2021

KADI, Justin, SCHNEIDER, Antonia and SEIDL, Roman. "Short-term rentals, housing markets and COVID-19: Theoretical considerations and empirical evidence from four Austrian cities". Critical Housing Analysis, 7(2), pp. 47-57, 2020. DOI: https://dx.doi.org/10.13060/23362839.2020.7.2.514 
KE, Qing. "Sharing means renting?: An entire-marketplace analysis of Airbnb". In: Proceedings of the 2017 ACM on Web Science Conference - WebSci '17, Troy, NY, USA, June 25-28, 2017. DOI: http://dx.doi.org/10.2139/ ssrn.2902840

NATURAL EARTH. < https://www.naturalearthdata.com/ >, 2021

OSKAM, Jeroen A. The future of Airbnb and the 'sharing economy': The collaborative consumption of our cities. Bristol: Channel View, 2019.

SCHAAL, Dennis. "Airbnb Share Price More Than Doubles in First Day of Historic Public Debut". Skift. < https:// skift.com/2020/12/10/airbnb-share-price-more-than-doubles-in-first-day-of-historic-public-debut/ >, 2020a

SCHAAL, Dennis. "Airbnb CEO Brian Chesky Poised for New Era of Travel Redistribution: The Long View This Week". Skift. <https://skift.com/2020/04/24/airbnb-ceo-brian-chesky-poised-for-new-era-of-travel-redistribution-the-long-view-this-week/ >, 2020b

SLEE, Tom. Data collection for Airbnb listings. < https://github.com/tomslee/airbnb-data-collection >, 2018

WEGMANN, Jake and JIAO, Junfeng. "Taming Airbnb: Toward guiding principles for local regulation of urban vacation rentals based on empirical results from five US cities". Land Use Policy, 69, pp. 494-501, 2017.

ZHANG, Mo, GENG, Rouqi, HUANG, Yuan and REN, Shengce. "Terminator or accelerator? Lessons from the peer-to-peer accommodation hosts in China in responses to COVID-19". International Journal of Hospitality Management, 102760, 2020.

Cita recomendada: ADAMIAK, Czesław. Cambios en la oferta de Airbnb durante la pandemia de COVID-19. Oikonomics [en línea]. Mayo 2021, no. 15, pp. 1-11. ISSN: 2339-9546. DOI: https://doi. org/10.7238/o.n15.2107

Los textos publicados en esta revista están sujetos -si no se indica lo contrario- a una licencia de Reconocimiento 4.0 Internacional de Creative Commons. Puede copiarlos, distribuirlos, comunicarlos públicamente, hacer obras derivadas siempre que reconozca los créditos de las obras (autoría, nombre de la revista, institución editora) de la manera especificada por los autores o por la revista. La licencia completa se puede consultar en https://creativecommons.org/licenses/by/4.0/deed.es_ES.
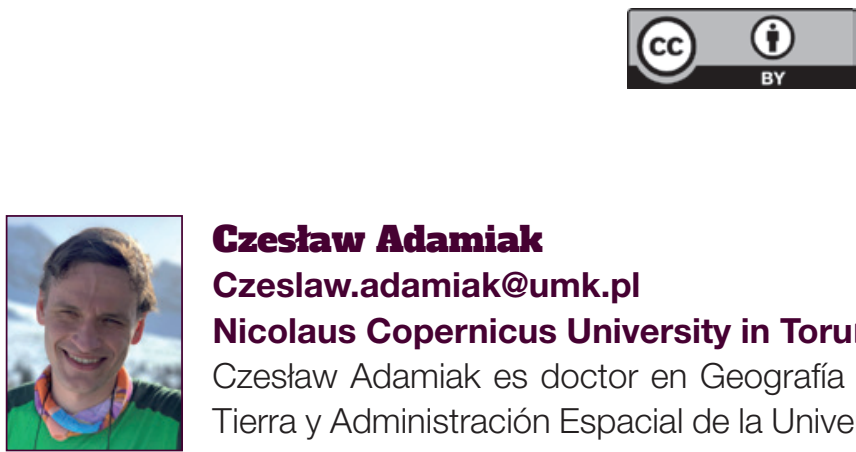

\section{Gzesław Adamiak \\ Czeslaw.adamiak@umk.pl \\ Nicolaus Copernicus University in Toruń}

Czesław Adamiak es doctor en Geografía y trabaja en la Escuela de Ciencias de la Tierra y Administración Espacial de la Universidad Nicolaus Copernicus de Toruń. Sus principales áreas de estudio incluyen la geografía del turismo, el desarrollo regional y las aplicaciones de los sistemas de información geográfica y el big data en las ciencias sociales. Actualmente sus investigaciones se centran principalmente en el papel que desempeñan las plataformas de alquiler digital P2P en el comportamiento del turismo y en la evolución de los destinos turísticos. 